\title{
Caminhos mais longos em grafos
}

\author{
Susanna Figueiredo de Rezende
}

\author{
DisSERTAÇÃO APRESENTADA \\ AO \\ Instituto De MatemáticA e EstatísticA \\ DA \\ Universidade DE SÃo PAUlo \\ PARA \\ OBTENÇÃO DO TÍTULO \\ DE \\ Mestre em CiÊnCIAS
}

\author{
Área de Concentração: Ciência da Computação \\ Orientadora: Prof ${ }^{\mathrm{a}}$. Dra ${ }^{\mathrm{a}}$. Yoshiko Wakabayashi
}

Durante o desenvolvimento deste trabalho a autora recebeu auxílio financeiro da FAPESP (Proc. 2011/16348-0)

São Paulo, 15 de agosto de 2014 


\section{Caminhos mais longos em grafos}

Esta versão da dissertação contém as correções e alterações sugeridas pela Comissão Julgadora durante a defesa da versão original do trabalho, realizada em 30/5/2014. Uma cópia da versão original está disponível no

Instituto de Matemática e Estatística da Universidade de São Paulo.

Comissão Julgadora:

- Prof $^{\mathrm{a}}$. Dra . Yoshiko Wakabayashi (orientadora) - IME-USP

- Prof ${ }^{\mathrm{a}}$. Dr ${ }^{\mathrm{a}}$. Christiane Neme Campos - UNICAMP

- Prof. Dr. Daniel Morgato Martin - UFABC 


\section{Agradecimentos}

Agradeço, em primeiro lugar, a Deus por me proporcionar a vida e seu sentido, por estar sempre comigo e por colocar tantas pessoas boas ao meu lado.

Aos meus pais, Pedro e Ketty, por tudo o que me ensinam, pelo exemplo que são, pelo apoio constante, pelos bons conselhos e principalmente por seu amor incondicional. Aos meus irmãos, Daniel, Adriana, Diana, Joel, Beatriz, Djenane e Denise, aos meus avós, Papito e Mamita, Haroldo e Djenane (in memoriam) e a toda minha família, pelo carinho, incentivo e alegria que sempre encontro em vocês.

Um agradecimento especial à minha orientadora, Professora Yoshiko, que me acompanha desde o primeiro ano da graduação e que frequentemente foi além do que eu poderia esperar, para me orientar e para me oferecer as melhores oportunidades acadêmicas. Muito obrigada pela dedicação, paciência, apoio, inestimáveis conselhos e constante preocupação pelo meu bem.

Agradeço à Professora Cristina e ao Professor Daniel que, juntamente com a Professora Yoshiko, me proporcionaram a primeira oportunidade de fazer pesquisa. Apesar da minha inexperiência, sempre me escutaram com atenção e, com extrema paciência, me esclareciam quaisquer que fossem as minhas dúvidas. Agradeço também à Professora Christiane, como membro da banca, pela leitura cuidadosa da dissertação e pelas sugestões para melhorar a apresentação.

Às minhas amigas e colegas de mestrado, Andressa e Ana, pelo apoio, pelas muitas conversas, pelos almoços e cafés, e por me ajudar com problemas de estatística. Enfim, obrigada pela amizade!

À minha querida amiga Suzana, que sempre teve tempo para conversarmos, sempre alegre e otimista, e sempre se interessava pelo que eu fazia, muito obrigada pela amizade e por todo carinho!

Aos colegas de laboratório, Phablo, Schouery, Tássio, Giulia, Letícia, Rafael, Fábio, Álvaro, Márcio, Henrique, Eric, Guilherme, Schultz, Alexandre, Josefran, Neuton e todos os demais, pelas conversas, discussões de problemas, grupo de estudos e cafés. À Karla, pelas horas de conversa; ao Chandu, por sempre ter um problema novo para apresentar; à Tina, pelas conversas divertidas; e à Andrea, pela atenção, por participar da minha qualificação e pelo interesse pelo meu trabalho.

Aos meus colegas do BCC, em particular à Ana Luiza, à Renata e ao Thiago. Às minhas amigas, em especial à Ana Lucia, Ana Luiza, Mari, Mônica, Stella, Isabel, Júlia e todas do Butantã, e também à Ludi e à Amanda, cuja amizade não quero perder nunca.

Às queridas amigas do Butantã, agradeço o imenso apoio que sempre me deram, o carinho, a amizade, o interesse e a força a cada etapa; tudo isso foi essencial para realizar esse trabalho. Não tenho palavras para dizer o quanto sou grata a cada uma.

Não poderia deixar de agradecer, particularmente, à minha querida irmã e amiga Diana pela sua ajuda concreta no meu planejamento, pelo seu acompanhamento incansável e pela sua disponibilidade.

À Fundação de Amparo à Pesquisa do Estado de São Paulo (Fapesp), pela concessão da bolsa de 
mestrado, processo 2011/16348-0. Aos professores que me deram aulas, aos funcionários do NUMEC e a todos que contribuíram direta ou indiretamente para esse trabalho. 


\section{Resumo}

DE REZENDE, S. F. Caminhos mais longos em grafos. 2014. 94 f. Dissertação (Mestrado) Instituto de Matemática e Estatística, Universidade de São Paulo, São Paulo, 2014.

O tema central deste trabalho é o estudo de problemas sobre caminhos mais longos em grafos, de pontos de vista tanto estrutural como algorítmico. A primeira parte tem como foco o estudo de problemas motivados pela seguinte questão levantada por T. Gallai em 1966: é verdade que em todo grafo conexo existe um vértice comum a todos os seus caminhos mais longos? Hoje, já se conhecem diversos grafos conexos cuja intersecção de todos os seus caminhos mais longos é vazia. Entretanto, existem classes de grafos para as quais a resposta à pergunta de Gallai é afirmativa. Nessa linha, apresentamos alguns resultados da literatura e duas novas classes que obtivemos: os grafos exoplanares e as 2-árvores. Motivado por esse problema, nos anos 80, T. Zamfirescu formulou a seguinte pergunta que permanece em aberto: é verdade que em todo grafo conexo existe um vértice comum a quaisquer três de seus caminhos mais longos? Apresentamos, além de alguns resultados conhecidos, uma prova de que a resposta é afirmativa para grafos em que todo bloco não trivial é hamiltoniano. Notamos que esse último resultado e o acima mencionado para grafos exoplanares generalizam um teorema de M. Axenovich (2009) que afirma que quaisquer três caminhos mais longos em um grafo exoplanar têm um vértice em comum. Finalmente, mencionamos alguns outros resultados da literatura relacionados com o tema. Na segunda parte, investigamos o problema de encontrar um caminho mais longo em um grafo. Este problema é NP-difícil para grafos arbitrários. Isto motiva investigações em duas linhas a respeito da busca de tais caminhos. Pode-se procurar classes especiais de grafos para as quais existem algoritmos polinomiais, ou pode-se abrir mão da busca de um caminho mais longo, e projetar um algoritmo eficiente que encontra um caminho cujo comprimento esteja próximo do comprimento de um mais longo. Nesse trabalho estudamos ambas as abordagens e apresentamos alguns resultados da literatura.

Palavras-chave: caminhos mais longos, intersecção, grafos exoplanares, 2-árvores, algoritmos de aproximação. 


\section{Abstract}

DE REZENDE, S. F. Longest paths in graphs. 2014. 94 f. Dissertação (Mestrado) - Instituto de Matemática e Estatística, Universidade de São Paulo, São Paulo, 2014.

The central theme of this thesis is the study of problems related to longest paths in graphs, both from a structural and an algorithmic point of view. The first part focuses on the study of problems motivated by the following question raised by T. Gallai in 1966: is it true that every connected graph has a vertex common to all its longest paths? Today, many connected graphs in which all longest paths have empty intersection are known. However, there are classes of graphs for which Gallai's question has a positive answer. In this direction, we present some results from the literature, as well as two new classes we obtained: outerplanar graphs and 2-trees. Motivated by this problem, T. Zamfirescu, in the 80 s, proposed the following question which remains open: is it true that every connected graph has a vertex common to any three of its longest paths? We present, in addition to some known results, a proof that the answer to this question is positive for graphs in which all non-trivial blocks are Hamiltonian. We note that this result and the one mentioned above for outerplanar graphs generalize a theorem of M. Axenovich (2009) that states that any three longest paths in an outerplanar graph have a common vertex. Finally, we mention some other related results from the literature. In the second part, we investigate the problem of finding a longest path in a graph. This problem is NP-hard for arbitrary graphs. This motivates investigations in two directions with respect to the search for such paths. We can look for special classes of graphs for which the problem is polynomially solvable, or we can relinquish the search for a longest path and design an efficient algorithm that finds a path whose length is close to that of a longest path. In this thesis we study both approaches and present some results from the literature. Keywords: longest paths, intersection, outerplanar graphs, 2-trees, approximation algorithms. 


\section{Sumário}

$\begin{array}{ll}\text { Lista de Figuras } & \text { ix }\end{array}$

Lista de Tabelas $\quad$ xi

1 Introdução $\quad \mathbf{1}$

1.1 A pergunta de Gallai . . . . . . . . . . . . . . . . . . . . . . . . . . . 1

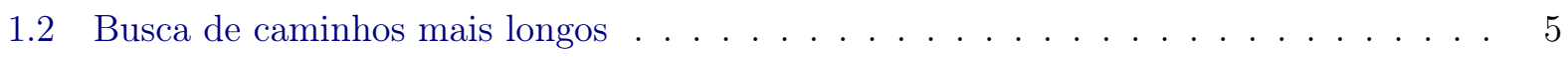

1.3 Organização do trabalho . . . . . . . . . . . . . . . . . . . . 6

$\begin{array}{lll}2 & \text { Preliminares } & 7\end{array}$

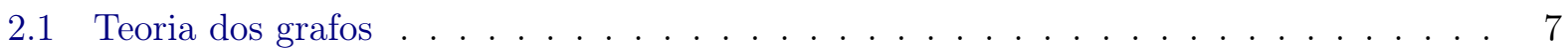

2.2 Classes de grafos $\ldots \ldots \ldots \ldots \ldots$

2.3 Algoritmos de aproximação . . . . . . . . . . . . . . . . . . . 10

$\begin{array}{lll}\text { I Resultados estruturais } & 13\end{array}$

3 Classes de grafos em que todos os caminhos mais longos se intersectam $\quad 15$

3.1 Resultados conhecidos . . . . . . . . . . . . . . . . . . 15

3.1 .1 Árvores . . . . . . . . . . . . . . . . . . . . . . . 15

3.1 .2 Grafos divididos . . . . . . . . . . . . . . . . . . . 16

3.1 .3 Grafos de intervalos . . . . . . . . . . . . . . . . . . . 17

3.1 .4 Uma condição necessária e suficiente . . . . . . . . . . . . . . . . 18

3.2 Resultados que obtivemos . . . . . . . . . . . . . . . . . . . 20

3.2.1 Grafos exoplanares . . . . . . . . . . . . . . . . . . 20

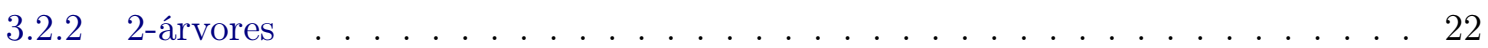

4 Classes de grafos em que quaisquer três caminhos mais longos se intersectam 27

4.1 Resultados conhecidos . . . . . . . . . . . . . . . . . 27

4.2 Resultados que obtivemos . . . . . . . . . . . . . . . . . . . 28

5 Outros resultados relacionados $\quad 33$

5.1 Vértices comuns a dois caminhos mais longos . . . . . . . . . . . . . . 33

5.2 Vértices evitados por caminhos mais longos . . . . . . . . . . . . . . . 38 
II Resultados algorítmicos

6 Busca de um caminho mais longo $\quad 45$

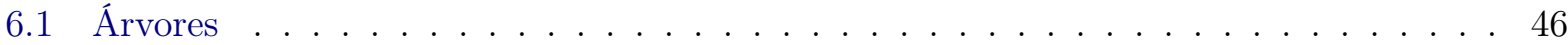

6.2 Grafos de intervalos . . . . . . . . . . . . . . . . . . . 48

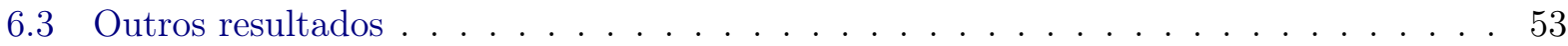

7 Algoritmos de aproximação $\quad 55$

7.1 Representantes de famílias . . . . . . . . . . . . . . . . . . . . . . 55

7.2 Método de codificação por cores . . . . . . . . . . . . . . . . . . . . 61

7.3 Árvore de decomposição em circuitos . . . . . . . . . . . . . . . . . . . . . 62

8 Resultados de inaproximabilidade $\quad 69$

8.1 Fator constante . . . . . . . . . . . . . . . . . . . . . . . 69

8.2 Conjectura sobre a dificuldade de aproximação $\ldots \ldots \ldots$. . . . . . . . . . 72

9 Considerações Finais $\quad \mathbf{7 5}$

9.1 Problemas correlatos em aberto . . . . . . . . . . . . . . . 75

9.2 Trabalhos publicados . . . . . . . . . . . . . . . . . . 77

$\begin{array}{ll}\text { Referências Bibliográficas } & \mathbf{7 9}\end{array}$ 


\section{Lista de Figuras}

1.1 Grafo cujos circuitos mais longos são dois a dois disjuntos. . . . . . . . . . . . . . . 2

1.2 Grafo de Petersen. . . . . . . . . . . . . . . . . . . . . . . 2

1.3 O grafo de Walther com 25 vértices. . . . . . . . . . . . . . . . . . . 3

1.4 O grafo menor de Walther e Voss, e Zamfirescu com 12 vértices. . . . . . . . . . . . . 3

1.5 O grafo planar menor de Schmitz com 17 vértices. . . . . . . . . . . . . . . . . . . 4

2.1 Relação entre classes de grafos perfeitos. . . . . . . . . . . . . . . . . . . . . . . 10

2.2 Relação entre classes de grafos não necessariamente perfeitos (as elipses em negrito indicam classes de grafos perfeitos) . . . . . . . . . . . . . . . . . . . 11

3.1 Caminho mais longo em $G$ e respectiva cadeia mais longa em $\mathcal{F}$. . . . . . . . . . 17

3.2 Suporte de $\mathcal{C} \ldots \ldots \ldots \ldots \ldots \ldots \ldots \ldots \ldots \ldots$

3.3 Um exemplo de um grafo $G$ (lado esquerdo) e sua árvore de blocos $T(G)$ (lado direito). Os vértices de corte em $G$ correspondem aos vértices menores em $T(G)$, e os blocos correspondem aos vértices maiores (os não triviais correspondem aos vértices de borda dupla). . . . . . . . . . . . . . . . . . . . . . . . . . . . . . 19

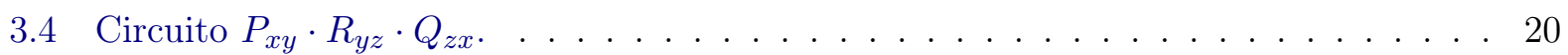

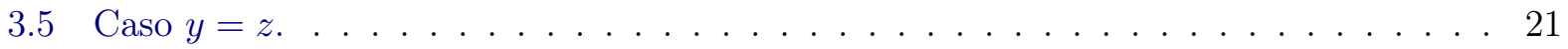

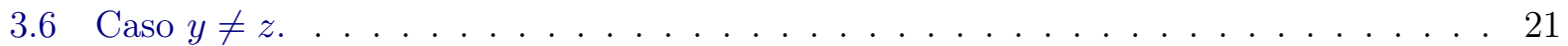

3.7 O caminho $Q$ contém $x$, mas não $y \ldots \ldots \ldots \ldots \ldots \ldots \ldots \ldots$

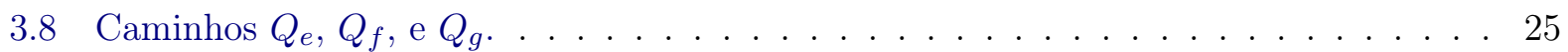

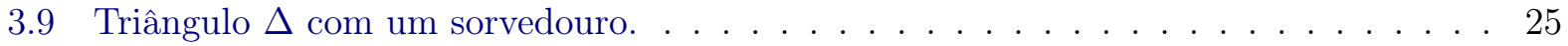

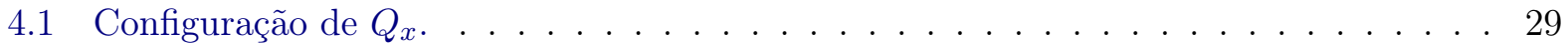

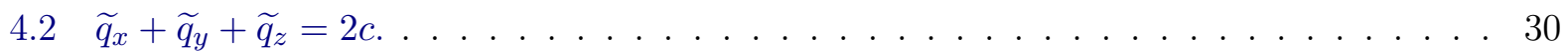

4.3 Configuração de $Q_{1} \ldots \ldots \ldots \ldots \ldots \ldots \ldots$

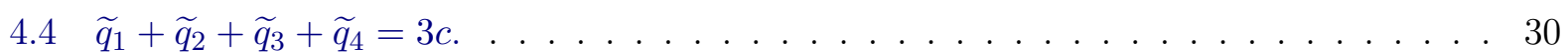

5.1 Grafo em que dois circuitos mais longos se intersectam em um conjunto $W$ de 5 vértices e $W$ não é um conjunto separador. . . . . . . . . . . . . . . . . . . 36

5.2 Dois caminhos mais longos em um $K_{5,12} \ldots \ldots \ldots \ldots \ldots \ldots \ldots \ldots$

5.3 Menor grafo 2 -conexo que mostra que $\boldsymbol{\Gamma}_{1}[2$-conexo $]<\infty \ldots \ldots \ldots$

5.4 Menor grafo 2-conexo planar que mostra que $\boldsymbol{\Gamma}_{1}[2$-conexo, planar $]<\infty$. . . . . . 40

5.5 Primeiro grafo 3 -conexo que provou que $\boldsymbol{\Gamma}_{1}[3$-conexo $]<\infty \ldots \ldots \ldots$

5.6 Menor grafo 3 -conexo que mostra que $\boldsymbol{\Gamma}_{1}[3$-conexo $]<\infty \ldots \ldots \ldots$ 
6.1 (a) Um grafo de intervalos $G$; (b) o modelo de interseç̧ão de $G$; (c) a r-ordenação

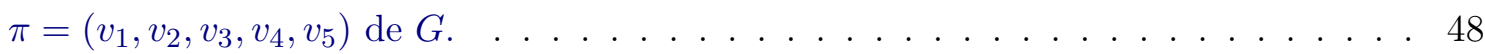

6.2 Modelo de intersecção do grafo $H \ldots \ldots \ldots$. . . . . . . . . . . . . 49

6.3 O subgrafo $H(4,15)$, sendo $\sigma=\left(u_{1}, u_{2}, \ldots u_{15}\right) \ldots \ldots \ldots \ldots \ldots \ldots$

6.4 O caminho $P\left(u_{8} ; 4,15\right)=\left(u_{4}, u_{6}, u_{5}, u_{15}, u_{7}, u_{9}, u_{8}\right)$ é um caminho binormal mais longo em $H(4,15)$ com término em $u_{8} \ldots \ldots \ldots \ldots \ldots$

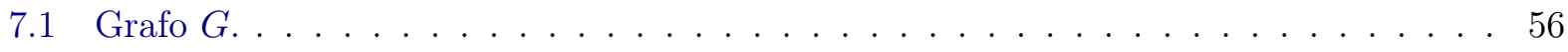

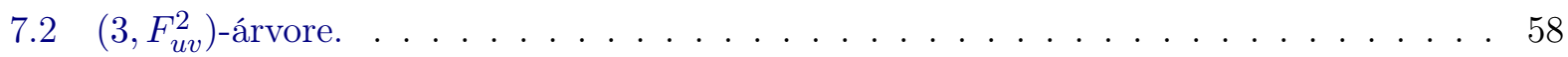

7.3 Afirmação 1 do Lema $53 . \quad \ldots \ldots \ldots$. . . . . . . . . . . . . . 65

7.4 Afirmação 2 do Lema $53 . \ldots \ldots$. . . . . . . . . . . . . . . . . 65 


\section{Lista de Tabelas}

5.1 Tabela com os valores atualizados de $\boldsymbol{\Gamma}_{j}[k$-conexo $] \ldots \ldots \ldots$. . . . . . . . . 39

5.2 Tabela com os valores atualizados de $\boldsymbol{\Gamma}_{j}[k$-conexo, planar $] \ldots \ldots \ldots \ldots$ 


\section{Capítulo 1}

\section{Introdução}

Alguns turistas, planejando a próxima viagem pelo Brasil, se reuniram para decidir quais cidades do país visitariam. Todos estavam de acordo que queriam visitar o maior número possível de cidades, com a única condição de não ter que repetir nenhuma. Coletaram todos os dados que necessitavam: quais eram as cidades e quais pares delas tinham ligação (aérea, terrestre ou fluvial) entre si.

Após dias de árduo estudo, fizeram pouco progresso para encontrar um tal trajeto. Alguns observaram que era impossível percorrer todas as cidades do país sem repetir nenhuma e outros notaram que provavelmente havia diversos percursos diferentes que passavam pelo maior número possível de cidades. Com isso surgiram novas perguntas. Se cada um deles escolhesse um tal percurso distinto, será que haveria alguma cidade que todos eles visitariam? E como parecia tão difícil encontrar um trajeto que passasse pelo maior número possível de cidades, será que ao menos poderiam encontrar um caminho longo o suficiente para garantir que visitariam ao menos uma fração do maior número possível de cidades?

Matematicamente, essas últimas questões podem ser reformuladas da seguinte forma. Em um grafo conexo, todos os caminhos mais longos têm um vértice em comum? É possível aproximar o problema de encontrar um caminho mais longo por alguma razão constante? A primeira pergunta foi feita por Gallai [35] em 1966 e respondida por Walther [96] em 1969. A segunda foi respondida em 1997 por Karger, Motwani e Ramkumar [66]. Outras perguntas relacionadas, porém, continuam em aberto.

Em particular, se houvesse apenas três turistas no grupo e se cada um tivesse escolhido um caminho dentre todos os caminhos mais longos e se não houvesse nenhuma cidade pela qual os três tivessem passado, teriam resolvido um antigo problema em teoria dos grafos. Até hoje não se sabe se existe necessariamente um vértice comum a quaisquer três desses caminhos.

Mais surpreendente ainda seria se tivessem desenvolvido um algoritmo polinomial que encontrasse, para qualquer grafo, um caminho cujo comprimento fosse garantidamente uma fração do comprimento de um caminho mais longo. Nesse caso, teriam resolvido um dos mais importantes dilemas da teoria da computação: "P $=\mathbf{N P}$ "?

O problema dos turistas acima mencionado foi inspirado num exemplo dado por Kensell [67].

\subsection{A pergunta de Gallai}

Em 1966, num colóquio em Tihany na área de grafos, Gallai [35] perguntou se todo grafo conexo tem um vértice que aparece em todos os caminhos mais longos. A pergunta de Gallai é natural, pois 
é bem conhecido o fato de que, em um grafo conexo, quaisquer dois caminhos mais longos sempre têm um vértice em comum (a prova desse resultado será apresentada mais adiante). Também é conhecido o fato de que, em um grafo 2-conexo, quaisquer dois circuitos mais longos têm um vértice em comum. (Para entender a razão da exigência da 2-conexidade do grafo quando tratamos de circuitos, basta observar o grafo da Figura 1.1, no qual todos seus circuitos mais longos são dois a dois disjuntos.)

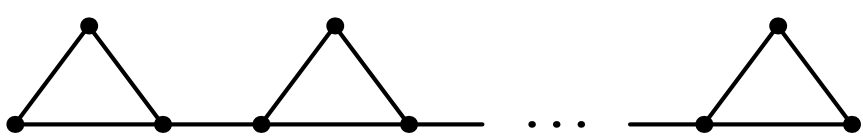

Figura 1.1: Grafo cujos circuitos mais longos são dois a dois disjuntos.

No entanto, quando Gallai formulou essa pergunta, já se conhecia um exemplo de um grafo 2-conexo que não possui um vértice comum a todos os seus circuitos mais longos. Esse exemplo é o bem conhecido grafo de Petersen (veja Figura 1.2), que é sabidamente hipo-hamiltoniano, ou seja, não possui um circuito hamiltoniano, mas o grafo obtido pela remoção de qualquer um de seus vértices é hamiltoniano. Portanto, o grafo de Petersen tem um circuito mais longo que evita qualquer vértice dado. Porém, até então, ninguém conhecia um exemplo equivalente para caminhos mais longos.

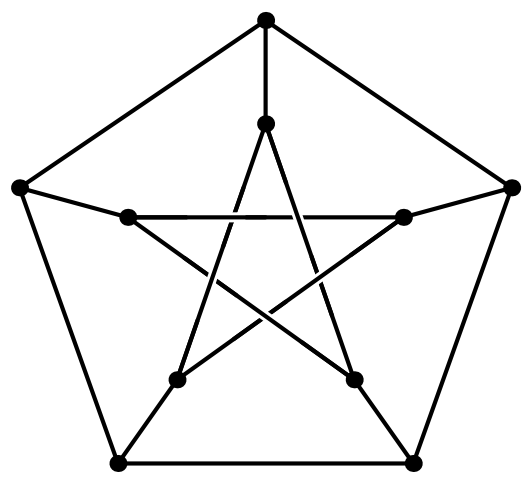

Figura 1.2: Grafo de Petersen.

Pouco tempo depois, Walther [96] pôde dar uma resposta a essa questão. Ele construiu um grafo (veja Figura 1.3) provando que não é sempre verdade que existe um vértice comum a todos os caminhos mais longos. Este grafo possui 25 vértices e seus caminhos mais longos têm comprimento 21. É possível encontrar 13 caminhos mais longos no grafo com intersecção vazia.

Então, Walther [96] formulou outras perguntas a esse respeito: Este exemplo é o menor possível? Qual o menor valor para $n$ tal que existe um grafo com $n$ vértices em que todos os caminhos mais longos têm intersecção vazia? Existe um número $j$ tal que, para todo grafo $G$, existe um conjunto de $j$ vértices cuja intersecção com qualquer caminho mais longo é não vazia? Se existe tal $j$, qual o menor valor para $j$ ?

No começo dos anos 70, Walther e Voss [94], e Zamfirescu [103], independentemente, encontraram um grafo menor, com 12 vértices, que responde negativamente à pergunta de Gallai (veja Figura 1.4) .

Observe que, nesse grafo, se identificarmos os vértices de grau 1, obtemos o grafo de Petersen. Assim, usando a simetria do grafo, podemos ver que não existe um vértice comum a todos os 


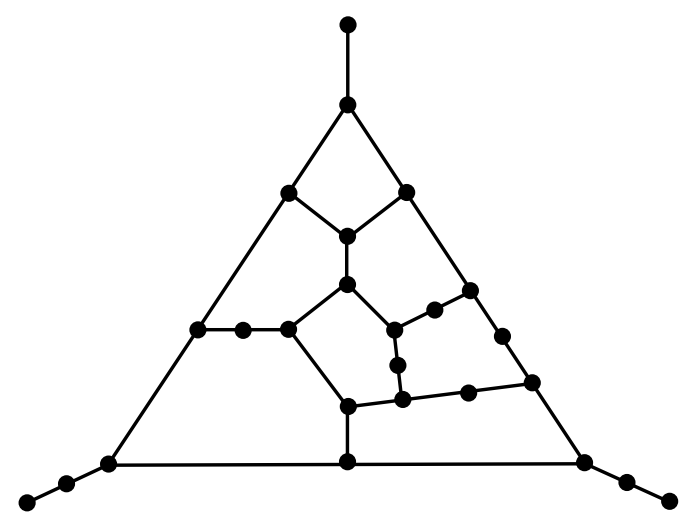

Figura 1.3: O grafo de Walther com 25 vértices.

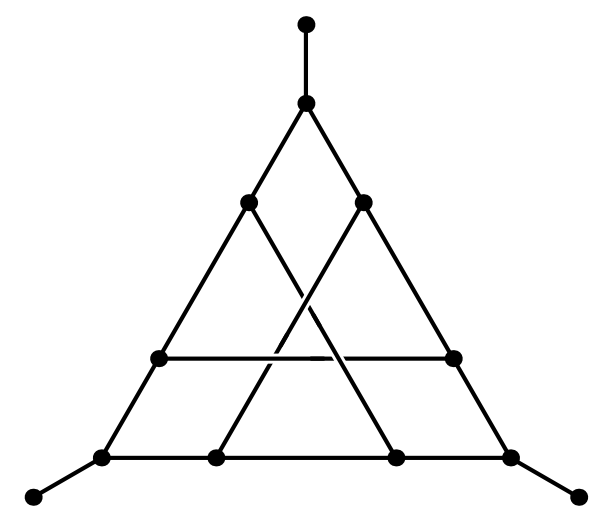

Figura 1.4: O grafo menor de Walther e Voss, e Zamfirescu com 12 vértices.

caminhos mais longos. Primeiramente, observe que qualquer caminho mais longo necessariamente não passa por um dos vértices de grau 1 e que, se ele passasse por todos os demais vértices, então esse caminho corresponderia a um circuito hamiltoniano no grafo de Petersen. Portanto, um caminho mais longo tem no máximo 10 vértices. Agora, para cada um dos 9 vértices de grau maior que 1 , construa o caminho correspondente a um circuito mais longo do grafo Petersen, que não passa por esse vértice. Esses caminhos têm 10 vértices e, portanto, são caminhos mais longos. Além disso, observe que quando um caminho não passa pelo vizinho de um vértice de grau 1, então também não passa pelo vértice de grau 1. Logo, esses 9 caminhos não possuem um vértice em comum.

Em 1972, Zamfirescu [100] formulou diversas perguntas, inclusive generalizando as de Walther: Se impusermos restrições nos grafos (maior conexidade, planaridade), será que ainda assim existem exemplos (e se existir, qual a menor ordem deles) em que a intersecção de todos os caminhos mais longos é vazia? E entre esses grafos, existem exemplos em que quaisquer $j$ vértices $(j \geq 2)$ são evitados por algum caminho mais longo? No Capítulo 5 apresentamos os progressos obtidos até hoje para obter respostas a essas perguntas.

Em particular, note que o primeiro grafo encontrado que responde negativamente à pergunta de Gallai é planar, mas o grafo da Figura 1.4 não o é. Até hoje, o menor grafo planar conhecido no qual todos os seus caminhos mais longos têm intersecção vazia é o da Figura 1.5, que foi obtido em 1975 por Schmitz [78] e possui 17 vértices. Neste grafo os caminhos mais longos têm comprimento 13 e é possível encontrar 7 tais caminhos com intersecção vazia. 


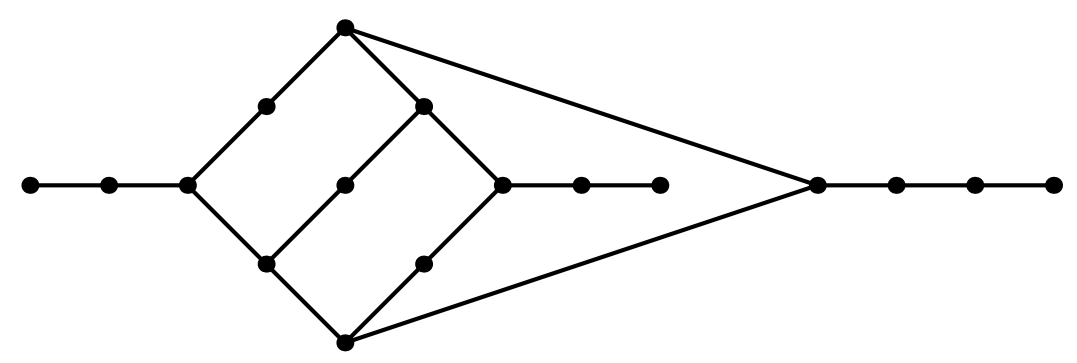

Figura 1.5: O grafo planar menor de Schmitz com 17 vértices.

Zamfirescu [102, 103] conjecturou que o grafo da Figura 1.4 e o grafo da Figura 1.5 são os menores grafos nos quais todos os caminhos mais longos têm intersecção vazia para o caso geral e para o caso planar, respectivamente. Recentemente, Brinkmann e Van Cleemput [79] provaram (usando computadores) que, no caso geral, 12 é de fato a menor ordem possível. Para o caso planar, porém, a questão permanece em aberto.

Observe que uma classe grande de grafos que respondem negativamente à pergunta de Gallai são os grafos hipotraçáveis. (Um grafo $G$ é hipotraçável se $G$ não tem um caminho hamiltoniano mas qualquer subgrafo de $G$ obtido pela remoção de um vértice tem um caminho hamiltoniano.) Thomassen [85] provou a existência de um número infinito de grafos planares hipotraçáveis.

Como intersecção não vazia de todos os caminhos mais longos não é uma propriedade comum a todos os grafos, é natural investigar duas vertentes desse problema. Por um lado, pode-se estudar classes de grafos para as quais a pergunta de Gallai tem resposta positiva; por outro pode-se considerar a intersecção de um número menor de caminhos mais longos.

Em 1990, Klavžar e Petkovšek [68] apresentaram algumas classes de grafos cujos caminhos mais longos possuem intersecção não vazia. Nos últimos 10 anos, houveram outros progressos nessa linha [10, 32, 34, 62, 77]. Tratamos mais dessa questão no Capítulo 3.

Por outro lado, é possível considerar a intersecção de um número pequeno de caminhos mais longos. Apresentamos a demonstração do resultado mencionado anteriormente que diz respeito a intersecção de dois caminhos mais longos.

Asserção 1 Se $G$ é um grafo conexo, então quaisquer dois caminhos mais longos de $G$ têm um vértice em comum.

Prova. Seja $G$ um grafo conexo e suponha, por contradição, que $P_{1}$ e $P_{2}$ sejam dois caminhos mais longos de comprimento $L$ cuja intersecção é vazia. Como $G$ é conexo, existe um caminho de $P_{1}$ a $P_{2}$. Escolha um caminho minimal $M$ que liga $P_{1}$ a $P_{2}$, ou seja, escolha $M$ tal que sua origem, $x$, esteja em $P_{1}$, o seu término, $y$, em $P_{2}$ e nenhum vértice interno de $M$ pertença a $P_{1}$ ou a $P_{2}$.

$\mathrm{O}$ vértice $x$ divide $P_{1}$ em dois caminhos. Seja $P_{1}^{\prime}$ o maior desses caminhos (com término $x$ ). Analogamente, $y$ divide $P_{2}$ em dois caminhos. Seja $P_{2}^{\prime}$ o maior desses caminhos (com origem $y$ ). Agora, seja $P$ o caminho obtido pela concatenação de $P_{1}^{\prime}, M$ e $P_{2}^{\prime}$. Como o comprimento de $M$ (denotado por $\|M\|$ ) é não nulo, $\left\|P_{1}^{\prime}\right\| \geq \frac{1}{2} L$ e $\left\|P_{2}^{\prime}\right\| \geq \frac{1}{2} L$, então $\|P\| \geq L+1$, o que contradiz o fato de $P_{1}$ e $P_{2}$ serem caminhos mais longos.

Enquanto é fácil provar que quaisquer dois caminhos mais longos têm um vértice comum, não é sabido se quaisquer três caminhos mais longos também compartilham um vértice. Em 2009, 
Axenovich [9] apresentou uma classe de grafos que satisfazem a propriedade de que quaisquer três de seus caminhos mais longos têm intersecção não vazia. Voltamos a tratar desse problema no Capítulo 4.

A esse respeito, podemos formular a seguinte pergunta mais geral: "Qual o maior valor de $p$ tal que quaisquer $p$ caminhos mais longos, em um grafo conexo, têm um vértice em comum?" O grafo da Figura 1.5 mostra que não é sempre verdade que quaisquer 7 caminhos mais longos têm um vértice em comum. Além disso, Skupień [81] obteve, para $n \geq 7$, um grafo conexo no qual existem $n$ caminhos mais longos cuja intersecção é vazia, mas quaisquer $n-1$ caminhos mais longos têm um vértice em comum. Portanto, sabe-se que $2 \leq p \leq 6$.

\subsection{Busca de caminhos mais longos}

Em outra direção, temos o problema clássico conhecido como o problema do caminho mais longo: encontrar um caminho de comprimento máximo em um grafo. Sabe-se que esse problema é NP-difícil [42] mesmo quando restrito a certas classes de grafos, como grafos planares [43], grafos grade [59], grafos círculo (circle graphs) [28], grafos cordais bipartidos, grafos divididos fortemente cordais (strongly chordal split graphs) [70], grafos de caminhos dirigidos (directed path graphs) [72] e grafos divididos (split graphs) [45].

Esse fato motiva investigações em duas linhas a respeito da busca de tais caminhos. Pode-se investigar classes especiais de grafos para as quais existem algoritmos polinomiais, ou pode-se abrir mão da busca de um caminho mais longo e projetar um algoritmo eficiente que encontra um caminho cujo comprimento esteja próximo do comprimento de um mais longo.

Existem classes de grafos para as quais já se conhece algoritmo polinomial para resolver o problema de encontrar um caminho mais longo. Em 1960, Dijkstra propôs um algoritmo linear bem simples para resolver o problema em árvores. Uma prova formal foi dada por Bulterman, Feijen, van der Sommen, van Gasteren, Verhoeff e Zwaan [19]. Nos anos 90, Bodlaender [15, 16] apresentou um algoritmo linear para $k$-árvores parciais, considerando $k$ fixo. Em 2005, Uehara e Uno [88] apresentaram algoritmos polinomiais para árvores com custos nos vértices/arestas, grafos blocos, cactos, entre outros. Em anos subsequentes, diversos autores [3, 23, 44, 49, 83, 89, 90] obtiveram novos resultados nessa linha. Em 2009, Ioannidou, Mertzios e Nikolopoulos [57] provaram que para os grafos de intervalos existe um algoritmo polinomial que encontra um caminho mais longo. Posteriormente, esse resultado foi provado para classes ainda mais gerais: os grafos de cocomparabilidade [27, 58] e os grafos arco-circulares [13]. Discutimos esses resultados no Capítulo 6.

Com relação a algoritmos de aproximação para o problema de encontrar um caminho mais longo, sabe-se que não existe algoritmo de aproximação com razão constante, a menos que $\mathbf{P}=\mathbf{N P}$ [66] Em 1985, surgiu o primeiro resultado de aproximação para esse problema. Monien [69] mostra um modo mais eficiente (embora ainda exponencial) de encontrar um caminho mais longo, o que tornou possível encontrar, em tempo polinomial, caminhos de comprimento $\Omega(\log n / \log \log n)$, se tais caminhos existirem. Dez anos depois, Alon, Yuster e Zwick [2] desenvolveram o método de codificação por cor (color-coding) que permite encontrar, em tempo polinomial, um caminho de comprimento logarítmico no número de vértices do grafo, se tal caminho existir. Em 2003, Björklund e Husfeldt [14] exibiram um algoritmo polinomial que encontra um caminho de comprimento $\Omega\left(\log ^{2} L / \log \log L\right)$, onde $L$ é o comprimento de um caminho mais longo. Diversos outros autores [25, 37, 38, 39, 92] 
trabalharam para conseguir algoritmos que fornecessem uma melhor razão de aproximação, mesmo que restrito a algumas classes especiais. Para o caso geral, a melhor razão de aproximação conhecida até hoje foi obtida por Gabow e Nie [41] em 2008. Eles mostram que é possível encontrar um caminho de comprimento $2^{\Omega(\sqrt{\log L})}$. Tratamos da questão de encontrar soluções aproximadas para o problema do caminho mais longo nos Capítulos 7 e 8 .

\subsection{Organização do trabalho}

No Capítulo 2, apresentamos algumas definições básicas e estabelecemos a notação que adotamos neste texto. Também definimos várias classes de grafos que mencionamos neste trabalho.

A primeira parte da dissertação trata de questões estruturais relacionadas com a intersecção de caminhos mais longos. No Capítulo 3, encontram-se os principais resultados conhecidos de classes de grafos para os quais se sabe que todos seus caminhos mais longos têm intersecção não vazia. Também apresentamos dois novos resultados que obtivemos recentemente. Exibimos no Capítulo 4 resultados análogos para o problema restrito a três caminhos mais longos e o resultado que obtivemos para esse problema. O Capítulo 5 contém outros problemas relacionados à questão central da dissertação que achamos de especial relevância e que, não só podem ser úteis para ajudar a solucionar o problema original, mas também são interessantes em si mesmos.

Na segunda parte do trabalho, apresentamos alguns resultados algorítmicos sobre o problema da busca de um caminho mais longo. O Capítulo 6 trata da dificuldade desse problema e dos algoritmos polinomiais conhecidos para certas classes de grafos. O Capítulo 7 exibe alguns algoritmos de aproximação para o problema e o Capítulo 8 contém resultados de inaproximabilidade do problema.

Algumas considerações finais e uma seleção de problemas em aberto são apresentados no Capítulo 9 . 


\section{Capítulo 2}

\section{Preliminares}

Neste capítulo, apresentamos alguns conceitos básicos sobre grafos e algoritmos, principalmente com a finalidade de estabelecer a notação que será usado nesta dissertação.

\section{$2.1 \quad$ Teoria dos grafos}

A maior parte dos conceitos a serem apresentados aqui são básicos e podem ser encontrados em qualquer livro introdutório sobre grafos. Seguimos mais de perto a terminologia usada no livro de Bondy e Murty [17].

Um grafo $G$ é um par ordenado $(V, E)$, onde $V$ é um conjunto finito de elementos chamados vértices e $E$ é um conjunto de elementos chamados arestas, sendo que cada aresta é um par não ordenado de vértices distintos. Quando conveniente, para nos referir ao conjunto de vértices (resp. arestas) de um grafo usamos a notação $V(G)$ (resp. $E(G)$ ).

Observamos que, na maioria dos textos, o objeto que definimos como grafo é chamado de grafos simples. Dizemos que a ordem de um grafo $G$ é o número de seus vértices e denotamos esse valor por $|G|$.

Se $e=\{u, v\}$ é uma aresta, dizemos que $e$ incide em $u$ e em $v$, ou que $u$ e $v$ são as extremidades de $e$, ou que e liga $u$ e $v$, ou ainda que $u$ e $v$ são adjacentes ou vizinhos. Também denotamos $\{u, v\}$ por $u v$. O grau de um vértice $v$ é o número de arestas que incidem em $v$.

Um caminho num grafo $G$ é uma sequência de vértices distintos $P=\left(v_{1}, v_{2}, \ldots, v_{k}\right)$, tal que $v_{i} v_{i+1} \in E(G)$ para $i=1, \ldots, k-1$. Denotamos por $P^{-1}$ o reverso do caminho $P$, ou seja, o caminho $\left(v_{k}, \ldots, v_{2}, v_{1}\right)$. Por simplicidade, consideramos que $P$ é um grafo e, neste caso, dizemos que $V(P)=\left\{v_{1}, \ldots, v_{k}\right\}$ e $E(P)=\left\{v_{i} v_{i+1}: i=1, \ldots, k-1\right\}$. Dizemos que $v_{1}$ é o início ou a origem de $P$ e $v_{k}$ é o término de $P$, e que ambos $v_{1}$ e $v_{k}$ são as extremidades de $P$. Ademais, dizemos que $P$ é um caminho de $v_{1}$ a $v_{k}$ ou um $v_{1} v_{k}$-caminho.

Se $x$ é um vértice (resp. uma aresta) em um grafo e $P$ é um caminho nesse grafo tal que $x \notin V(P)$ (resp. $x \notin E(P)$ ), dizemos que $P$ evita $v$, e se $Q$ é um caminho tal que $x \in V(Q)$ (resp. $x \in E(Q)$ ), dizemos que $Q$ passa por $x$. Se $P$ é um caminho com término no vértice $v$ e $Q$ é um caminho com início em $v$, então $P \cdot Q$ denota a concatenação de $P$ e $Q$. Por simplicidade, se $u$ é um vértice adjacente a $v$, denotamos $P \cdot(v, u)$ por $P u$, e $(u, v) \cdot Q$ por $u Q$.

Se $P=\left(v_{1}, v_{2}, \ldots, v_{k}\right)$ é um caminho em um grafo, $k \geq 3$, e $v_{k}$ e $v_{1}$ são adjacentes, então $C=\left(v_{1}, v_{2}, \ldots, v_{k}, v_{1}\right)$ é um circuito. O comprimento de um caminho ou de um circuito $H$ é $|E(H)|$ e é denotado por $\|H\|$. Observe que o comprimento de um caminho é a sua ordem menos 1. 
A distância entre dois vértice $v_{1}$ e $v_{2}$ em um grafo $G$ é o comprimento do menor caminho entre eles e é denotado por $d_{G}\left(v_{1}, v_{2}\right)$ (ou apenas $d\left(v_{1}, v_{2}\right)$, se $G$ está claro no contexto). Se não existe caminho entre $v_{1}$ e $v_{2}$, então estabelecemos que $d_{G}\left(v_{1}, v_{2}\right):=\infty$.

Por simplicidade, em algumas demonstrações, denotamos caminhos por letras maiúsculas (por exemplo, $P, Q, R)$ e denotamos seus comprimentos pela respectiva letra minúscula $(p, q, r)$. Se $P$ é um caminho e $x$ e $y$ são vértices de $P$, denotamos por $P_{x y}$ a secção de $P$ de $x$ a $y$. Analogamente, se $C$ é um circuito, então $c$ denota seu comprimento; e se $C$ está desenhado no plano sem cruzamento de suas arestas e $x$ e $y$ são vértices de $C$, denotamos por $C_{x y}$ a secção de $C$ de $x$ a $y$ em sentido horário.

Se $G$ é um grafo e $H$ é um caminho (resp. um circuito) em $G$ tal que $|H|=|G|$, dizemos que $H$ é um caminho hamiltoniano (resp. um circuito hamiltoniano) de $G$. Um grafo é hamiltoniano se contém um circuito hamiltoniano e é traçável se contém um caminho hamiltoniano. Um grafo $G$ é hipo-hamiltoniano (resp. hipotraçável) se não é hamiltoniano (resp. traçável), mas se removermos qualquer vértice de $G$, o grafo resultante é hamiltoniano (resp. traçável).

Se dois grafos $G=(V, E)$ e $H=(W, F)$ são tais que $W \subseteq V$ e $F \subseteq G$, então $H$ é dito ser um subgrafo de $G$ e $G$ é dito um supergrafo de $H$. Se $X \subseteq V$, então o subgrafo de $G$ induzido por $X$, denotado por $G[X]$, é o grafo cujo conjunto de vértices é $X$ e cujo conjunto de arestas consiste nas arestas de $G$ com ambos os extremos em $X$. Se $Y$ é um conjunto de vértices, denotamos por $G-Y$ o subgrafo obtido de $G$ removendo-se $Y$, definido como sendo o grafo induzido por $V \backslash Y$, isto é $G[V \backslash Y]$. Por simplicidade, se $y$ é um vértice, em vez de $G-\{y\}$ escrevemos $G-y$. Se $G$ é um caminho, então um subgrafo de $G$ que é um caminho é chamado de subcaminho.

Se $H$ é um caminho (resp. circuito) em um grafo $G$, dizemos que $H$ é um caminho mais longo (resp. circuito mais longo) em $G$, se $H$ é um caminho (resp. circuito) de comprimento máximo. A circunferência do grafo $G$ é o comprimento de um circuito mais longo em $G$.

Dizemos que dois grafos $G$ e $H$ se intersectam se $V(G) \cap V(H) \neq \emptyset$. Também dizemos que um conjunto de vértices $W$ e um grafo $G$ se intersectam se $W \cap V(G) \neq \emptyset$. Nesse caso, se $W=\{w\}$ e $W \cap V(G) \neq \emptyset$, dizemos simplesmente que $w$ intersecta $G$.

Um grafo $G$ é conexo se para quaisquer vértices distintos $u$ e $v$ em $G$ existe um caminho com extremidades $u$ e $v$. Um grafo $G$ é $k$-conexo se o grafo resultante após a remoção de qualquer conjunto de $k-1$ vértices de $G$ é conexo. Dizemos que um conjunto $W$ de vértices de um grafo $G$ é um conjunto separador se $G-W$ é desconexo. Em um grafo $G$, se, para algum vértice $v,\{v\}$ é um conjunto separador de $G$, então dizemos que $v$ é um vértice de corte.

Um grafo $G$ é hamiltoniano-conexo se para todo par de vértices distintos $u$ e $v$ existe em $G$ um caminho hamiltoniano de $u$ a $v$.

Um subgrafo $H$ é dito maximal em relação a uma certa propriedade $\mathcal{P}$ (por exemplo, ser conexo) se $H$ tem a propriedade $\mathcal{P}$, mas nenhum supergrafo próprio de $H$ tem a propriedade $\mathcal{P}$.

Uma componente de um grafo $G$ é um subgrafo conexo maximal de $G$. Um bloco de um grafo $G$ é um subgrafo 2-conexo maximal de $G$ ou um par de vértices ligados por uma aresta que não faz parte de uma componente 2-conexa ou um vértice isolado. Um bloco não trivial é um subgrafo 2-conexo maximal.

Um clique em um grafo é um conjunto de vértices dois a dois adjacentes. Um conjunto de vértices $I$ em um grafo é independente ou estável se os vértices de $I$ são dois a dois não adjacentes.

Definimos a operação de subdividir uma aresta $e=\{u, v\}$ de um grafo da seguinte forma: 
remove-se a aresta $e$ e acrescenta-se um vértice novo $w$ adjacente a $u$ e $v$. Dizemos que um grafo $G$ é uma subdivisão de um grafo $H$ se $G$ pode ser obtido a partir de $H$ através de operações de subdivisão. Dizemos que um grafo $G$ contém um grafo $H$ como menor topológico, se $G$ contém um subgrafo que é uma subdivisão de $H$.

Para um bloco não trivial $B$ de um grafo $G$, dizemos que um caminho $P$ em $G$ de comprimento pelo menos um é um caminho pendente de $B$ se $P$ intersecta $B$ precisamente na sua origem e é maximal na direção do seu término.

\subsection{Classes de grafos}

Nessa seção, definimos as classes de grafos mais relevantes para essa dissertação e apresentamos dois diagramas que retratam a relação de inclusão entre as classes citadas nesse trabalho. Para mais informações sobre classes de grafos, sugerimos o livro de Brandstädt, Le e Spinrad [18].

Uma árvore é um grafo conexo sem circuitos. Um cacto é um grafo conexo cujos blocos são arestas ou circuitos. Um grafo de blocos é um grafo conexo cujos blocos são arestas ou cliques.

Um grafo completo com $n$ vértices é um grafo em que todo par de vértices distintos é ligado por uma aresta e é denotado por $K_{n}$. Um $K_{3}$ também é chamado de triângulo. Um grafo $G$ é bipartido se existe uma bipartição $\{X, Y\}$ dos vértices de $G$ tal que toda aresta de $G$ tem uma extremidade em $X$ e outra em $Y$. Um grafo bipartido $G$ com partes de ordem $m$ e $n$ é dito bipartido completo e denotado $K_{m, n}$, se todo par de vértices de partes distintas é ligado por uma aresta.

Um grafo é um grafo dividido (ou um grafo split) se o conjunto de seus vértices pode ser particionado em dois conjuntos $X$ e $Y$, tais que $X$ induz um clique e $Y$ um conjunto independente.

Um grafo é planar se pode ser desenhado no plano sem que as curvas que representam arestas se cruzem (dizemos que duas arestas se cruzam se estas se intersectam em algum ponto que não suas extremidades). Chamamos um tal desenho de imersão planar do grafo.

Um grafo é exoplanar se possui uma imersão planar na qual todos os vértices pertencem à fronteira da face externa. Um grafo $G$ é $k$-exoplanar se para $k=1, G$ é exoplanar e para $k>1, G$ possui uma imersão planar na qual a remoção de todos os vértices pertencentes à fronteira da face externa resulta em um grafo $(k-1)$-exoplanar.

Uma $k$-árvore é definida recursivamente da seguinte maneira. $\mathrm{O}$ grafo completo com $k$ vértices é uma $k$-árvore. O grafo obtido a partir de uma $k$-árvore $G$ adicionando um vértice adjacente a todos os vértices de um clique de ordem $k$ de $G$ é uma $k$-árvore. Uma $k$-árvore parcial é um grafo que é um subgrafo de alguma $k$-árvore.

Um grafo é um grafo de intervalos se existir um conjunto de intervalos na reta real tal que cada vértice do grafo esteja associado a um intervalo e existe uma aresta entre dois vértices se e somente se os intervalos correspondentes se intersectam.

Os diagramas das Figuras 2.1 e 2.2 retratam a relação de inclusão entre algumas classes de grafos. Uma seta de um conjunto $A$ para um conjunto $B$ indica que $B \subset A$. Explicamos no Capítulo 6 o motivo de algumas elipses estarem hachuradas, outras com fundo branco e outras com fundo mais escuro.

O diagrama da Figura 2.1 retrata a relação de inclusão entre algumas classes de grafos perfeitos que mencionamos ao longo do trabalho. 


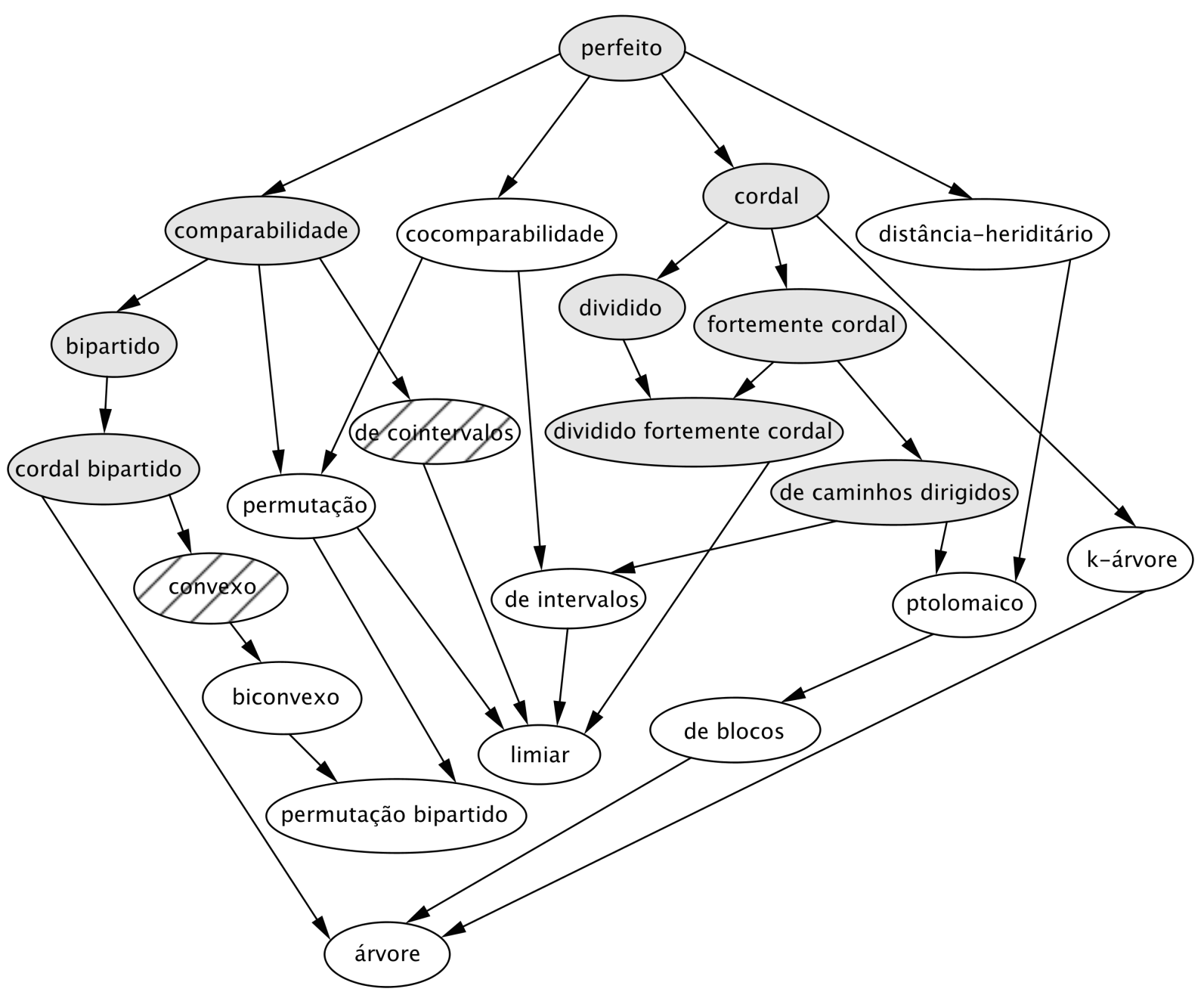

Figura 2.1: Relação entre classes de grafos perfeitos.

O diagrama da Figura 2.2 retrata a relação de inclusão entre algumas classes de grafos não necessariamente perfeitos. As elipses com bordas em negrito são as que se referem a grafos perfeitos. Tais grafos, excetuando-se o grafo de permutação, são subgrafos dos grafos cordais.

\subsection{Algoritmos de aproximação}

Nesta seção definimos alguns conceitos relacionados com algoritmos de aproximação. Para mais detalhes, recomendamos consultar o livro Approximation Algorithms de Vazirani [91]. Para termos usuais de complexidade não definidos aqui (por exemplo, $\mathbf{P}, \mathbf{N P}, \mathrm{O}(f(n)), \Theta(f(n)), \Omega(f(n))$ ), sugerimos o livro de Garey e Johnson [42].

Seja $\mathcal{A}$ um algoritmo que encontra uma solução viável para qualquer instância de um problema de maximização (resp. minimização) $P$. Dizemos que $\mathcal{A}$ é uma $\alpha$-aproximação para $P$ se, para qualquer instância $I$ do problema, o algoritmo $\mathcal{A}$ produz, em tempo polinomial no tamanho da instância $I$, uma solução $\mathcal{A}(I)$ tal que valor $(\mathcal{A}(I)) \geq \alpha \operatorname{opt}(I)$ (resp. valor $(\mathcal{A}(I)) \leq \alpha \operatorname{opt}(I)$ ), onde $\alpha$ é uma constante ou uma função que depende de $I$, e opt $(I)$ denota o valor de uma solução ótima para a instância $I$. Dizemos que $\alpha$ é a razão de aproximação do algoritmo $\mathcal{A}$. Note que, no caso de um problema de maximização, $0<\alpha \leq 1$. 


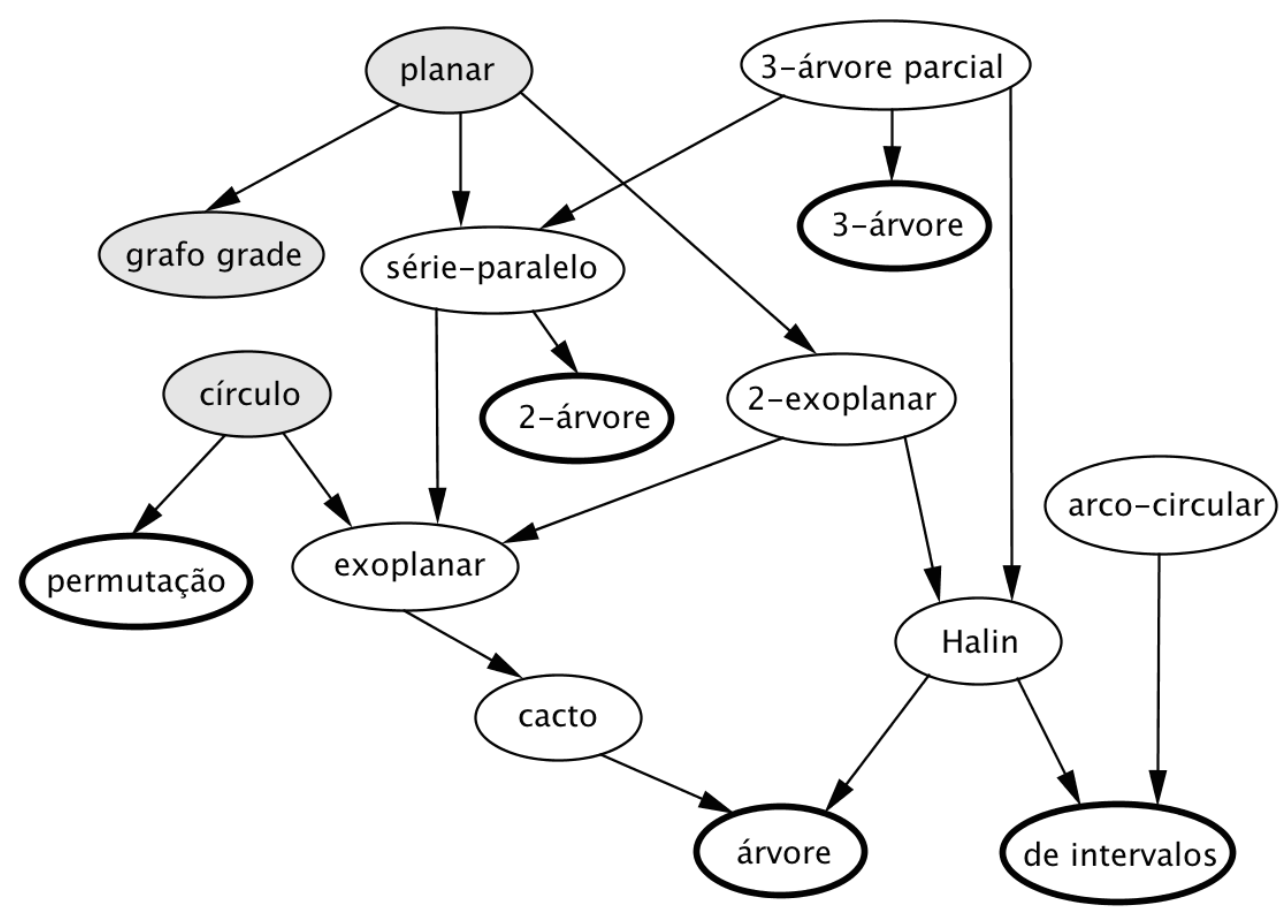

Figura 2.2: Relação entre classes de grafos não necessariamente perfeitos (as elipses em negrito indicam classes de grafos perfeitos).

Assim, no problema de encontrar um caminho mais longo, para qualquer instância $G$ do problema, um algoritmo $\mathcal{A}$ é uma $\alpha$-aproximação para esse problema se $\mathcal{A}$ encontra, em tempo polinomial, um caminho $P$ em $G$ tal que $\|P\| \geq \alpha \operatorname{opt}(G)$, onde opt $(G)$ é o comprimento de um caminho mais longo em $G$.

Claramente, os algoritmos de aproximação mais desejados são aqueles que obtêm valores mais próximos do ótimo. Os algoritmos que encontram soluções com valor tão próximo quanto se queira de uma solução ótima, em tempo polinomial no tamanho da instância, são chamados de PTAS (Polynomial Time Approximation Scheme). Mais precisamente, para cada constante positiva $\epsilon$ (que pode ser tomada tão pequena quanto se queira) tais algoritmos têm fatores de aproximação $(1-\epsilon)$, no caso de problemas de maximização, e $(1+\epsilon)$, no caso de problemas de minimização, e são polinomiais considerando $\epsilon$ fixo.

Observamos que, conforme a definição que adotamos, algoritmos de aproximação são sempre polinomiais (no tamanho da entrada).

Problemas nos quais algum parâmetro $k$ é fixado, são chamados de problemas parametrizados. Dizemos que um problema $P$ é FPT (Fixed Parameter Tractable) com respeito ao parâmetro $k$, se existe um algoritmo de complexidade $\mathrm{O}\left(f(k) n^{\mathrm{O}(1)}\right)$ para $P$, onde $f$ é uma função de $k$ que independe de $n$, o tamanho da instância considerada. 
Parte I

\section{Resultados estruturais}





\section{Capítulo 3}

\section{Classes de grafos em que todos os caminhos mais longos se intersectam}

Embora tenhamos visto diversos grafos para os quais a pergunta de Gallai tem resposta negativa, existem classes de grafos para as quais a resposta é sempre positiva. Por exemplo, em uma árvore, todos os caminhos mais longos contêm o(s) seu(s) centro(s). Em 1990, Klavžar e Petkovšek [68] provaram que a resposta também é positiva para grafos divididos, cactos e algumas outras classes de grafos. Mais recentemente, Balister, Győri, Lehel e Schelp [10] estabeleceram um resultado semelhante para a classe dos grafos de intervalo. Apresentamos alguns desses resultados nas subseções a seguir. Para facilitar a compreensão, procuramos detalhar algumas passagens que nos pareceram de maior relevância.

Mais adiante nessa seção, demonstramos os resultados que obtivemos [32] nessa direção. Provamos que, para grafos exoplanares e 2-árvores, a resposta à pergunta de Gallai também é positiva. Recentemente, Ehremüller, Fernandes e Heise [34] provaram que o mesmo vale para grafos sérieparalelos, uma superclasse dos grafos exoplanares e das 2-árvores. Entretanto, há diversas classes de grafos para as quais o problema continua em aberto.

Para evitar confusão, note que em algumas publicações [11, 65, 71, 80], é dito que a pergunta de Gallai foi: Existem grafos conexos tais que todo vértice é evitado por algum caminho mais longo? Embora as duas perguntas sejam equivalentes, pode surgir confusão quanto ao significado de que a pergunta de Gallai tem resposta positiva para um grafo (ou uma classe de grafos). Enquanto que nos artigos citados acima é dito que a pergunta de Gallai tem resposta positiva para um grafo (ou que um grafo tem a propriedade de Gallai) se a intersecção de todos os seus caminhos mais longos é vazia, nessa dissertação decidimos seguir a definição mais usual da pergunta de Gallai, que é também aquela que aparece na ata do colóquio em Tihany [35]. Portanto, dizemos que a pergunta de Gallai tem resposta positiva para uma classe de grafos se, para qualquer grafo dessa classe, todos os seus caminhos mais longos têm necessariamente um vértice em comum.

\subsection{Resultados conhecidos}

\subsection{1 Árvores}

Um primeiro resultado, fácil de se provar, é que em árvores todos os caminhos mais longos têm um vértice em comum. Isso é um corolário da seguinte proposição, que pode ser demonstrada por 
indução no número de vértices do grafo.

Proposição 2 Seja $G$ uma árvore e seja $\mathscr{P}$ um conjunto de subárvores de $G$. Se duas a duas todas as árvores de $\mathscr{P}$ se intersectam, então todas se intersectam em pelo menos um vértice.

Prova. Vamos provar, por indução no número de vértices de $G$, que existe um vértice $v \in V(G)$ tal que $v \in \bigcap_{P \in \mathscr{P}} P$. Suponha que o resultado vale para todas as árvores com no máximo $n-1$ vértices e seja $G$ uma árvore com $n$ vértices.

Se alguma árvore $P^{*} \in \mathscr{P}$ está constituída de um único vértice $v$, então necessariamente $\bigcap_{P \in \mathscr{P}} P=\{v\}$ (pois $P^{*} \cap P \neq \emptyset$ para todo $P \in \mathscr{P}$ ). Então podemos supor que toda árvore em $\mathscr{P}$ tem ao menos dois vértices.

Seja $u$ um vértice de grau 1 em $G$ e seja $w$ o único vizinho de $u$. Seja $G^{\prime}=G-u$ e seja $\mathscr{P}^{\prime}=\{P-u: P \in \mathscr{P}\}$. Precisamos mostrar que duas a duas todas as árvores de $\mathscr{P}^{\prime}$ se intersectam. Sejam $Q^{\prime}$ e $R^{\prime}$ duas árvores quaisquer de $\mathscr{P}^{\prime}$ e sejam $Q$ e $R$ as árvores correspondente em $\mathscr{P}$. Seja $v$ um vértice tal que $v \in Q \cap R$. Se $v \neq u$, então $v \in Q^{\prime} \cap R^{\prime}$. Se $v=u$, como $Q$ e $R$ têm ao menos dois vértices, então $w \in Q \cap R$ e, portanto, $w \in Q^{\prime} \cap R^{\prime}$. Concluímos, pela hipótese de indução, que $\bigcap_{P^{\prime} \in \mathscr{P}^{\prime}} P^{\prime} \neq \emptyset, \log 0 \bigcap_{P \in \mathscr{P}} P \neq \emptyset$.

O resultado acima mostra que conjuntos de subárvores de uma árvore têm a chamada "Propriedade Helly".

Dado um grafo $G$, dizemos que um vértice $v \in V(G)$ é um centro do grafo se $\max \{d(v, u)$ : $u \in V(G)\}$ é o menor possível. Um resultado bem conhecido, provado em 1869 por Jordan [64], estabelece que toda árvore possui 1 ou 2 centros, sendo que, neste último caso, os centros são adjacentes. No caso em que as subárvores na Proposição 2 são caminhos mais longos em $G$, é possível provar que todos os caminhos mais longos contêm o(s) centro(s) da árvore.

\subsubsection{Grafos divididos}

Klavžar e Petkovšek [68] provaram que grafos divididos têm pelo menos um vértice na intersecção de todos os caminhos mais longos.

Teorema 3 Para todo grafo dividido conexo $G$, existe um vértice comum a todos os caminhos mais longos em $G$.

Prova. Seja $\mathscr{P}$ o conjunto de todos os caminhos mais longos de $G$. Seja $V(G)=K \cup S$, onde $K$ é um clique e $S$ é um conjunto independente com $|S|$ é maximal. Seja $x \in K$ (se não existisse tal $x$, como $G$ é conexo, $G$ possuiria apenas um vértice, e a afirmação seria imediata). Suponha que exista um caminho mais longo $P$ que não passe por $x$. Como $S$ é um conjunto independente maximal, existe um vértice $y \in S$ tal que $x y$ é uma aresta de $G$.

Suponha que $P$ não passe por $y$. Observe que ambas as extremidades de $P$ pertencem a $S$, pois caso contrário $P x$ ou $x P$ seria um caminho mais longo que $P$. Portanto, $P=P^{\prime} u v$, onde $u \in K$ e $v \in S$. Nesse caso, $P^{\prime} u x y$ seria um caminho maior que $P$.

Suponha, então, que $P$ passe por $y$. Seja $w \in K$ um vizinho de $y$ em $P$. Note que é possível construir um caminho maior que $P$ inserindo $x$ entre $w$ e $y$.

Em ambos os casos, a suposição de que $x$ não está no caminho $P$ levou a uma contradição. Segue que $K \subseteq \bigcap \mathscr{P}$, e, portanto, a intersecção dos caminhos mais longos não é vazia. 


\subsubsection{Grafos de intervalos}

Balister e outros [10] provaram que grafos de intervalos têm pelo menos um vértice na intersecção de todos os caminhos mais longos.

Teorema 4 Para todo grafo de intervalos conexo $G$, existe um vértice comum a todos os caminhos mais longos em $G$.

Prova. Seja $\mathcal{F}$ uma coleção de intervalos abertos na reta real associados ao grafo $G$. Dizemos que $\mathcal{C}=\left(I_{1}, I_{2}, \ldots, I_{t}\right)$ é uma $t$-cadeia em $\mathcal{F}$ se, para $I_{i}, I_{j} \in \mathcal{F}$, temos que $I_{i} \neq I_{j}$, se $i \neq j$, e $I_{k} \cap I_{k+1} \neq \emptyset$ para todo $k \in\{1 \ldots t-1\}$. Uma cadeia que contém o maior número de intervalos é chamada de cadeia mais longa de $\mathcal{F}$. Observe que cadeias em $\mathcal{F}$ correspondem a caminhos em $G$ (veja Figura 3.1).

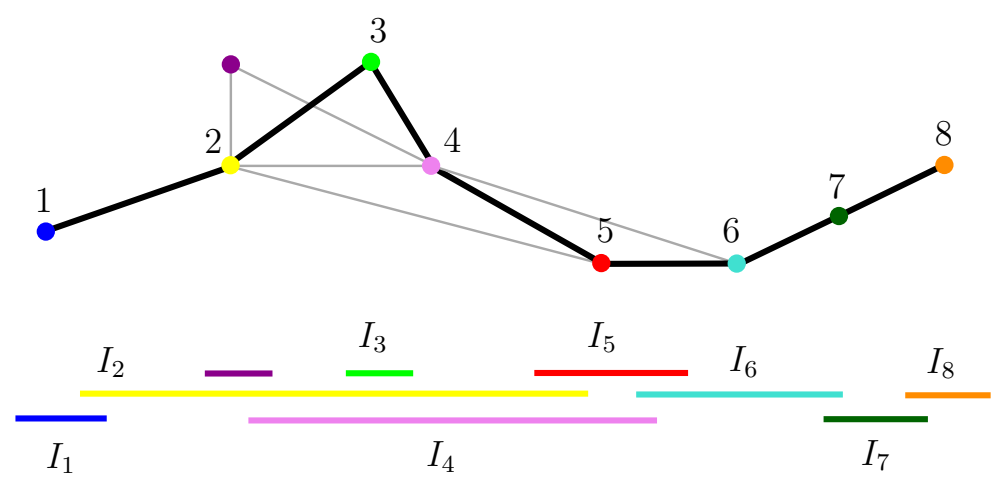

Figura 3.1: Caminho mais longo em $G$ e respectiva cadeia mais longa em $\mathcal{F}$.

O suporte de uma cadeia $\mathcal{C}$ (veja Figura 3.2) é definido como o conjunto

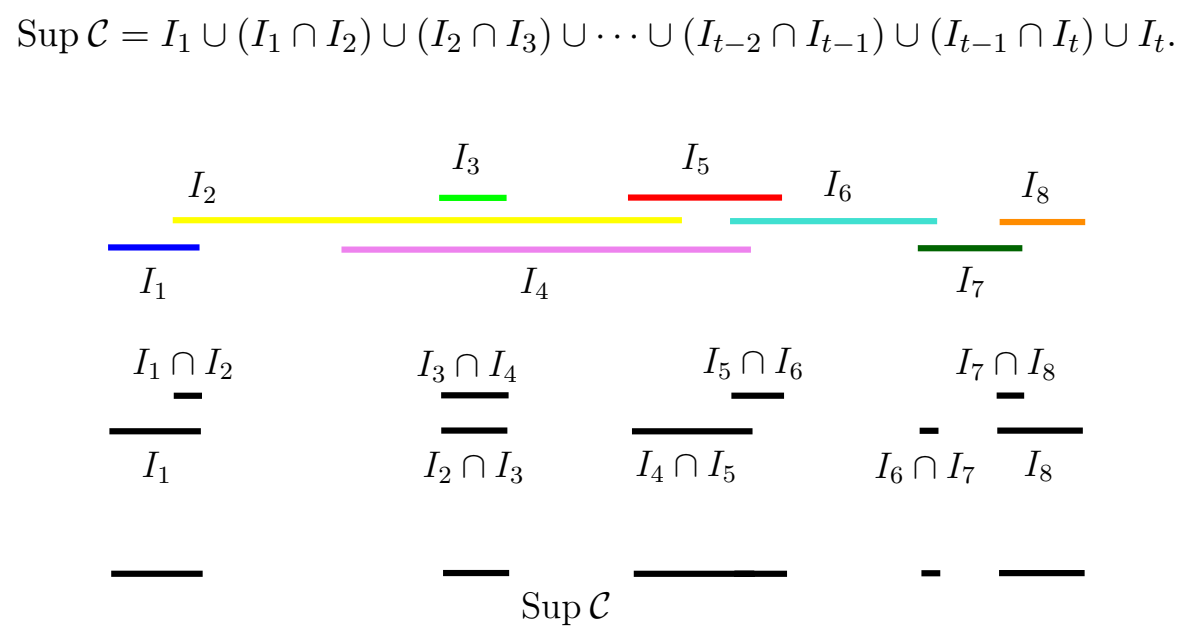

Figura 3.2: Suporte de $\mathcal{C}$.

Observe que para uma cadeia mais longa $\mathcal{C}$ e um intervalo $J \in \mathcal{F}$, temos que $J \in \mathcal{C}$ se e somente se $J \cap \operatorname{Sup} \mathcal{C} \neq \emptyset$. Pela definição de $\operatorname{Sup} \mathcal{C}$, não é difícil ver que, se $J \in \mathcal{C}$, então $J \cap \operatorname{Sup} \mathcal{C} \neq \emptyset$. Para provar a outra direção do bicondicional, observe que se $J \notin \mathcal{C}$ e $J \cap \operatorname{Sup} \mathcal{C} \neq \emptyset$, então é possível aumentar a cadeia $\mathcal{C}$. De fato, se $J \cap\left(I_{k} \cap I_{k+1}\right) \neq \emptyset$, para algum $k \in\{1 \ldots t-1\}$, então $J$ pode 
ser inserido entre $I_{k}$ e $I_{k+1}$; se $J \cap I_{1} \neq \emptyset$, então $J$ pode ser inserido ao início de $\mathcal{C}$; e se $J \cap I_{t} \neq \emptyset$, então $J$ pode ser inserido ao final de $\mathcal{C}$. Isso contradiz o fato de $\mathcal{C}$ ser maximal.

Vamos mostrar que existe um intervalo comum a todas as cadeias mais longas de $\mathcal{F}$. Suponha que $t$ seja o maior número de intervalos de uma cadeia em $\mathcal{F}$, e seja $L$ o número de $t$-cadeias em $\mathcal{F}$. Vamos provar, por indução no número de $t$-cadeias, que todo conjunto de $\ell t$-cadeias de $\mathcal{F}$ têm um intervalo em comum. Pela correspondência entre cadeias e caminhos, temos, pela Asserção 1, que isso é verdade para $\ell=2$.

Para $\ell \geq 3$, sejam $\mathcal{C}_{1}, \mathcal{C}_{2}, \ldots, \mathcal{C}_{\ell} \ell$ cadeias mais longas de $\mathcal{F}$, onde $\mathcal{C}_{k}=\left(I_{1}^{k}, \ldots, I_{t}^{k}\right), 1 \leq k \leq \ell$. Pela hipótese de indução temos que, para cada $k \in\{1 \ldots \ell\}$, existe um intervalo $J_{k} \in \mathcal{F}$ tal que

$$
J_{k} \in \bigcap\left\{\mathcal{C}_{i}: 1 \leq i \leq \ell \text { e } i \neq k\right\}
$$

Se $J_{k} \cap \operatorname{Sup} \mathcal{C}_{k} \neq \emptyset$, então $J_{k} \in \mathcal{C}_{k}$, e a prova está completa. Logo, podemos supor que $J_{k} \cap \operatorname{Sup} \mathcal{C}_{k}=\emptyset$. Na realidade podemos supor algo mais forte: $J_{k} \cap \operatorname{Conv}\left(\operatorname{Sup} \mathcal{C}_{k}\right)=\emptyset$, onde $\operatorname{Conv}\left(\operatorname{Sup} \mathcal{C}_{k}\right)$ é o fecho convexo de $\operatorname{Sup} \mathcal{C}_{k}$, ou seja, o menor intervalo contendo $\operatorname{Sup} \mathcal{C}_{k}$. De fato, considerando que $J_{k} \cap \operatorname{Sup} \mathcal{C}_{k}=\emptyset$, suponha que $J_{k} \cap \operatorname{Conv}\left(\operatorname{Sup} \mathcal{C}_{k}\right) \neq \emptyset$ (ou seja, estamos supondo que existam pontos de $\operatorname{Sup} \mathcal{C}_{k}$ de ambos os lados de $J_{k}$ ). Logo, existe $r \in\{1 \ldots t\}$ tal que $J_{k}$ está entre os intervalos $I_{r-1}^{k} \cap I_{r}^{k}$ e $I_{r}^{k} \cap I_{r+1}^{k}$. Portanto, temos que $I_{r}^{k} \supseteq J_{k}$. Para cada $i \in\{1 \ldots \ell\}$, $i \neq k$, como $J_{k} \in \mathcal{C}_{i}$, temos que $I_{r}^{k} \cap \operatorname{Sup} \mathcal{C}_{i} \neq \emptyset$ o que implica que $I_{r}^{k} \in \mathcal{C}_{i}$. Ademais, $I_{r}^{k} \in \mathcal{C}_{k}$, logo concluímos que $I_{r}^{k} \in \bigcap\left\{\mathcal{C}_{i}: 1 \leq i \leq \ell\right\}$.

Agora suponha $J_{k} \cap \operatorname{Conv}\left(\operatorname{Sup} \mathcal{C}_{k}\right)=\emptyset$, para cada $k \in\{1 \ldots \ell\}$. Isso significa que, para cada $k \in\{1 \ldots \ell\}$, ou $J_{k}<\operatorname{Sup} \mathcal{C}_{k}$ ou $J_{k}>\operatorname{Sup} \mathcal{C}_{k}$, onde a desigualdade representa a ordenação da esquerda para direita de intervalos disjuntos. Como $\ell \geq 3$, existem dois índices para os quais a desigualdade vale no mesmo sentido. Sem perda de generalidade, vamos supor que Sup $\mathcal{C}_{1}<J_{1}$ e $\operatorname{Sup} \mathcal{C}_{2}<J_{2}$. Assim, temos que $\operatorname{Sup} \mathcal{C}_{1}<J_{2}$ ou $\operatorname{Sup} \mathcal{C}_{2}<J_{1}$. Em qualquer caso, isso contradiz a hipótese de indução que $J_{2} \in \mathcal{C}_{1}$ e $J_{1} \in \mathcal{C}_{2}$.

Uma classe de grafos que inclui os grafos de intervalos é a dos grafos cordais (veja Figura 2.1), que também contém a classe dos grafos divididos, para a qual o resultado já foi provado na Seção 3.1.2. Embora Balister e outros [10] também tenham estudado esse problema para os grafos cordais, não conseguiram generalizar a prova apresentada acima, e, portanto, o problema continua aberto para essa classe.

Outra classe de grafos que inclui os grafos de intervalos são os grafos arco-circulares (veja Figura 2.2). Esses mesmo autores [10] procuraram generalizar o resultado de grafos de intervalos para incluir os grafos arco-circulares mas, embora no artigo citado acima afirmem que seja possível fazer isso, existe uma falha na generalização, conforme observa Rautenbach e Sereni [77]. Recentemente, Joos [62] afirma ter conseguido sanar a falha, e, portanto, o resultado vale também para grafos arco-circulares.

\subsubsection{Uma condição necessária e suficiente}

Klavžar e Petkovšek [68] apresentaram uma caracterização para grafos que têm um vértice comum a todos os seus caminhos mais longos em termos de uma condição restrita aos seus blocos. 
Teorema 5 Seja $G$ um grafo conexo e seja $\mathscr{P}$ o conjunto de todos os seus caminhos mais longos. Existe um vértice comum a todos os caminhos de $\mathscr{P}$ se e somente se, para todo bloco $B$ de $G$, todos os caminhos de $\mathscr{P}$ que têm pelo menos uma aresta em $B$ têm um vértice em comum.

Em vista desse resultado, para mostrar que todos os caminhos mais longos têm um vértice em comum, basta provar que, para cada bloco $B$ de $G$, todos os caminhos mais longos que usam ao menos uma aresta de $B$ têm um vértice em comum.

Se $\mathscr{P}$ é um conjunto de caminhos mais longos, chamamos de $\mathscr{P}_{B}$ o subconjunto de $\mathscr{P}$ formado pelos caminhos que possuem pelo menos uma aresta de $B$. O Teorema 5 pode ser escrito como: se $\widetilde{\mathscr{P}}$ é o conjunto de todos os caminhos mais longos de $G$, então $\bigcap \widetilde{\mathscr{P}} \neq \emptyset \Leftrightarrow \bigcap \widetilde{\mathscr{P}}_{B} \neq \emptyset$ para todo bloco $B$ de $G$.

A prova (da suficiência da condição nos blocos) desse teorema de Klavžar e Petkovšek na realidade demonstra o seguinte teorema, que é um pouco mais forte do que o resultado que enunciam. Note que o conjunto $\mathscr{P}$ do teorema a seguir não é necessariamente o conjunto de todos os caminhos mais longos do grafo, como no enunciado do Teorema 5.

Teorema 6 Seja $G$ um grafo conexo e seja $\mathscr{P}$ um conjunto qualquer de caminhos mais longos. Se não existe um vértice comum a todos os caminhos de $\mathscr{P}$, então existe um bloco de $G$ que contém ao menos uma aresta de cada caminho de $\mathscr{P}$.

Prova. Queremos provar que ou todos os caminhos de $\mathscr{P}$ se intersectam ou existe um bloco $B$ tal que $\mathscr{P}_{B}=\mathscr{P}$. Vamos distinguir dois casos.

Caso 1: Para cada par de caminhos, existe um bloco no qual ambos têm uma aresta.

Nesse caso, seja $T(G)$ a árvore de blocos associada a $G$. Considere $\mathscr{B}$ o conjunto de blocos de $G$ e $\mathscr{W}$ o conjunto de vértices de corte de $G$. Nesse caso, o conjunto de vértices de $T(G)$ é $\mathscr{B} \cup \mathscr{W}$ e existe uma aresta com extremidades $B \in \mathscr{B}$ e $w \in \mathscr{W}$ se $w \in B$. Se $P$ é um caminho em $G$, denotamos por $f(P)$ a imagem de $P$ em $T(G)$, ou seja, $f(P)$ é o caminho em $T(G)$ tal que um vértice $x$ de $T(G)$ pertence a $f(P)$ se e somente se $x$ intersecta $P$.

Sejam $f\left(P_{1}\right)$ e $f\left(P_{2}\right)$ um par de caminhos em $\{f(P): P \in \mathscr{P}\}$. Pela hipótese, existe um bloco em $G$ no qual $P_{1}$ e $P_{2}$ têm uma aresta, e, portanto, $f\left(P_{1}\right)$ e $f\left(P_{2}\right)$ se intersectam em $T(G)$. Como isso vale para qualquer par de caminhos em $\{f(P): P \in \mathscr{P}\}$, então, pela Proposição 2, existe $v \in \bigcap\{f(P): P \in \mathscr{P}\}$. Se $v$ corresponde a um vértice de corte $x$ de $G$, então $x \in \bigcap \mathscr{P}$. Se $v$ corresponde a um bloco $B$ de $G$, então $\mathscr{P}=\mathscr{P}_{B}$.
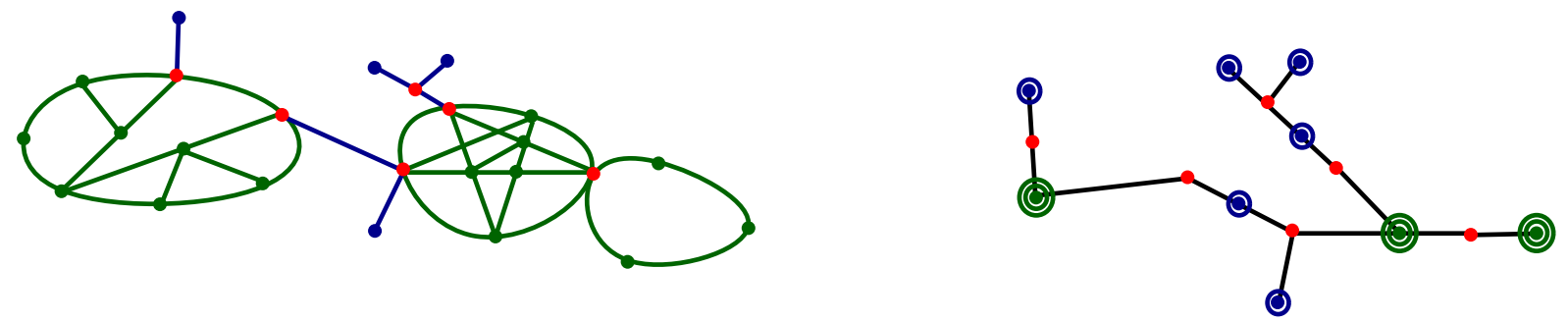

Figura 3.3: Um exemplo de um grafo $G$ (lado esquerdo) e sua árvore de blocos $T(G)$ (lado direito). Os vértices de corte em $G$ correspondem aos vértices menores em $T(G)$, e os blocos correspondem aos vértices maiores (os não triviais correspondem aos vértices de borda dupla).

Caso 2: Existem dois caminhos $P, Q \in \mathscr{P}$ tais que não existe nenhum bloco no qual ambos têm uma aresta. 
Nesse caso, $P$ e $Q$ não têm mais de um vértice em comum, pois se tivessem, ou teriam uma aresta em comum ou existiria um circuito em $G$ formado por arestas de $P$ e $Q$. Em ambos os casos, existiria um bloco no qual ambos têm uma aresta. Logo, seja $x$ o único vértice em $P \cap Q$. Afirmamos que $x \in \bigcap \mathscr{P}$. Suponha, por contradição, que $R \in \mathscr{P}$ não contenha $x$. Sabemos pela Asserção 1 que $R$ intersecta $P$ e intersecta $Q$. Seja $y \in P \cap R$ tal que $P_{x y}$ é mínimo (não existe nenhum vértice interno de $P_{x y}$ que pertence a $R$ ) e seja $z \in Q \cap R$ tal que $Q_{x z}$ é mínimo. Como $R$ não contém $x$, temos que $x \neq y$ e $x \neq z$. Além disso, como $x$ é o único vértice que pertence a $P$ e $Q$, então $y \neq z$ (veja Figura 3.4).

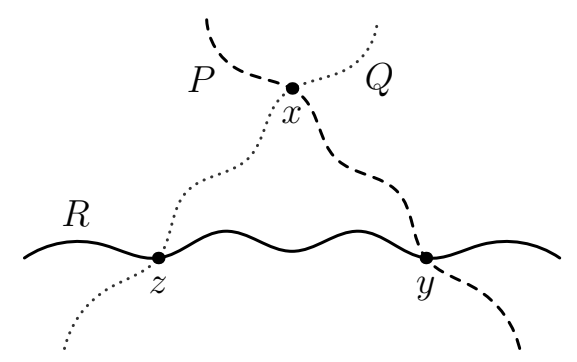

Figura 3.4: Circuito $P_{x y} \cdot R_{y z} \cdot Q_{z x}$.

Observe que $P_{x y} \cdot R_{y z} \cdot Q_{z x}$ forma um circuito. Como $\left\|P_{x y}\right\| \geq 1$ e $\left\|Q_{z x}\right\| \geq 1$, temos que existe um bloco que contém pelo menos uma aresta de $P$ e pelo menos uma aresta de $Q$, o que é uma contradição. Logo, todo caminho em $\mathscr{P}$ necessariamente contém $x$.

Observe que o Teorema 5 implica que, se $G$ é um cacto, um grafo de blocos ou se todo bloco de $G$ é hamiltoniano-conexo, então todos os caminhos mais longos de $G$ têm um vértice em comum.

\subsection{Resultados que obtivemos}

Apresentamos, nessa seção, duas classes de grafos para os quais provamos que a intersecção de todos os seus caminhos é não vazia.

\subsubsection{Grafos exoplanares}

Uma classe de grafos que contém os cactos é a classe dos grafos exoplanares. Como já mencionamos, Klavžar and Petkovšek [68] provaram que a resposta para a pergunta de Gallai é positiva para cactos, enquanto Axenovich [9] provou que quaisquer três caminhos mais longos se intersectam em grafos exoplanares. Nessa seção, generalizamos [32] esses dois resultados, provando que a resposta à pergunta de Gallai é positiva para grafos exoplanares.

Lembramos que, para um bloco não trivial $B$ de um grafo $G$, dizemos que um caminho $P$ em $G$ de comprimento pelo menos um é um caminho pendente de $B$ se $P$ intersecta $B$ precisamente na sua origem e é maximal na direção do seu término.

Teorema 7 Para todo grafo exoplanar conexo $G$, existe um vértice comum a todos os caminhos mais longos em $G$.

Prova. Seja $\mathscr{P}$ o conjunto de todos os caminhos mais longos de $G$, e suponha, por contradição, que $\bigcap \mathscr{P}=\emptyset$. Pelo Teorema 6 , existe um bloco $B$ de $G$ tal que cada caminho em $\mathscr{P}$ tem ao menos 
uma aresta em $B$. Se $B$ é um bloco trivial, segue imediatamente que todos os caminhos em $\mathscr{P}$ têm um vértice em comum. Portanto, suponha que $B$ seja um bloco não trivial.

Seja $C$ um circuito hamiltoniano em $B$ (tal circuito existe pois $G$ é exoplanar). Seja $R^{\star}$ um caminho pendente mais longo de $B$, e denote por $v$ a origem de $R^{\star}$. Vamos provar que todos os caminhos em $\mathscr{P}$ contêm $v$.

Suponha que exista um caminho $P$ em $\mathscr{P}$ que não contém $v$. Considere uma imersão planar do grafo $G$ em que todos os vértices pertencem à fronteira de sua face externa. (Lembre que $c_{u v}$ denota o comprimento de $C_{u v}$, o caminho no sentido horário em $C$ do vértice $u$ ao vértice $v$.) Seja $x$ o vértice em $V(P) \cap V(B)$ tal que $c_{x v}$ é mínimo e seja $y$ o vértice em $V(P) \cap V(B)$ tal que $c_{v y}$ é mínimo. Note que $x \neq y$, caso contrário $P$ intersectaria $B$ somente em $x$.

Agora seja $z$ o vértice tal que $x z \in E(P) \cap E(B)$ e $c_{y z}$ é mínimo. Suponha $y=z$, em outras palavras, suponha que $x$ seja adjacente a $y$ em $P$ (veja a Figura 3.5). Neste caso, considere o caminho $P^{\prime}$ obtido de $P$ substituindo a aresta $x y$ pelo caminho $C_{x y}$, isto é, $P^{\prime}=(P-x y) \cup C_{x y}$. Observe que $P^{\prime}$ é de fato um caminho, pois $C_{x y}$ só intersecta $P$ nos vértices $x$ e $y$. Como $v$ está no interior de $C_{x y}$, então $p^{\prime}=p-1+c_{x y} \geq p-1+2$. Portanto, $p^{\prime}>p$, o que contradiz o fato de $P$ ser um caminho mais longo.

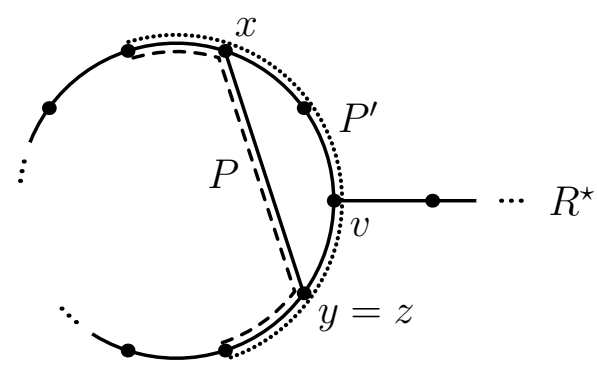

Figura 3.5: Caso $y=z$.

Suponha, então, que $y \neq z$. Sejam $P_{1}$ e $P_{2}$ os dois subcaminhos de $P$ tais que $V\left(P_{1}\right) \cap V\left(P_{2}\right)=$ $\{z\}, P=P_{1} \cdot P_{2}, x \in V\left(P_{1}\right)$ e $y \in V\left(P_{2}\right)$ (veja Figura 3.6). Como $G$ é exoplanar, $P_{2}$ contém somente vértices de $C_{y z}$ e possivelmente um caminho pendente, digamos $R$. Logo, $c_{y z} \geq p_{2}-r$. Agora, considere o caminho $P^{\prime}=P_{1} \cdot C_{v z}^{-1} \cdot R^{\star}$. Temos que $p^{\prime}=p_{1}+c_{v y}+c_{y z}+r^{\star} \geq p_{1}+c_{v y}+p_{2}-r+r^{\star}$. Como $r^{\star} \geq r$ e $c_{v y}>0$, concluímos que $p^{\prime}>p_{1}+p_{2}=p$, o que contradiz o fato de $P$ ser um caminho mais longo em $G$. Portanto, $P$ contém $v$, e isso completa a prova.

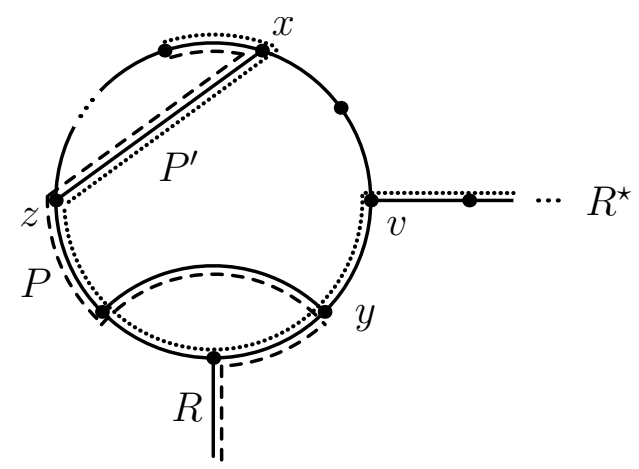

Figura 3.6: Caso $y \neq z$. 
Como vimos anteriormente, a resposta para a pergunta de Gallai é negativa para grafos planares (como nos mostra o grafo da Figura 1.3, o da Figura 1.5 e os grafos planares hipotraçáveis [85]). De fato, a resposta é negativa até para grafos 2-exoplanares, pois o grafo da Figura 1.3 e o da Figura 1.5 são 2-exoplanares. Portanto, nesse sentido, o resultado anterior é justo.

\subsubsection{2-árvores}

O resultado principal que mostramos [32] nessa seção é que para 2-árvores (definidas mais adiante), a resposta para a pergunta de Gallai é positiva. Primeiramente, definimos alguns conceitos e apresentamos alguns resultados auxiliares que valem para grafos arbitrários.

Dados um caminho $P$ em um grafo $G$ e uma aresta $e=x y$, dizemos que $e$ confina $P$ se $P-x-y$ está contido em uma única componente de $G-x-y$. Se $e$ não confina $P$, dizemos que $P$ cruza e. Além disso, se $\mathscr{P}$ denota um conjunto de caminhos mais longos em $G$, então $\mathscr{P}_{e}$ denota o subconjunto de caminhos de $\mathscr{P}$ que cruzam $e$. Observe que se $G-x-y$ é conexo, $\mathscr{P}_{e}$ é vazio.

Lema 8 Seja $G$ um grafo conexo e seja $\mathscr{P}$ o conjunto de todos os caminhos mais longos de $G$. Para cada aresta e de $G$, uma de suas extremidades está contida em todos os caminhos de $\mathscr{P}_{e}$.

Prova. Seja $e=x y$ uma aresta de $G$. Suponha que existam dois caminhos $P$ e $Q$ em $\mathscr{P}_{e}$ tais que $P$ contém $x$, mas não $y$, e $Q$ contém $y$, mas não $x$. Sejam $P=P^{\prime} \cdot P^{\prime \prime} \operatorname{com}\{x\}=V\left(P^{\prime}\right) \cap V\left(P^{\prime \prime}\right)$ e $Q=Q^{\prime} \cdot Q^{\prime \prime} \operatorname{com}\{y\}=V\left(Q^{\prime}\right) \cap V\left(Q^{\prime \prime}\right)$. Como ambos $P$ e $Q$ cruzam $e$, podemos supor, sem perda de generalidade, que $P^{\prime}$ e $Q^{\prime \prime}$ estejam em componentes distintas de $G-x-y$ e que $p^{\prime} \geq q^{\prime}$. Por conseguinte, $P^{\prime} \cdot(x, y) \cdot Q^{\prime \prime}$ é um caminho e é mais longo que $Q$, uma contradição.

Dados um caminho $P$ em um grafo $G$ e uma aresta $e=x y$, defina $C_{e}(P)$ como sendo a união dos conjuntos de vértices das componentes de $G-x-y$ que contêm ao menos um vértice de $P$. Usamos a notação simplificada $C_{e}(v)$ para nos referir a $C_{e}(P)$ quando $P$ consiste apenas no vértice $v$.

Lema 9 Se um grafo conexo $G$ contém caminhos mais longos $P$ e $Q$ e uma aresta e tais que $C_{e}(P) \cap C_{e}(Q)=\emptyset$, então todos os caminhos mais longos em $G$ têm um vértice em comum.

Prova. Suponha que a condição do lema esteja satisfeita, e seja $\mathscr{P}$ o conjunto de todos os caminhos mais longos em $G$. Apresentamos dois casos.

Caso 1: Existe uma escolha para $e, P$ e $Q$ tais que $Q$ intersecta apenas uma extremidade de $e$.

Sejam $x$ e $y$ as extremidades de $e$, e suponha que $Q$ contenha $x$, mas não $y$. Note que $P$ necessariamente contém $x$ pois $C_{e}(P) \cap C_{e}(Q)=\emptyset$, e, pela Asserção $1, P$ e $Q$ necessariamente se intersectam. Seja $P=P^{\prime} \cdot P^{\prime \prime} \operatorname{com}\{x\}=V\left(P^{\prime}\right) \cap V\left(P^{\prime \prime}\right)$ e $y \notin V\left(P^{\prime}\right)$, e $Q=Q^{\prime} \cdot Q^{\prime \prime} \operatorname{com}$ $\{x\}=V\left(Q^{\prime}\right) \cap V\left(Q^{\prime \prime}\right)$. Como $C_{e}(P) \cap C_{e}(Q)=\emptyset$, segue que $P^{\prime} \cdot Q^{\prime}$ é um caminho em $G$. Chame esse caminho de $R$. Na Figura 3.7 mostramos as duas possibilidades para o caminho $P$ : (a) $P$ contém $x$ mas não $y$; (b) $P$ contém $x$ e $y$ (possivelmente a secção de $P$ de $x$ a $y$ é simplesmente a aresta $e$ ). 
(a)

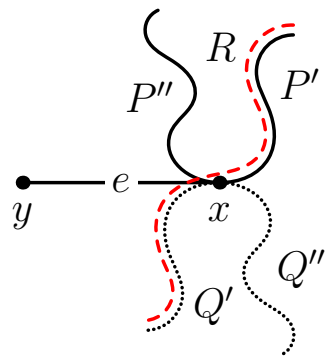

(b)

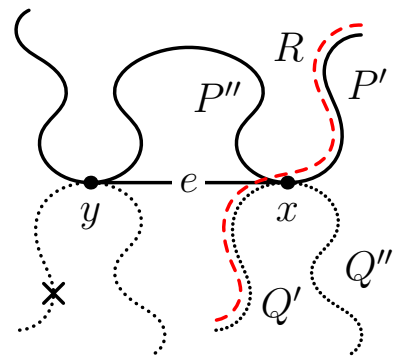

Figura 3.7: $O$ caminho $Q$ contém $x$, mas não $y$.

Note que $R$ cruza $e$, pois $C_{e}\left(P^{\prime}\right) \cap C_{e}\left(Q^{\prime}\right)=\emptyset$. Como $P$ e $Q$ são caminhos mais longos, $P^{\prime}, P^{\prime \prime}$, $Q^{\prime}$, e $Q^{\prime \prime}$ devem ter o mesmo comprimento. Logo, $R$ é também um caminho mais longo. Como $R$ contém $x$ e não $y$, pelo Lema 8 , todos os caminhos em $\mathscr{P}_{e}$ contêm $x$.

Por outro lado, todo caminho mais longo $S$ confinado por $e$ é tal que ou $C_{e}(S) \cap C_{e}(P)=\emptyset$ ou $C_{e}(S) \cap C_{e}(Q)=\emptyset$, pois $C_{e}(P) \cap C_{e}(Q)=\emptyset$. Vamos mostrar que $S$ contém $x$. Suponha que não. Portanto, necessariamente $C_{e}(S) \subseteq C_{e}(Q)$ (caso contrário $S$ não intersectaria $Q$ ) e $S$ necessariamente intersecta $P$ em $y$ como na Figura 3.7(b). Seja $S=S^{\prime} \cdot S^{\prime \prime} \operatorname{com}\{y\}=V\left(S^{\prime}\right) \cap V\left(S^{\prime \prime}\right)$, e suponha que $s^{\prime \prime} \geq s^{\prime}$. Logo, $P^{\prime} \cdot(x, y) \cdot S^{\prime \prime}$ é um caminho mais longo que $P$, uma contradição. Portanto, $S$ contém $x$, e concluímos que todos os caminhos mais longos confinados por $e$ contêm $x$.

Caso 2: Para qualquer escolha de $e=x y, P$ e $Q$ tal que $C_{e}(P) \cap C_{e}(Q)=\emptyset$, vale que ambos $P$ e $Q$ contêm $x$ e $y$.

Seja $S$ um caminho mais longo confinado pela aresta $e$. Nesse caso, ou $C_{e}(S) \cap C_{e}(P)=\emptyset$, ou $C_{e}(S) \cap C_{e}(Q)=\emptyset$. Afirmamos que $S$ contém ambos $x$ e $y$. De fato, se esse não fosse o caso, então $e, S$ e ou $P$ ou $Q$ contradiriam a suposição do caso. Portanto, todos os caminhos mais longos confinados por $e$ contêm ambos $x$ e $y$. Esse fato, juntamente com o Lema 8 , implica que ou $x$ ou $y$ é comum a todos os caminhos mais longos.

Notamos que, no Lema 9, se $G$ é 2-conexo, então a prova acima se reduz somente ao Caso 2, já que é sabido (como veremos no Capítulo 5) que quaisquer dois caminhos mais longos em um grafo 2-conexo se intersectam em ao menos dois vértices. Na prova do resultado principal, só aplicamos o Lema 9 a grafos 2-conexos, mas preferimos provar um resultado mas geral que se aplica também a grafos que não são 2-conexos.

Uma 2-árvore é definida recursivamente da seguinte maneira. Uma aresta é uma 2-árvore. Qualquer grafo obtido a partir de uma 2-árvore adicionando um vértice novo e fazendo-o adjacente às extremidades de uma aresta existente é também uma 2-árvore. Dizemos que uma 2-árvore é não trivial se contém ao menos três vértices. Note que toda aresta em uma 2-árvore não trivial pertence a um triângulo. É sabido [95] que 2-árvores não contêm $K_{4}$ como menor topológico.

Seja $\Delta$ um triângulo em um dado grafo. Para cada aresta $e$ em $\Delta$, denotamos por $v_{e}$ o vértice de $\Delta$ no qual $e$ não incide.

Lema 10 Se $\Delta$ é um triângulo em um grafo $G$, então ou $G$ contém $K_{4}$ como menor topológico ou $C_{e}\left(v_{e}\right) \cap C_{f}\left(v_{f}\right) \cap C_{g}\left(v_{g}\right)=\emptyset$, onde $E(\Delta)=\{e, f, g\}$.

Prova. Suponha que exista $u \in C_{e}\left(v_{e}\right) \cap C_{f}\left(v_{f}\right) \cap C_{g}\left(v_{g}\right)$. Como $u \in C_{e}\left(v_{e}\right)$, temos que $u \notin\left\{v_{f}, v_{g}\right\}$. Semelhantemente, $u \in C_{f}\left(v_{f}\right)$ implica que $u \neq v_{e}$. Logo, $u \notin\left\{v_{e}, v_{f}, v_{g}\right\}$. Além disso, existe um 
caminho, internamente disjunto de $\Delta$, de $u$ para cada vértice de $\Delta$. Portanto, a união desses três caminhos e $\Delta$ gera $K_{4}$ como menor topológico.

O conceito definido a seguir tem um papel importante na prova do resultado principal. Um triângulo $\Delta$ em um grafo conexo $G$ é dito forte se, para cada aresta $e$ em $\Delta$, existe um caminho mais longo $P$ em $G$ tal que $e$ confina $P$, e $C_{e}(P)=C_{e}\left(v_{e}\right)$. Tal caminho é chamado de $e$-confinado, supondo que $\Delta$ esteja claro no contexto.

Lema 11 Se toda aresta de uma 2-árvore não trivial $G$ confina um caminho mais longo então $G$ contém um triângulo forte.

Prova. Seja $G$ uma 2-árvore não trivial em que toda aresta confina um caminho mais longo. Seja $D$ um digrafo construído da seguinte forma. O conjunto de vértice de $D$ é $A \cup B$, onde $A=E(G)$ e $B$ é o conjunto de todos os triângulos em $G$. O conjunto de arcos de $D$ é definido a seguir. Temos um arco $(e, \Delta)$ com $e \in A$ e $\Delta \in B$ se $e$ é uma aresta de $\Delta$ e existe um caminho mais longo $P$ em $G$ que é $e$-confinado.

Pela hipótese do lema, toda aresta em $A$ tem grau de saída ao menos um em $D$. Portanto, existem ao menos $|A| \operatorname{arcos}$ em $D$. Note que, como $G$ é uma 2-árvore, $|A|=2|B|+1$. Logo, existe um triângulo $\Delta$ com grau de entrada pelo menos três em $D$. Pela definição de $D$, temos que $\Delta$ é um triângulo forte em $G$.

Teorema 12 Para toda 2-árvore $G$, existe um vértice comum a todos os caminhos mais longos em $G$.

Prova. Seja $G$ uma 2-árvore não trivial (caso contrário o resultado é imediato). Se existe uma aresta $e$ em $G$ que não confina um caminho mais longo, então todos os caminhos mais longos cruzam e, e, pelo Lema 8, a intersecção de todos os caminhos mais longos é não vazia. Logo, podemos supor que toda aresta em $G$ confina um caminho mais longo e portanto, pelo Lema 11, existe um triângulo forte $\Delta$ em $G$.

Se existe um caminho mais longo $P$ confinado por uma aresta $e$ de $\Delta$ tal que $C_{e}(P) \neq C_{e}\left(v_{e}\right)$ então, pelo Lema 9 , a prova segue. Caso contrário, para cada aresta $e$ em $\Delta$, todo caminho mais longo $P$ confinado por e é tal que $C_{e}(P)=C_{e}\left(v_{e}\right)$, ou seja, é $e$-confinado.

Se todo caminho mais longo $e$-confinado contém ambas as extremidades de $e$, para alguma aresta $e$ em $\Delta$, então, pelo Lema 8 , a interseç̧ão de todos os caminhos mais longos é não vazia.

Se um caminho mais longo $P$ é confinado simultaneamente por todas as arestas de $\Delta$, então $C_{e}(P)=C_{e}\left(v_{e}\right)$ para toda aresta $e$ em $\Delta$. Como $G$ é uma 2-árvore, $G$ não contém um $K_{4}$ como menor topológico. Logo, o Lema 10 implica que $P$ tem apenas (e todos os) vértices em $\Delta$, ou seja, $G$ é precisamente o triângulo $\Delta$, e a prova segue. Portanto, podemos supor que cada caminho mais longo é confinado por no máximo duas arestas de $\Delta$.

Sejam $e, f$ e $g$ as arestas de $\Delta$ e seja $P$ um caminho mais longo confinado por $e$ e $g$. Logo, $P$ cruza $f$. Note que qualquer vértice $u$ de $P$ que não está em $\Delta$ pertence a $C_{g}(P) \cap C_{e}(P)=$ $C_{g}\left(v_{g}\right) \cap C_{e}\left(v_{e}\right)$. Novamente, pelo Lema 10, temos que $u \notin C_{f}\left(v_{f}\right)$. Logo, o único vértice em $C_{f}\left(v_{f}\right)$ que $P$ pode conter é $v_{f}$. Entretanto, como $P$ é um caminho mais longo, se $P$ contém $v_{f}$, então necessariamente contém todos os vértices em $\Delta$. Se $P$ não contém nenhum vértice de $C_{f}\left(v_{f}\right)$, concluímos a prova do teorema aplicando o Lema 9 a $f, P$ e qualquer caminho mais longo $f$-confinado. 
Portanto, daqui em diante supomos que todo caminho mais longo confinado por precisamente duas arestas de $\Delta$ contenha todos os vértices de $\Delta$.

Seja $\mathscr{P}$ o conjunto de todos os caminhos mais longos em $G$. Vamos mostrar que um dos vértices de $\Delta$ está em todos os caminhos em $\mathscr{P}$.

Pelo Lema 8, sabemos que uma das extremidades de cada aresta $h$ de $\Delta$ está contida em todos os caminhos em $\mathscr{P}_{h}$. (Mais adiante dizemos porque cada $\mathscr{P}_{h}$ é não vazio.) Oriente $h$ em direção a tal extremidade. Assim temos uma orientação de $e, f$, e $g$.

Se, com essa orientação, $\Delta$ é um circuito dirigido, sem perda de generalidade, podemos supor que $\Delta$ está orientado como na Figura 3.8.

Para cada aresta $h$ de $\Delta$, seja $Q_{h}$ um caminho mais longo $h$-confinado que não contém ambas as extremidades de $h$. O caminho $Q_{h}$ é confinado por apenas uma aresta de $\Delta$, a saber $h$, e, portanto, cruza as outras duas arestas de $\Delta$. Logo, $\mathscr{P}_{h}$ é não vazio para cada aresta $h$ de $\Delta$. Pela orientação de $f$ e $g$, o caminho $Q_{e}$ contém ambos $v_{e}$ e $v_{f}$. Analogamente, $Q_{f}$ contém ambos $v_{f}$ e $v_{g}$, e $Q_{g}$ contém ambos $v_{g}$ e $v_{e}$. Veja a Figura 3.8.

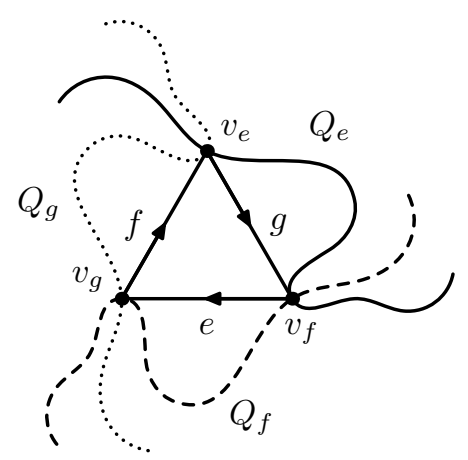

Figura 3.8: Caminhos $Q_{e}, Q_{f}$, e $Q_{g}$.

Seja $Q_{e}=Q_{e}^{\prime} \cdot Q_{e}^{\prime \prime} \operatorname{com}\left\{v_{e}\right\}=Q_{e}^{\prime} \cap Q_{e}^{\prime \prime}$ e $v_{f}$ em $Q_{e}^{\prime \prime}$. Semelhantemente, defina $Q_{f}^{\prime}, Q_{f}^{\prime \prime}$, $Q_{g}^{\prime}$, e $Q_{g}^{\prime \prime}$. Seja $Q=Q_{g}^{\prime} \cdot\left(v_{g}, v_{e}\right) \cdot Q_{e}^{\prime \prime}$. Como esse caminho não pode ser mais longo que $Q_{e}$, temos que $q_{e}^{\prime}>q_{g}^{\prime}$. Analogamente, podemos concluir que $q_{g}^{\prime}>q_{f}^{\prime}>q_{e}^{\prime}$, o que leva a uma contradição.

Resta analisar o caso em que $\Delta$ tem um sorvedouro. Sem perda de generalidade, suponha que $v_{f}$ seja o sorvedouro (veja a Figura 3.9).

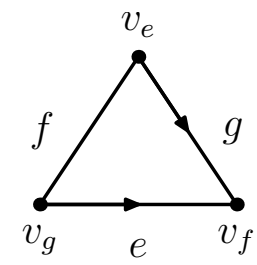

Figura 3.9: Triângulo $\Delta$ com um sorvedouro.

Vamos mostrar que $v_{f}$ está em todos os caminhos mais longos. Seja $P$ um caminho mais longo. Como já observamos, se $P$ é confinado por duas arestas de $\Delta, P$ contém os três vértices de $\Delta$, logo contém $v_{f}$. Suponha que $P$ seja confinado por no máximo uma aresta de $\Delta$. Se $P$ cruza $e$, então $P$ contém $v_{f}$ (pela orientação de $e$ ). Caso contrário $P$ é confinado por $e$ e, portanto, cruza $f$ e $g$. Mas, se $P$ cruza $g$, pela orientação de $g, P$ contém $v_{f}$, e o teorema segue. 


\section{Capítulo 4}

\section{Classes de grafos em que quaisquer três caminhos mais longos se intersectam}

Como vimos anteriormente, não é sabido se quaisquer três caminhos mais longos compartilham um vértice. Essa pergunta foi levantada por Zamfirescu [93, 104] na década de 80 [105]. A questão foi mencionada na $15^{\mathrm{a}}$ Conferência Britânica de Combinatória [21], aparece como conjectura no livro Combinatorics and Graph Theory de Harris, Hirst e Mossinghoff [51] e como um problema aberto na lista coletada e mantida por West [98].

Conjectura 13 Para todo grafo conexo, quaisquer três caminhos mais longos têm um vértice em comum.

\subsection{Resultados conhecidos}

Excluindo os resultados que abrangem a intersecção de todos os caminhos mais longos, um dos primeiros progressos na Conjectura 13 foi obtido por Axenovich [9], que provou o seguinte resultado.

Teorema 14 Se G é um grafo conexo exoplanar, então quaisquer três caminhos mais longos em $G$ têm um vértice em comum.

A principal técnica usada para provar o Teorema 14 foi a de estabelecer configurações que não ocorrem quando se considera a união de três caminhos mais longos, mostrando que, se ocorressem, então seria possível construir um caminho de comprimento maior que o mais longo. A partir dessas configurações foi possível obter alguns outros resultados interessantes, por exemplo:

Lema 15 Seja $G$ um grafo conexo que é a união de três caminhos mais longos, digamos $P_{1}, P_{2} e$ $P_{3}$. Se $P_{1} \cup P_{2}$ tem no máximo um circuito, então existe um vértice comum a $P_{1}, P_{2}$ e $P_{3}$.

Além da técnica citada acima, outro método utilizado foi o de considerar um contraexemplo minimal para a Conjectura 13, ou seja, um grafo com menor número possível de arestas no qual três caminhos mais longo não têm um vértice em comum. Se for possível chegar a uma contradição, supondo que tal grafo exista, então sabe-se que a Conjectura 13 é válida.

Axenovich [9] considera um contraexemplo minimal dentro da classe dos grafos exoplanares. Observe que não se pode usar essa técnica para qualquer classe de grafos, pois ao contrairmos ou 
removermos uma aresta, o grafo resultante pode não estar na classe original. Portanto, além do caso em que se considera o problema geral para qualquer grafo, só é possível usar essa técnica para classes de grafos que são fechadas para operações de remoção/contração de arestas, como é o caso da classe dos grafos exoplanares ou dos planares.

Axenovich [9] provou que, para qualquer classe de grafos fechada para operações de remoção/contração de arestas, um contraexemplo minimal para a Conjectura 13 possui apenas um bloco não trivial.

Essa técnica também foi explorada por Kensell [67], que obteve outros resultados, dentre eles algumas características de um contraexemplo minimal como, por exemplo, cintura pelo menos 4 . Kensell obteve uma leve generalização do Teorema 14, provando que o resultado vale para grafos que são subdivisões de grafos exoplanares.

Não reproduzimos aqui a prova de Axenovich [9] para o Teorema 14, pois é muito extensa. Ademais, este segue como corolário do Teorema 7 e, como veremos a seguir, também segue do Teorema 16.

\subsection{Resultados que obtivemos}

Nessa seção, apresentamos um resultado que obtivemos [32] para grafos conexos cujos blocos não triviais são hamiltonianos. Essa classe inclui os exoplanares e, portanto, esse teorema também generaliza o Teorema 14.

Lembramos que, para um bloco não trivial $B$ de $G$, dizemos que um caminho $P$ de comprimento pelo menos um é um caminho pendente de $B$ se $P$ intersecta $B$ precisamente na sua origem e é maximal na direção do seu término. Além disso, se $P$ é um caminho e $B$ é um bloco que está claro no contexto, denotamos por $\widetilde{P}$ a intersecção de $P \operatorname{com} B$, ou seja, $\widetilde{P}=B \cap P$.

Teorema 16 Se G é um grafo conexo em que todos os blocos não triviais são hamiltonianos, então quaisquer três caminhos mais longos em $G$ têm um vértice em comum.

Prova. Seja $\mathscr{P}$ um conjunto de três caminhos mais longos de $G$ e suponha, por contradição, que $\bigcap \mathscr{P}=\emptyset$. Pelo Teorema 6 , existe um bloco $B$ de $G$ que contém pelo menos uma aresta de cada caminho em $\mathscr{P}$. Vamos supor que esse bloco seja não trivial, caso contrário o resultado é imediato.

Seja $C$ um circuito hamiltoniano de $B$. Lembramos que $\widetilde{p}$ denota o comprimento de $\widetilde{P}$ e $c$ o comprimento de $C$. Queremos mostrar que

$$
\sum_{P \in \mathscr{P}} \widetilde{p} \geq 2 c
$$

Note que, se provarmos que a desigualdade (4.1) vale, então, pelo Princípio da Casa dos Pombos, podemos concluir que existe pelo menos um vértice que aparece nos três caminhos de $\mathscr{P}$. Observe que a desigualdade (4.1) não necessita ser estrita, pois estamos considerando o comprimento dos caminhos (ou seja, o número de arestas).

Se um caminho de $\mathscr{P}$ contém todos os vértices de $B$, então o resultado segue pois os outros dois caminhos necessariamente se intersectam em $B$. Portanto, podemos supor que todos os caminhos em $\mathscr{P}$ contenham dois caminhos pendentes de $B$. Doravante, consideramos apenas caminhos pendentes 
de $B$ que estão contidos em algum caminho de $\mathscr{P}$. Observe que possivelmente existem dois caminhos pendentes com a mesma origem (nesse caso eles têm necessariamente o mesmo comprimento).

Se todos os caminhos pendentes intersectam o bloco $B$ em apenas dois vértices, então o resultado é imediato. Logo, sejam $T_{x}, T_{y}$ e $T_{z}$ três caminhos pendentes de $B$ que são disjuntos e são os três mais longos possíveis, onde $x, y$ e $z$ denotam suas origens, respectivamente.

Caso 1: Existe uma função $f$ bijetora de $\{x, y, z\}$ para $\mathscr{P}$ tal que $f(u)$ não contém um caminho pendente com origem $u$. Ou seja, existe um mapeamento $f$ entre os vértices $\{x, y, z\}$ e os caminhos em $\mathscr{P}$ tal que, para cada $u$, existe um caminho $f(u) \in \mathscr{P}$ que não contém um caminho pendente com origem $u$ e, além disso, $f(u) \neq f(v)$, para $u \neq v$.

Por simplicidade, suponha que $x, y$ e $z$ apareçam em sentido horário em $C$. Seja $P_{u}=f(u)$, para cada $u$ em $\{x, y, z\}$. Para provar (4.1), vamos encontrar um limite inferior para cada $\widetilde{p}_{u}$ e mostrar que a soma dos três limites inferiores é pelo menos $2 c$.

Considere os caminhos pendentes $R$ e $R^{\prime}$ tais que $P_{x}=R^{-1} \cdot \widetilde{P}_{x} \cdot R^{\prime}$. Observe que $t_{y}+t_{z} \geq r+r^{\prime}$, pois $\left\{T_{x}, T_{y}, T_{z}\right\}$ é um conjunto de três caminhos pendentes de $B$, que são disjuntos e os mais longos possíveis, e $P_{x}$ não contém nenhum caminho pendente com origem $x$. Considere o caminho

$$
Q_{x}=T_{z}^{-1} \cdot C_{z x} \cdot C_{x y} \cdot T_{y}
$$

como na Figura 4.1. Lembrando que $p_{x} \geq q_{x}$ (ou seja, $r+\widetilde{p}_{x}+r^{\prime} \geq t_{y}+\widetilde{q}_{x}+t_{z}$ ) e, como $t_{y}+t_{z} \geq r+r^{\prime}$, temos que $\widetilde{p}_{x} \geq \widetilde{q}_{x}$.

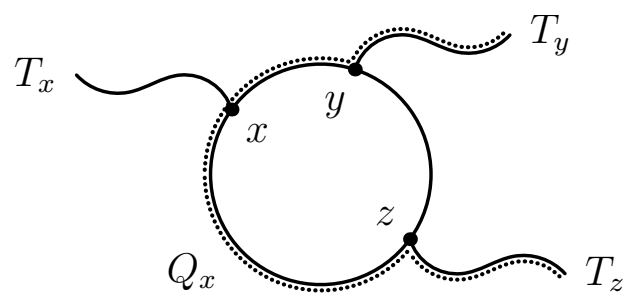

Figura 4.1: Configuração de $Q_{x}$.

Analogamente, considerando

$$
\begin{aligned}
& Q_{y}=T_{x}^{-1} \cdot C_{x y} \cdot C_{y z} \cdot T_{z}, \\
& Q_{z}=T_{y}^{-1} \cdot C_{y z} \cdot C_{z x} \cdot T_{x},
\end{aligned}
$$

temos que $\widetilde{p}_{y} \geq \widetilde{q}_{y}$ e $\widetilde{p}_{z} \geq \widetilde{q}_{z}$. Logo, concluímos que $\widetilde{p}_{x}+\widetilde{p}_{y}+\widetilde{p}_{z} \geq \widetilde{q}_{x}+\widetilde{q}_{y}+\widetilde{q}_{z}$. Como $\widetilde{q}_{x}+\widetilde{q}_{y}+\widetilde{q}_{z}=2 c$ (veja Figura 4.2), a desigualdade (4.1) vale.

Caso 2: Não existe tal função $f$.

Nesse caso, existem dois caminhos em $\mathscr{P}$, digamos $P_{1}$ e $P_{2}$, cujos caminhos pendentes compartilham as mesmas origens. Podemos considerar que o terceiro caminho em $\mathscr{P}$, digamos $P_{3}$, possui dois caminhos pendentes com origens distintas das origens dos caminhos pendentes de $P_{1}$, pois, caso contrário, já teríamos um vértice comum aos três caminhos.

Logo, $B$ tem quatro caminhos pendentes com origens distintas. Suponha que as origens $w, x, y$ e $z$ dos caminhos pendentes de $B$ apareçam em sentido horário em $C$. Seja $T_{u}$ um caminho pendente 


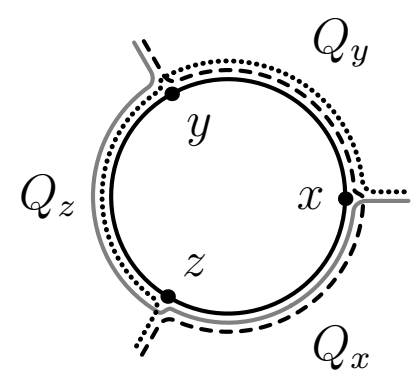

Figura 4.2: $\widetilde{q}_{x}+\widetilde{q}_{y}+\widetilde{q}_{z}=2 c$.

com origem $u$, para $u \in\{w, x, y, z\}$. Analogamente ao caso 1 , construímos caminhos que forneçam um limitante inferior para $\widetilde{p}_{1}+\widetilde{p}_{2}+\widetilde{p}_{3}$, mas, nesse caso, não para cada $\widetilde{p}_{i}$ individualmente.

Considere os caminhos

$$
\begin{aligned}
& Q_{1}=T_{z}^{-1} \cdot C_{z w} \cdot C_{w x} \cdot C_{x y} \cdot T_{y}, \\
& Q_{2}=T_{w}^{-1} \cdot C_{w x} \cdot C_{x y} \cdot C_{y z} \cdot T_{z}, \\
& Q_{3}=T_{x}^{-1} \cdot C_{x y} \cdot C_{y z} \cdot C_{z w} \cdot T_{w}, \\
& Q_{4}=T_{y}^{-1} \cdot C_{y z} \cdot C_{z w} \cdot C_{w x} \cdot T_{x} .
\end{aligned}
$$

Figura 4.3 mostra a configuração de $Q_{1}$.

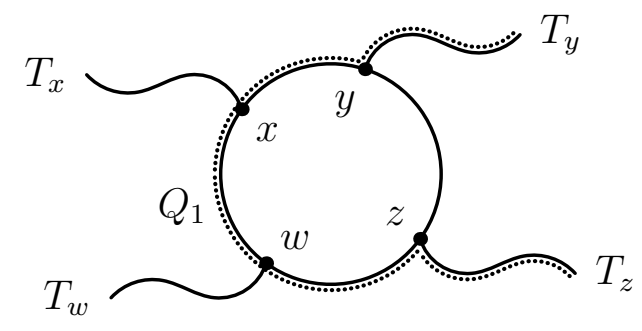

Figura 4.3: Configuração de $Q_{1}$.

Somando os comprimentos e considerando que $\widetilde{q}_{1}+\widetilde{q}_{2}+\widetilde{q}_{3}+\widetilde{q}_{4}=3 c$ (veja Figura 4.4), temos

$$
q_{1}+q_{2}+q_{3}+q_{4}=2\left(t_{w}+t_{x}+t_{y}+t_{z}\right)+3 c .
$$

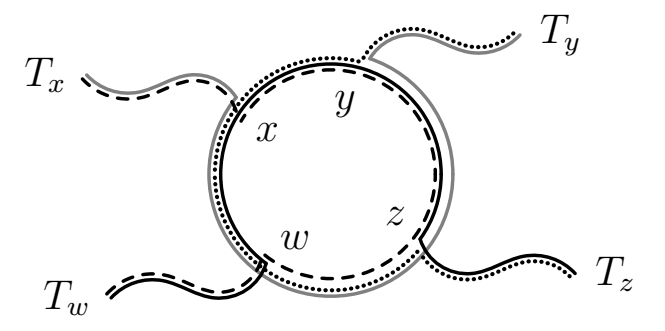

Figura 4.4: $\widetilde{q}_{1}+\widetilde{q}_{2}+\widetilde{q}_{3}+\widetilde{q}_{4}=3 c$.

Lembre que os caminhos pendentes de $P_{1}$ e $P_{2}$ compartilham as mesmas origens e são disjuntos 
dos caminhos pendentes de $P_{3}$. Portanto,

$$
p_{1}+p_{2}+2 p_{3}=2\left(t_{w}+t_{x}+t_{y}+t_{z}\right)+\widetilde{p}_{1}+\widetilde{p}_{2}+2 \widetilde{p}_{3} .
$$

Como $p_{i} \geq q_{j}$ para cada $i \in\{1,2,3\}$ e $j \in\{1,2,3,4\}$, então

$$
p_{1}+p_{2}+2 p_{3} \geq q_{1}+q_{2}+q_{3}+q_{4} .
$$

Por (4.2), (4.3) e (4.4), concluímos que $\widetilde{p}_{1}+\widetilde{p}_{2}+2 \widetilde{p}_{3} \geq 3 c$. Como $\widetilde{p}_{3}<c$, então (4.1) vale. Logo, necessariamente existe um vértice comum a $P_{1}, P_{2}$ e $P_{3}$.

A seguinte pergunta, relacionada com o teorema anterior, surge de maneira natural: é possível substituir "três caminhos mais longos" por "todos os caminhos mais longos" e garantir que a afirmação correspondente vale? A resposta é não, como nos mostram os grafos das Figuras 1.4 e 1.5. 


\section{Capítulo 5}

\section{Outros resultados relacionados}

Sabemos que quaisquer dois caminhos mais longos se intersectam. Mas em quantos vértices? Isso depende da conexidade do grafo. Tratamos dessa questão na primeira seção desse capítulo.

Também sabemos que não é verdade que todo grafo possui um vértice que pertence a todos os caminhos mais longos. Mas será que todo grafo possui dois vértices tais que todo caminho mais longo contém ao menos um dos dois? Se a resposta a essa pergunta for negativa, será que, no lugar de dois, podemos colocar alguma constante para que a resposta seja positiva? Essas questões serão tratadas na segunda seção.

\subsection{Vértices comuns a dois caminhos mais longos}

É bem conhecido o fato de que, em grafos 2-conexos, quaisquer dois caminhos mais longos têm ao menos dois vértices em comum. Também é verdade que, em grafos 2-conexos, quaisquer dois circuitos mais longos têm ao menos dois vértices em comum. Esses resultados estão relacionados, como mostramos mais a diante. Em 1984, Grötschel [46] apresentou a seguinte conjectura, que diz respeito a circuitos mais longos.

Conjectura 17 Em todo grafo $k$-conexo, $k \geq 2$, quaisquer dois circuitos mais longos têm ao menos $k$ vértices em comum.

No artigo citado acima, Grötschel afirma que, por comunicação de R. Häggkvist e J. A. Bondy, soube que essa conjectura foi feita por Scott Smith em 1979, quando ainda era aluno de ensino médio, e que a veracidade dessa conjectura provavelmente já foi verificada para $k \leq 10$ (até $k \leq 8$ segue como corolário dos Teoremas 22, 23 e 25 que apresentamos a seguir). Não encontramos nenhuma prova de que o resultado vale para $k=9$ ou $k=10$, e para o caso geral a conjectura permanece em aberto.

Burr e Zamfirescu [20, 104] provaram que, para $k \geq 2$, em todo grafo $k$-conexo, quaisquer dois circuitos mais longos têm ao menos $\sqrt{k}$ vértices em comum. Essa demonstração não foi publicada, mas Hippchen [54] apresentou uma prova do resultado na sua tese de mestrado. Chen, Faudree e Gould [24] obtiveram um resultado assintoticamente melhor. Eles provaram que, para $k \geq 2$, em todo grafo $k$-conexo, quaisquer dois circuitos mais longos têm ao menos $c k^{3 / 5}$ vértices em comum, onde $c \approx 0,2615$.

Com relação a caminhos mais longos, Hippchen [54] conjecturou que a afirmação análoga é verdade. 
Conjectura 18 Em todo grafo $k$-conexo, quaisquer dois caminhos mais longos têm ao menos $k$ vértices em comum.

Os resultados e as demonstrações que apresentamos a seguir e que não possuem referência, foram inspirados pela demonstração do Teorema 3.11.11 de Voss [93] e, até onde sabemos, não se encontram dessa forma na literatura.

Primeiramente, provamos que a Conjectura 17 implica a Conjectura 18.

Lema 19 Dados inteiros $k$ e $\ell$, se em todo grafo $k$-conexo quaisquer dois circuitos mais longos se intersectam em ao menos $\ell$ vértices, então em todo grafo $(k-1)$-conexo quaisquer dois caminhos mais longos se intersectam em ao menos $\ell-1$ vértices.

Prova. Seja $G=(V, E)$ um grafo $(k-1)$-conexo e sejam $P$ e $Q$ dois caminhos mais longos em $G$. Adicione um vértice novo, digamos $x$, e faça-o adjacente a todos os vértices de $G$. Chame esse novo grafo de $H$. Observe que $x P x$ e $x Q x$ são circuitos mais longos de $H$. Note também que, se $G$ é $(k-1)$-conexo, então $H$ é $k$-conexo. Logo, se $x P x$ e $x Q x$ se intersectam em ao menos $\ell$ vértices, então $P$ e $Q$ se intersectam em ao menos $\ell-1$ vértices.

Não sabemos se a afirmação recíproca é verdadeira, ou seja, se a Conjectura 18 implica a Conjectura 17. O que sabemos é que se a seguinte versão mais forte da Conjectura 18 for verdadeira, então a Conjectura 17 também é. Nesta conjectura estamos considerando caminhos de extremidades fixas, ou seja, primeiro se fixa as extremidades e depois se encontra o maior caminho dentre os caminhos que ligam essas extremidades. Lembramos que um uv-caminho é um caminho com extremidades $u$ e $v$.

Conjectura 20 Seja $G$ um grafo $k$-conexo e sejam $u_{1}, u_{2}, v_{1}, v_{2}$ vértices quaisquer de $G$. Seja $P$ um $u_{1} u_{2}$-caminho mais longo e $Q$ um $v_{1} v_{2}$-caminho mais longo. Então, $P$ e $Q$ têm ao menos $k$ vértices em comum.

A prova de que essa conjectura implica a Conjectura 17 é semelhante à prova do Lema 19. Esse fato é interessante, pois para alguns problemas, como o da intersecção de três caminhos mais longos (veja [32, Proposição 11]), as versões com e sem extremidades fixas estão intimamente relacionadas.

Lema 21 Dados inteiros $k$ e $\ell$, se em todo grafo $k$-conexo $G$, para quaisquer vértices $u_{1}, u_{2}, v_{1}, v_{2}$ de $G$, qualquer $u_{1} u_{2}$-caminho mais longo e qualquer $v_{1} v_{2}$-caminho mais longo se intersectam em ao menos $\ell$ vértices, então em todo grafo $(k+1)$-conexo, quaisquer 2 circuitos mais longos se intersectam em ao menos $\ell+1$ vértices.

Prova. Seja $G=(V, E)$ um grafo $(k+1)$-conexo e sejam $C$ e $D$ dois circuitos mais longos em $G$. Sabemos que $C$ e $D$ têm ao menos dois vértices em comum. Seja $x$ um desses vértices, sejam $u_{1} \mathrm{e}$ $u_{2}$ os dois vizinhos de $x$ em $C$ e sejam $v_{1}$ e $v_{2}$ os dois vizinhos de $x$ em $D$. Remova $x$ de $G$ e chame esse novo grafo de $H$. Observe que $C-x$ é um $u_{1} u_{2}$-caminho mais longo e $D-x$ é um $v_{1} v_{2}$-caminho mais longo de $H$. Note também que, se $G$ é $(k+1)$-conexo, então $H$ é $k$-conexo. Logo, se $C-x$ e $D-x$ se intersectam em ao menos $\ell$ vértices, então $C$ e $D$ se intersectam em ao menos $\ell+1$ vértices. 
É conhecido o fato de que a Conjectura 18 vale para $k \leq 3$ (Jain e Sakalle [60] e Hippchen [54] apresentam uma prova desse fato). Os seguintes resultados de Grötschel [46, 47] implicam que a Conjectura 17 vale para $k \leq 6$, e, portanto, pelo Lema 19, a Conjectura 18 vale para $k \leq 5$. É interessante notar que Grötschel buscava caracterizações de grafos em que dois circuitos/caminhos mais longos se intersectam em apenas $k$ vértices, e que os resultados que ele obteve podem ser úteis no estudo da interseç̧ão de vários caminhos mais longos.

Lembramos que um conjunto separador de um grafo é um conjunto de vértices do grafo tal que sua remoção resulta em um grafo desconexo.

Teorema 22 Seja $G=(V, E)$ um grafo conexo, e sejam $C$ e $D$ dois circuitos mais longos distintos que se intersectam em exatamente dois vértices, digamos u e v. Sejam $C=P_{1} \cup P_{2}$ e $D=Q_{1} \cup Q_{2}$, onde $P_{i}$ e $Q_{i}, i \in\{1,2\}$, são segmentos de u a $v$ de $C$ e $D$, respectivamente. As seguintes afirmações valem:

1. $\{u, v\}$ é um conjunto separador;

2. $\left\|P_{1}\right\|=\left\|P_{2}\right\|=\left\|Q_{1}\right\|=\left\|Q_{2}\right\|$, logo o circuito tem comprimento par;

3. os caminhos truncados $\bar{P}_{1}, \bar{P}_{2}, \bar{Q}_{1}, \bar{Q}_{2}$ obtidos removendo os vértices $u$ e $v$ das extremidades de $P_{1}, P_{2}, Q_{1}, Q_{2}$ estão em componentes distintas de $G-\{u, v\}$;

4. todo circuito mais longo de $G$ contém ambos u e v;

5. para todo circuito mais longo $B$ de $G$, os dois caminhos de $B-\{u, v\}$ pertencem a componentes distintas de $G-\{u, v\}$.

Teorema 23 Seja $k \in\{3,4\}$, e seja $G=(V, E)$ um grafo conexo com pelo menos $k+1$ vértices. Suponha que $C$ e $D$ sejam dois circuitos mais longos distintos que se intersectam em um conjunto $W$ de $k$ vértices de $G$. As seguintes afirmações valem:

1. W é um conjunto separador;

2. se $k=3$, os caminhos obtidos removendo $W$ de $C$ e $D$ estão em componentes distintas de $G-W$.

Lembramos que a circunferência de um grafo é o comprimento de um circuito mais longo do grafo. Grötschel enunciou esse resultado para $k \in\{3,4,5\}$ e conjecturou que, se adicionarmos no Teorema 23 a hipótese de que a circunferência do grafo seja ao menos $k+1$, o mesmo vale para $k \in\{6,7\}$. Na realidade, Grötschel não percebeu que essa hipótese também é necessária para $k=5$. De fato, observe o grafo da Figura 5.1. É fácil ver que esse grafo não é hamiltoniano. Portanto, $C=v_{1} v_{2} v_{3} v_{4} v_{5} v_{1}$ é um circuito mais longo e também o é $D=v_{1} v_{2} v_{4} v_{3} v_{5} v_{1}$. Portanto $C$ e $D$ se intersectam no conjunto $W=\left\{v_{1}, v_{2}, v_{3}, v_{4}, v_{5}\right\}$ e $|W|=5$, mas $W$ não é um conjunto separador.

Note que a circunferência desse grafo é $k=5$ e os circuitos $C$ e $D$ são sobre um mesmo conjunto de vértices. Se exigirmos que a circunferência do grafo seja ao menos $k+1$ ou que os circuitos mais longos não possam ser sobre o mesmo conjunto de vértices, a prova de Grötschel está correta. 


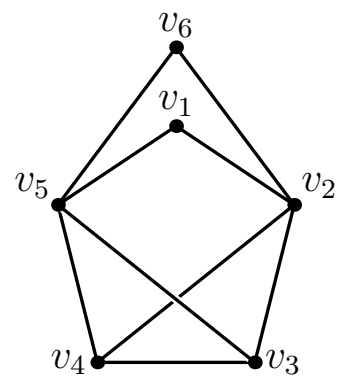

Figura 5.1: Grafo em que dois circuitos mais longos se intersectam em um conjunto $W$ de 5 vértices e $W$ não é um conjunto separador.

Teorema $24 S e G=(V, E)$ é um grafo conexo com circunferência pelo menos 6 , e $C$ e $D$ são dois circuitos mais longos distintos que se intersectam em um conjunto $W$ de 5 vértices de $G$, então $W$ é um conjunto separador.

Ademais, com a hipótese adicional de que a circunferência do grafo seja ao menos $k+1$, o Teorema 23 vale não só para $k=5$, mas também para $k=6$ e $k=7$. Esse fato foi provado por Stewart [82] em 1987, usando essencialmente a mesma técnica de Grötschel. A abordagem de Grötschel foi a de analisar — na força bruta — os diversos modos em que dois circuitos podem se intersectar em $k$ vértices. Obviamente, quanto maior o $k$, maior o número de casos que precisam ser analisados. Para $k=5$, são 4 casos; já para $k=6$ são 10 casos e para $k=7$ são 25 casos! Assim, para $k$ grande, o método de Grötschel se torna inviável. Stewart utiliza um computador para sistematizar a análise dos casos. Segundo o autor, embora este não seja o método mais elegante e muitos possam ver essa prova com certo ceticismo, o computador é uma ferramenta que pode ter um papel muito importante em teoria dos grafos e, quando os programas são simples de ser implementados e verificados, os resultados não devem ser desacreditados.

Teorema 25 Seja $k \in\{6,7\}$ e seja $G$ um grafo com circunferência ao menos $k+1$. Se $C$ e $D$ são dois circuitos mais longos que se intersectam em um conjunto $W$ de exatamente $k$ vértices, então $W$ é um conjunto separador.

O mesmo resultado não vale para $k=8$, como podemos ver pelo grafo de Petersen. De fato, este grafo tem 10 vértices e é hipo-hamiltoniano, ou seja, ele não é hamiltoniano, e, dado qualquer vértice, é possível encontrar um circuito hamiltoniano que não passa por ele. Logo, um circuito mais longo tem comprimento 9. Além disso, dado qualquer aresta uv do grafo de Petersen, é possível encontrar um circuito mais longo $C$ que não passa por $u$ e um circuito mais longo $D$ que não passa por $v$. A intersecção de $C$ e $D$ são todos os vértices exceto $u$ e $v$. Logo, $W=C \cap D$ não é um conjunto separador, pois existe uma aresta entre $u$ e $v$. Note, porém, que isso não implica que a Conjectura 17 não vale para $k=9$, apenas que não é possível prová-la exatamente da mesma maneira que provamos para $k \leq 8$.

Ao tratar de grafos $k$-conexos, temos a vantagem de saber que os circuitos mais longos são necessariamente longos. Dirac [33] provou o seguinte resultado.

Teorema 26 Seja $G$ um grafo 2-conexo com $n$ vértices e grau mínimo $\delta$. Um circuito mais longo em $G$ tem comprimento ao menos $\min \{2 \delta, n\}$. 
Observe que um grafo $k$-conexo tem grau mínimo pelo menos $k$. Logo, podemos dizer que um grafo $k$-conexo, $k \geq 2$, é hamiltoniano ou tem um circuito de comprimento pelo menos $2 k$.

Corolário 27 Seja $G$ um grafo $k$-conexo, $k \geq 2$, com $n$ vértices. Um circuito mais longo em $G$ tem comprimento ao menos $\min \{2 k, n\}$.

O seguinte resultado relaciona conexidade e cardinalidade de um conjunto independente máximo com a circunferência de um grafo.

Teorema 28 Seja $G$ um grafo, seja $\alpha$ a cardinalidade de um conjunto independente máximo de $G$ e seja $k$ o maior número inteiro tal que $G$ é um grafo $k$-conexo.

1. Se $k \geq \alpha$, então $G$ é hamiltoniano.

2. Se $k \leq \alpha$, então um circuito mais longo em $G$ tem comprimento ao menos $\frac{k(n+\alpha-k)}{\alpha}$.

A primeira parte desse teorema foi obtida por Chvátal e Erdős [26] e a segunda por O, West e Wu [73]. Observe que $\alpha \leq n-k$, pois todo vértice em $G$ tem ao menos $k$ vizinhos. Logo, a segunda parte do teorema está supondo que $k \leq \alpha \leq n-k$, o que implica que $n \geq 2 k$. Usando a desigualdade $\alpha \leq n-k$, é fácil ver que $\frac{k(n+\alpha-k)}{\alpha} \geq 2 k$. Portanto, o Teorema 28 também implica o Corolário 27.

Como mencionamos anteriormente, o seguinte resultado é um corolário dos Teoremas 22, 23, 24 e 25 .

Corolário 29 Em todo grafo $k$-conexo, $2 \leq k \leq 8$, quaisquer dois circuitos mais longos têm ao menos $k$ vértices em comum.

Prova. Seja $G$ um grafo $k$-conexo, $2 \leq k \leq 8$, e sejam $C$ e $D$ dois circuitos mais longos em $G$. Seja $W$ o conjunto de vértices que estão em ambos os circuitos. Suponha, por contradição, que $|W|<k$. Pelo Corolário 27, sabemos que $G$ tem circunferência pelo menos $\min \{2 k, n\} \geq k+1$, logo podemos aplicar o Teorema 22, 23, 24 ou 25 e concluir que $W$ é um conjunto separador. Mas isso é uma contradição, pois $G$ é $k$-conexo e $|W|<k$.

Pelo Corolário 29 e pelo Lema 19, o seguinte resultado é imediato.

Corolário 30 Em todo grafo $k$-conexo, $1 \leq k \leq 7$, quaisquer dois caminhos mais longos têm ao menos $k$ vértices em comum.

Usando a mesma ideia da prova do Lema 19, podemos provar um resultado um pouco mais forte que o Corolário 30 a partir dos resultados de Grötschel, como foi observado por Voss [93], e a partir do resultado de Stewart, adicionando a hipótese de que os caminhos mais longos tenham comprimento pelo menos $k+1$.

Teorema 31 Seja $G$ um grafo conexo, e sejam $P$ e $Q$ dois caminhos mais longos em $G$, de comprimento pelo menos $k+1$, que se intersectam em um conjunto $W$ de $k$ vértices de $G, 1 \leq k \leq 6$. Então 
1. W é um conjunto separador;

2. se $k=1$, todo caminho mais longos contém o único vértice de $W$;

3. se $k=2$, todo caminho mais longos contém ao menos um dos vértices de $W$.

Observe que o grafo bipartido $K_{k, 2 k+2}$ (veja Figura 5.2) mostra que a Conjectura 18 é justa.

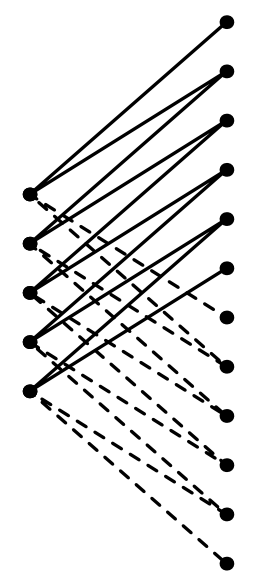

Figura 5.2: Dois caminhos mais longos em um $K_{5,12}$.

\subsection{Vértices evitados por caminhos mais longos}

A pergunta de Gallai de 1966 deu origem a muitas outras. Algumas das mais estudadas tiveram como inspiração uma pergunta de Sachs [36], feita também no colóquio em Tihany de 1966, que diz respeito a circuitos mais longos. Sachs perguntava se, para todo grafo 3-conexo, existem dois vértices tais que todo circuito mais longo contém ao menos um dos dois. Walther [97] mostrou, através de um grafo com 220 vértices, que isso não é sempre verdade.

Perguntas similares que dizem respeito a caminhos mais longos foram levantadas por Walther [96] em 1969 e por Zamfirescu [100] em 1972. Walther perguntou: "Existe um número $j$ tal que todo grafo conexo possui um conjunto de $j$ vértices que intersecta todo caminho mais longo?" Zamfirescu fez essa pergunta para classes específicas de grafos, como os $k$-conexos e os planares.

Neste trabalho, a fim de facilitar a compreensão, adotamos uma notação distinta da que foi introduzida por Zamfirescu [100] em 1972 e que inclusive é mais geral. Se existir um grafo no qual, dado um conjunto qualquer de $j$ vértices, algum caminho mais longo evita esses $j$ vértices, então denotamos por $\boldsymbol{\Gamma}_{j}$ o menor número de vértices de um tal grafo. Se tal grafo não existir, dizemos que $\boldsymbol{\Gamma}_{j}=\infty$. Se quisermos adicionar alguma restrição na classe de grafos que estamos considerando, explicitamos essa restrição entre colchetes. Por exemplo, se estamos considerando o problema restrito a grafos $k$-conexos planares, dizemos $\boldsymbol{\Gamma}_{j}[k$-conexo, planar $]$.

Com essa nomenclatura, podemos reescrever a pergunta de Gallai como: $\boldsymbol{\Gamma}_{1}=\infty$ ? E a pergunta de Walther como: $\boldsymbol{\Gamma}_{j}<\infty$ para algum $j$ ? Pelo grafo da Figura 1.4, sabemos que $\boldsymbol{\Gamma}_{1} \leq 12$ (como mencionamos na Seção 1.1, já foi provado que $\boldsymbol{\Gamma}_{1}=12$ ) e pelo grafo da Figura 1.5, sabemos que $\boldsymbol{\Gamma}_{1}[$ planar $] \leq 17$.

Várias pessoas, em particular Grünbaum, Hatzel, Schmitz, Thomassen, Walther, C. Zamfirescu e T. Zamfirescu [48, 53, 78, 86, 94, 99, 100, 102, 103], trabalharam para descobrir limitantes superiores 
para os $\boldsymbol{\Gamma}_{j}$ 's ou provar que os limitantes são justos. Não houve progressos no estabelecimento de limitantes para os $\boldsymbol{\Gamma}_{j}[k$-conexo]'s desde os anos 70 , mas recentemente foram encontrados limitantes mais justos para os $\boldsymbol{\Gamma}_{j}$ [3-conexo, planar]'s, utilizando grafos hipo-hamiltonianos planares menores [4, 63], que não eram conhecidos anteriormente. Zamfirescu [103] traz um resumo dos progressos feitos até 1976 e Voss [93] exibe duas tabelas com essas informações. Kensell [67] reúne esses resultados e alguns mais recentes. Abaixo reproduzimos as tabelas com os valores atualizados.

\begin{tabular}{|c|c|c|c|c|}
\hline & \multicolumn{3}{|c|}{$j$} \\
\hline & & 1 & 2 & 3 \\
\hline & 1 & $=12$ & $\leq 93$ & $?$ \\
\hline$k$ & 2 & $\leq 26$ & $\leq 270$ & $?$ \\
\hline & 3 & $\leq 36$ & $\leq 270$ & $?$ \\
\hline & 4 & $\bar{?}$ & $\bar{?}$ & $?$ \\
\hline
\end{tabular}

Tabela 5.1: Tabela com os valores atualizados de $\boldsymbol{\Gamma}_{j}[k$-conexo $]$.

\begin{tabular}{|c|c|c|c|c|}
\hline & & & J & \\
\hline & & 1 & 2 & 3 \\
\hline & 1 & $\leq 17$ & $\leq 308$ & 7 \\
\hline , & 2 & $\leq 32$ & $\leq 914$ & \\
\hline & 3 & $\leq 156$ & $\leq 10.350$ & \\
\hline & 4 & & & \\
\hline
\end{tabular}

Tabela 5.2: Tabela com os valores atualizados de $\boldsymbol{\Gamma}_{j}[k$-conexo, planar $]$.

Apresentamos aqui os resultados das Tabelas 5.1 e 5.2. Uma primeira pergunta que se procura responder é: para que valores de $j$ e $k$ vale que $\boldsymbol{\Gamma}_{j}[k$-conexo $]<\infty$ (ou $\boldsymbol{\Gamma}_{j}[k$-conexo, planar $\left.]<\infty\right)$ ? Primeiramente, consideramos o caso em que $j=1$. Já falamos anteriormente dos grafos que mostram que $\boldsymbol{\Gamma}_{1}<\infty$ e $\boldsymbol{\Gamma}_{1}$ [planar] $<\infty$. Já para provar que $\boldsymbol{\Gamma}_{1}$ [2-conexo], o primeiro exemplo encontrado foi um grafo 2-conexo de 82 vértices, obtido por Zamfirescu [100] em 1972, que, por ser planar, também provava que $\boldsymbol{\Gamma}_{1}$ [2-conexo, planar] $<\infty$. Hoje, os menores exemplos 2-conexo e 2-conexo planar conhecidos têm, respectivamente, 26 e 32 vértices [81, 103] (veja Figuras 5.3 e 5.4).

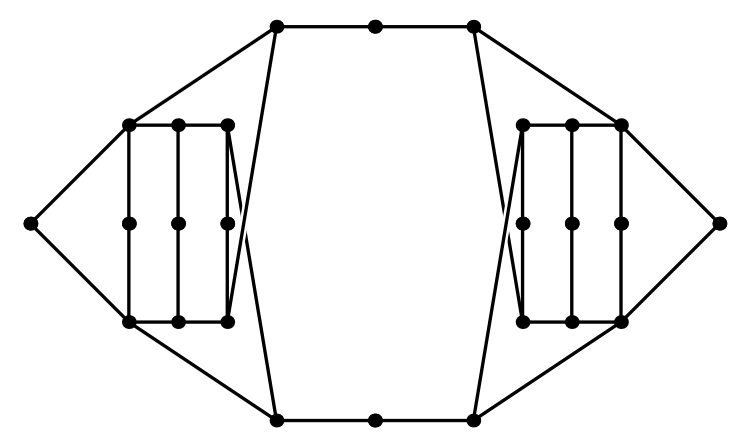

Figura 5.3: Menor grafo 2-conexo que mostra que $\boldsymbol{\Gamma}_{1}[2$-conexo $]<\infty$.

O mesmo problema para grafos 3-conexos tem uma resposta dada por um grafo hipotraçável com 40 vértices obtido por Horton [50,55] (veja Figura 5.5). Um fato interessante é que este foi o primeiro grafo hipotraçável conhecido [50], embora atualmente se conheça grafos hipotraçáveis me- 


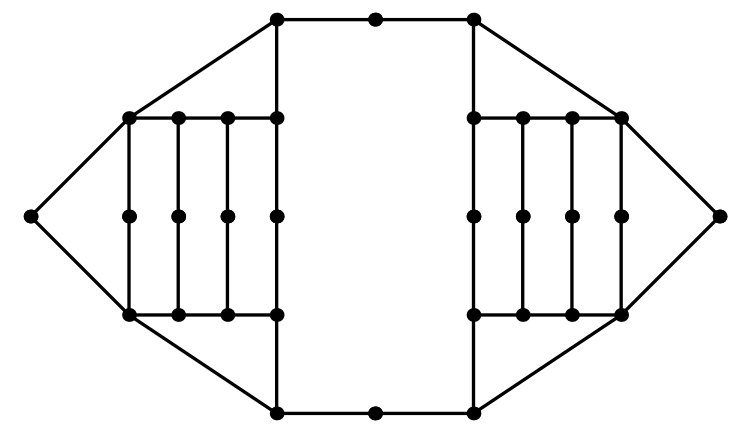

Figura 5.4: Menor grafo 2-conexo planar que mostra que $\boldsymbol{\Gamma}_{1}[2$-conexo, planar $]<\infty$.

nores [84]. Zamfirescu [103] produziu uma resposta melhor para $\boldsymbol{\Gamma}_{1}$ [3-conexo] com 36 vértices (veja Figura 5.6). Esse grafo é obtido através da vértice-substituição do $K_{4}$ pelo grafo de Petersen. Falamos mais sobre essa construção a seguir. Nesse último grafo pode-se verificar que qualquer vértice pode ser evitado por um caminho mais longo através da simetria do grafo e da hipo-hamiltonicidade do grafo de Petersen.

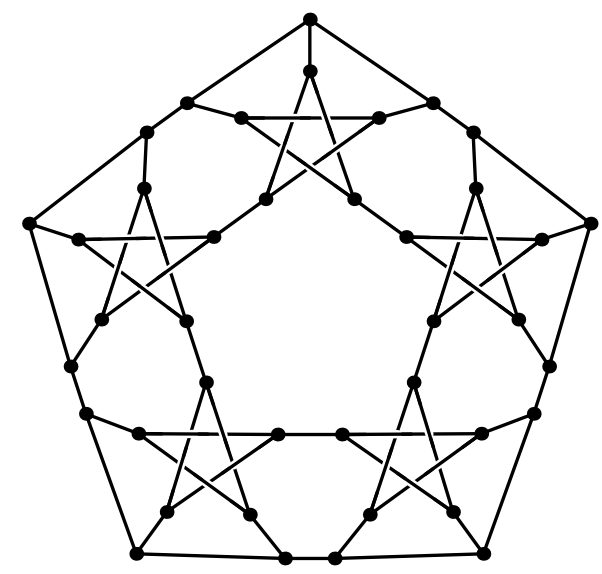

Figura 5.5: Primeiro grafo 3-conexo que provou que $\boldsymbol{\Gamma}_{1}[3$-conexo $]<\infty$.

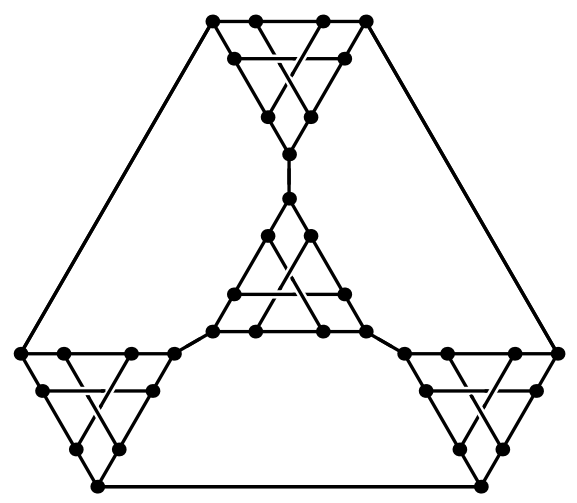

Figura 5.6: Menor grafo 3-conexo que mostra que $\boldsymbol{\Gamma}_{1}[3$-conexo $]<\infty$.

Para grafos 3-conexos planares, Grünbaum [48] foi o primeiro a responder a questão através de um exemplo com 484 vértices. A ideia que utilizou para construir o grafo é a mesma que continua sendo utilizada para produzir exemplos menores. Primeiramente apresentamos o método utilizado 
para construir o grafo da Figura 5.6 e que pode ser utilizado para obter outros grafos 3-conexos nos quais não existe vértice comum a todos os caminhos mais longos.

Seja $H$ um grafo hipo-hamiltoniano com pelo menos um vértice de grau três. Note que todo grafo hipo-hamiltoniano é 3-conexo, pois a remoção de qualquer vértice resulta em um grafo que tem um circuito hamiltoniano e, portanto, 2-conexo. Definimos a operação de vértice-substituição do grafo $K_{4}$ pelo grafo $H$ da seguinte forma. Primeiramente, escolhe-se um vértice de grau três de $H$, digamos $v$. Sejam $x, y$ e $z$ os vizinhos de $v$. Para $i=0,1,2,3$, seja $H_{i}$ um grafo isomorfo a $H-v$, e sejam $x_{i}, y_{i}$ e $z_{i}$ os vértices de $H_{i}$ correspondentes aos vértices $x, y$ e $z$. Considere que os grafos $H_{i}$ são dois a dois disjuntos. Sejam $u_{0}, u_{1}, u_{2}$ e $u_{3}$ os vértices do $K_{4}$. O grafo resultante da vérticesubstituição do $K_{4}$ por $H$ é obtido substituindo sucessivamente cada vértice do $K_{4}$ por um $H_{i}$ da seguinte maneira: inserimos $H_{i}$ no lugar de $u_{i}$ e tornamos cada um dos vértices $x_{i}, y_{i}$ e $z_{i}$ adjacentes a um vizinho distinto de $u_{i}$. Note que pode haver diferentes modos de fazer tais substituições (que podem eventualmente dar origem a grafos distintos). Descrevemos passo a passo um desses modos. Primeiramente, substituímos $u_{0}$ por $H_{0}$ e adicionamos as arestas $u_{1} x_{0}, u_{2} y_{0}$ e $u_{3} z_{0}$. Em seguida, substituímos $u_{1}$ por $H_{1}$ e adicionamos as arestas $x_{0} x_{1}, u_{2} y_{1}$ e $u_{3} z_{1}$; logo, $u_{2}$ por $H_{2}$ e adicionamos as arestas $y_{0} x_{2}, y_{1} y_{2}$ e $u_{3} z_{2}$; e, finalmente, $u_{3}$ por $H_{3}$ e adicionamos as arestas $z_{0} x_{3}, z_{1} y_{3}$ e $z_{2} z_{3}$. $\mathrm{O}$ grafo resultante dessa operação é 3-conexo e pela construção é fácil ver que existe um caminho mais longo que evita qualquer dado vértice. Observe que, se $H$ é o grafo de Petersen, o grafo que resulta da vértice-substituição do grafo $K_{4}$ por $H$ é isomorfo ao grafo da Figura 5.6.

Para construir grafos 3-conexos planares em que não existe vértice comum a todos os caminhos mais longos o processo é semelhante. A diferença é que, nesse caso, não se pode tomar qualquer grafo $H$ hipo-hamiltoniano, é necessário que $H$ seja planar. Como atualmente têm sido descobertos grafos hipo-hamiltonianos planares cada vez menores [85] [53] [99] [5] [63], o limitante superior de $\boldsymbol{\Gamma}_{1}$ [3-conexo, planar] tem sido atualizado algumas vezes nos últimos anos. Atualmente, os menores grafos hipo-hamiltonianos planares conhecidos têm 40 vértices [63] e todos possuem diversos vértices de grau três. Através da vértice-substituição do $K_{4}$ por um desses grafos hipo-hamiltonianos planares de 40 vértices obtém-se um grafo com $(40-1) \times 4=156$ vértices.

Observe que, em vez de se utilizar o $K_{4}$ como grafo inicial, pode-se utilizar outros grafos cúbicos (grafos em que todos os vértice têm grau três), desde que sejam "bons". Dizemos que um grafo é bom se, para quaisquer duas arestas, existe um caminho mais longo que as evita. Essa estratégia foi utilizada para obter grafos que deram limitantes para outros $\boldsymbol{\Gamma}_{j}$ 's, como vemos adiante. (Observamos que a operação de vértice-substituição para esses grafos é definida analogamente.)

Para grafos 4-conexos, não se conhece nenhum exemplo que mostre que $\boldsymbol{\Gamma}_{1}[4$-conexo] $<\infty$. Já para grafos 4-conexos planares, tal exemplo não existe, ou seja, $\boldsymbol{\Gamma}_{1}[4$-conexo, planar] $=\infty$. Isso é consequência direta do célebre Teorema de Tutte que afirma que todo grafo 4-conexo planar é hamiltoniano. Na realidade, o Teorema de Tutte implica que $\boldsymbol{\Gamma}_{j}[4$-conexo, planar] $=\infty$ para todo $j \geq 1$.

Consideramos, agora, o caso em que $j=2$ (buscamos grafos nos quais, para quaisquer dois vértices, existe um caminho mais longo que evita ambos). O primeiro grafo encontrado que prova que $\boldsymbol{\Gamma}_{2}<\infty$, foi obtido por Grünbaum [48] em 1974, tem 324 vértices e é 3-conexo (ou seja, também determina que $\boldsymbol{\Gamma}_{2}[2$-conexo $]<\infty$ e $\boldsymbol{\Gamma}_{2}[3$-conexo] $<\infty)$. Esse grafo foi obtido através da vérticesubstituição do $K_{4}$ pelo grafo de Petersen (obtendo o grafo da Figura 5.6, que, por sua vez, é um grafo cúbico bom) e depois fazendo uma vértice-substituição desse novo grafo pelo grafo de Petersen. 
Assim o grafo resultante tem $(4 \times 9) \times 9=324$ vértices. Zamfirescu [103] observou que é possível contrair as arestas originais do $K_{4}$ (que são 6 ), obtendo um grafo de $(4 \times 9-6) \times 9=270$ vértices. Esse grafo gerou os menores limitantes superiores que se conhece para $\boldsymbol{\Gamma}_{2}$ [2-conexo] e para $\boldsymbol{\Gamma}_{2}$ [3-conexo].

Para $\boldsymbol{\Gamma}_{2}$, Zamfirescu [101] obteve um resultado melhor com 93 vértices. Esse grafo foi obtido através da vértice-substituição do grafo da Figura 1.4 (o menor grafo responde negativamente à pergunta de Gallai, que é um grafo bom) pelo grafo de Petersen e depois contraindo as arestas do grafo inicial (que são 15). Assim o grafo resultante tem $12 \times 9-15=93$ vértices.

Ainda para $j=2$, considerando apenas grafos planares, um grafo de ordem 308 e um grafo 2-conexo de ordem 914, encontrados em 1975 por Zamfirescu [101], continuam sendo os menores conhecidos. Já no caso dos grafos 3-conexos planares, a descoberta de grafos hipo-hamiltonianos planares cada vez menores, tem diminuído o limitante superior de $\boldsymbol{\Gamma}_{2}$ [3-conexo, planar]. A ideia utilizada para obter um grafo que produza tal limitante, é a mesma apresentada anteriormente, mas desta vez é necessário utilizar um grafo hipo-hamiltoniano planar cúbico. O menor tal grafo que conhecemos tem 70 vértices e foi encontrado recentemente por Araya e Wiener [4] (melhorando o limitante de 94 vértices que fora obtido por Thomassen em 1981 e que era o menor conhecido até então). Denote por $H$ este grafo e por $G$ o menor grafo hipo-hamiltoniano planar conhecido (de 40 vértices). Para construir o grafo que buscamos, fazemos uma vértice-substituição do $K_{4}$ por $H$, depois fazemos uma vértice-substituição desse novo grafo por $G$ e finalmente contrai-se as arestas originais do $K_{4}$ (que são 6) e das 4 cópias de $H^{\prime}$ (onde $H^{\prime}$ é o grafo obtido removendo-se algum vértice de grau três de $H$ ). Como $H$ tem $\frac{3 \times 70}{2}=105$ arestas, cada cópia de $H^{\prime}$ possui 102 aresta. Desta forma, é possível obter um grafo de $4 \times 69 \times 39-(6+4 \times 102)=10.350$ vértices, produzindo o menor limitante superior que conhecemos para $\boldsymbol{\Gamma}_{2}$ [3-conexo, planar].

Interessantemente, não se sabe nada sobre o valor de $\boldsymbol{\Gamma}_{3}$. Pode, inclusive, ser verdade que, para qualquer grafo conexo, existe um conjunto de três vértices que intersecta todos os caminhos mais longos do grafo (ou seja, é possível que $\boldsymbol{\Gamma}_{3}=\infty$ ). 


\section{Parte II}

\section{Resultados algorítmicos}





\section{Capítulo 6}

\section{Busca de um caminho mais longo}

Em teoria dos grafos, "o problema do caminho mais longo" se refere, usualmente, ao problema de encontrar um caminho de comprimento máximo em um dado grafo. Embora esse problema não esteja diretamente relacionado à pergunta de Gallai, é possível que resultados de um problema sejam úteis para achar soluções de outro.

Por exemplo, um algoritmo eficiente para encontrar caminhos mais longos em uma determinada classe de grafos pode facilitar o estudo da caracterização estrutural desses caminhos, tanto por meio da análise do algoritmo, como da observação de resultados em algumas instâncias.

Também é possível que um resultado estrutural possibilite o desenvolvimento de um algoritmo eficiente. Por exemplo, Grötschel e Nemhauser [47] usam diversas propriedades estruturais de grafos, inclusive algumas das apresentadas na Seção 5.1 relacionadas com intersecção de circuitos mais longos, para obter um algoritmo polinomial que resolve o problema do corte máximo para grafos sem circuitos ímpares longos, e sugerem que esses resultados de intersecção de circuitos mais longos possam ser úteis para o desenvolvimento de algoritmos recursivos para problemas de otimização combinatória.

Portanto, o estudo dessa questão algorítmica pode ser tanto um instrumento quanto uma motivação para o estudo de caracterizações estruturais de intersecção de caminhos mais longos.

Considere o problema de decisão correlato definido a seguir.

Problema 32 Dado um grafo $G$ e um natural $k$, decidir se existe em $G$ um caminho de comprimento maior ou igual a $k$.

Note que o problema do caminho mais longo e o Problema 32 são equivalentes no sentido de que, se houvesse um algoritmo polinomial para resolver este problema de decisão, então haveria um algoritmo polinomial para resolver o problema do caminho mais longo. De fato, suponha que a função CAminho $(k, G)$ receba um inteiro $k$ e um grafo $G$ e devolva sim se existe um caminho de comprimento maior ou igual a $k \mathrm{em} G$ e devolva não, caso contrário. Se esta função fosse polinomial, então o algoritmo abaixo, que encontra um caminho de comprimento máximo em um grafo $G$, seria polinomial.

Note que as linhas 2 e 3 são executadas no máximo $|V(G)|$ vezes e o bloco de linhas 5-8 no máximo $|E(G)|$ vezes. Portanto, a função $\operatorname{CAminho}(k, G)$ é chamada no máximo $|V(G)|+|E(G)|$ vezes. 


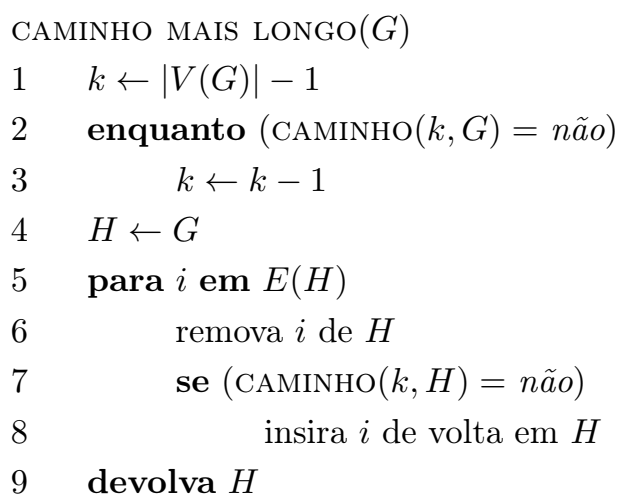

Como vemos a seguir, isso implica que, a menos que $\mathbf{P}=\mathbf{N P}$, não existe algoritmo polinomial que encontra um caminho mais longo em um grafo qualquer.

Proposição 33 O Problema 32 é NP-completo.

Prova. É trivial ver que o problema está em NP, pois um certificado para a instância sim do problema é a descrição de um caminho de comprimento maior ou igual a $k$. A proposição segue do fato de que o problema do caminho hamiltoniano (que é conhecidamente NP-completo [42]) é um caso especial do Problema 32.

Como vimos na introdução, existem duas possíveis direções de pesquisa para o problema de encontrar caminhos mais longos. Nesta seção, discutimos classes especiais de grafos para as quais existem algoritmos polinomiais. Em particular, apresentamos algoritmos polinomiais que resolvem o problema para duas classes: árvores e grafos de intervalos.

Para algumas classes de grafos, sabe-se que o problema de encontrar um caminho hamiltoniano admite solução polinomial, como grafos de intervalos [6, 22, 29], grafos arco-circulares [29], grafos biconvexos [8] e grafos de cocomparabilidade [30]. Portanto, é natural que tenha sido investigado se, para essas classes, existem algoritmos polinomiais para o problema do caminho mais longo. Na realidade, esse fato foi provado para todas as classes mencionadas acima.

\section{1 Árvores}

O primeiro algoritmo polinomial para encontrar caminhos mais longos em uma determinada classe de grafos, foi proposto por Dijkstra por volta de 1960 e encontra, em tempo linear, um caminho mais longo em uma árvore. É interessante notar que uma prova formal só foi apresentada em 2002 por Bulterman, Feijen, van der Sommen, van Gasteren, Verhoeff e Zwaan [19].

\section{CAMINHO MAIS LONGO EM ÁRVORE $(G)$}

1 Escolha um vértice qualquer da árvore $G$ e nomeie-o $x$

2 Encontre um caminho mais longo em $G$ com início $x$.

3 Chame a outra extremidade deste caminho de $y$.

4 Encontre um caminho mais longo em $G$ com início $y$.

5 Chame a outra extremidade deste caminho de $z$.

6 Devolva o caminho de $y$ a $z$. Este é um caminho mais longo em $G$. 
Para compreender melhor o algoritmo, os autores [19] descreveram-no de uma forma muito tangível. Imagine que nos é dado um modelo físico da árvore em que cada dois vértices adjacentes são ligados por um pedaço de barbante de mesmo comprimento. Agora escolha um vértice $x$ qualquer da árvore física e segure a árvore a partir de $x$, deixando o restante pendurado. Chame de $y$ o vértice mais distante de $x$ (o que está mais em baixo no modelo físico). Segure a árvore a partir de $y$ e chame de $z$ o vértice mais distante de $y$. O caminho entre $y$ e $z$ é um caminho mais longo na árvore.

É fácil ver que esse algoritmo é polinomial. A prova de que esse algoritmo está correto se baseia em três propriedades de caminhos em árvores. Note que em uma árvore existe apenas um caminho entre quaisquer dois vértices, logo a distância entre dois vértices é o comprimento do caminho mais longo entre esses dois vértices. O algoritmo garante que:

$$
\begin{aligned}
& d(x, w) \leq d(x, y), \forall w \in V(G) \\
& d(y, w) \leq d(y, z), \forall w \in V(G) .
\end{aligned}
$$

Para $u$ e $v$ vértices da árvore, seja $P(u, v)$ o caminho de $u$ a $v$. Sejam $a, b, c$ e $d$ vértices quaisquer da árvore. As seguintes propriedades valem para árvores.

$$
\begin{array}{r}
d(a, b) \leq d(a, c)+d(c, b) ; \\
c \in P(a, b) \Rightarrow d(a, b)=d(a, c)+d(c, b) ; \\
\exists m \in P(a, b) \cap P(c, d) \text { ou } \exists m \in P(a, c) \cap P(b, d) .
\end{array}
$$

Com essas propriedades é possível obter a seguinte prova. Sejam $x, y$ e $z$ conforme o algoritmo e sejam $u$ e $v$ vértices quaisquer da árvore. Queremos provar que $d(u, v) \leq d(y, z)$.

Por (6.5) temos que $\exists m \in P(x, v) \cap P(u, y)$ ou $\exists m \in P(x, u) \cap P(v, y)$. Vamos supor que o primeiro ocorre e seja $m \in P(x, v) \cap P(u, y)$.

$$
\begin{aligned}
& d(x, v) \leq d(x, y) \\
\Rightarrow & d(x, m)+d(m, v) \leq d(x, m)+d(m, y)(\text { por }(6.4), \text { pois } m \in P(x, v), \text { e por (6.1)) } \\
\Rightarrow & d(m, v) \leq d(m, y) \\
\Rightarrow & d(u, m)+d(m, v) \leq d(u, m)+d(m, y) \\
\Rightarrow & d(u, v) \leq d(u, y) \quad \quad(\text { por }(6.3) \text { e por }(6.4), \text { pois } m \in P(u, y)) .
\end{aligned}
$$

Com um argumento análogo, trocando $u$ e $v$, temos que a seguinte implicação é verdadeira: $\exists m \in P(x, u) \cap P(v, y) \Rightarrow d(u, v) \leq d(v, y)$. Logo,

$$
\begin{aligned}
& \exists m \in P(x, v) \cap P(u, y) \text { ou } \exists m \in P(x, u) \cap P(v, y) \text { (por (6.5)) } \\
\Rightarrow & d(u, v) \leq d(u, y) \text { ou } d(u, v) \leq d(v, y) \\
\Rightarrow & \exists w \mid d(u, v) \leq d(w, y) \\
\Rightarrow & d(u, v) \leq d(z, y)
\end{aligned}
$$




\subsection{Grafos de intervalos}

Em 2009, Ioannidou, Mertzios e Nikolopoulos [57] desenvolveram um algoritmo polinomial que encontra um caminho mais longo em grafos de intervalos, uma superclasse dos grafos limiares (para os quais já se conhecia algoritmo polinomial [88]). Apresentamos aqui a ideia desse algoritmo. Para isso, enunciamos, mas não provamos, alguns lemas que ajudam a compreender o algoritmo e que são usados para provar que o mesmo está correto (a prova formal deste fato pode ser encontrada no artigo de Ioannidou e outros [57]).

Antes de apresentar o algoritmo precisamos de algumas definições. Seja $G$ um grafo de intervalos. É interessante notar que todo subgrafo induzido de $G$ é também um grafo de intervalos.

Definição 34 Uma r-ordenação (ou "right-end ordering") dos vértices de G é uma ordenação $\pi=\left(v_{1}, v_{2}, \ldots v_{n}\right)$ tal que se $i<j<k$ e $v_{i} v_{k} \in E(G)$, então $v_{j} v_{k} \in E(G)$. Ademais, se $i<j$ então dizemos que $v_{i}<_{\pi} v_{j}$.

Essa ordenação (veja Figura 6.1) foi proposta por Ramalingam e Rangan [76]. Eles provam que todo grafo de intervalos possui uma r-ordenação.

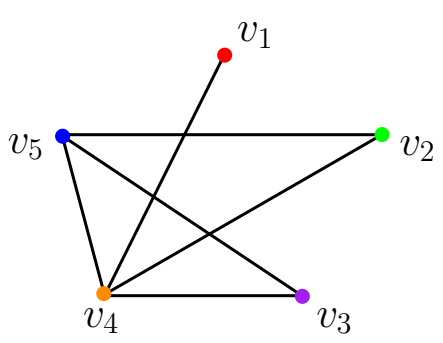

(a)

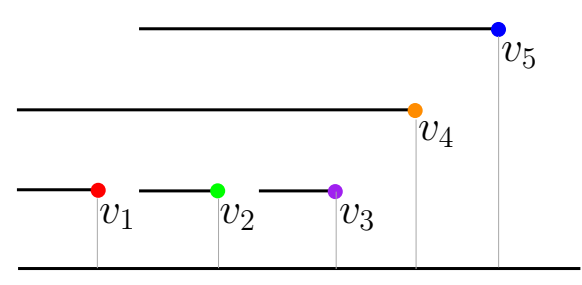

(b)

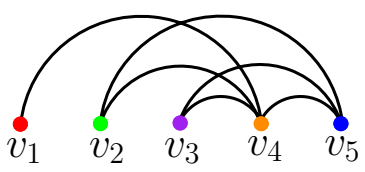

(c)

Figura 6.1: (a) Um grafo de intervalos $G$; (b) o modelo de intersecção de $G$; (c) a r-ordenação $\pi=\left(v_{1}, v_{2}, v_{3}, v_{4}, v_{5}\right)$ de $G$.

Ramalingam e Rangan [76] mostram que é possível conseguir essa ordenação em tempo proporcional a $|V(G)|+|E(G)|$. Essa ordenação tem sido útil para provar diversas propriedades de grafos de intervalos $[6,76]$.

O algoritmo que chamamos de Algoritmo CML_Intervalos (abreviação para Caminho Mais Longo em Grafos de Intervalos) encontra um caminho mais longo em um dado grafo de intervalos. Esse algoritmo é composto de três fases.

- Fase 1: Recebe um grafo de intervalos $G$ e constrói um grafo de intervalos auxiliar $H$;

- Fase 2: Encontra um caminho binormal mais longo $P$ de $H$ pelo Algoritmo CML_em_H;

- Fase 3: Encontra um caminho mais longo $\hat{P}$ de $G$ a partir de $P$.

Ou seja, o algoritmo produz um grafo auxiliar no qual encontra um caminho binormal (definido mais a diante) mais longo, e a partir desse caminho encontra um caminho mais longo do grafo original. Descrevemos, a seguir, cada uma das três etapas em mais detalhes. 


\section{Fase 1: construindo o grafo auxiliar $H$}

Apresentamos aqui a primeira fase do algoritmo: dado um grafo de intervalos $G$ e uma r-ordenação $\pi$ de $G$ (que pode ser obtida em tempo polinomial), construímos um grafo de intervalos $H$ e uma r-ordenação $\sigma$ de $H$.

Construção do grafo auxiliar $H$ e de uma r-ordenação $\sigma$ de $H$ : Seja $n=|V(G)|$ e seja $\pi=\left(v_{1}, v_{2}, \ldots v_{n}\right)$ uma r-ordenação de $G$. Para $v \in V(G)$, denotamos por $N(v)$ o conjunto de vértices adjacentes a $v$ em $G$. Inicialmente $H$ é uma cópia de $G$ e $\sigma=\pi$. Ademais, $S(H)=\emptyset$, onde $S(H)$ é o conjunto de vértices de $H$ que não são vértices de $G$. Percorra os vértices de $\pi$ da esquerda para a direita e, para cada $v_{i}$, adicione dois vértices $a_{i, 1}$ e $a_{i, 2}$ a $V(H)$ e faça ambos serem adjacentes a $v_{i}$ e a todo $v_{j} \in N\left(v_{i}\right) \operatorname{com} j>i$. Adicione $a_{i, 1}$ e $a_{i, 2}$ ao conjunto $S(H)$. Atualize $\sigma$ tal que $a_{1,1}<_{\sigma} a_{1,2}<_{\sigma} v_{1}$ e $v_{i-1}<_{\sigma} a_{i, 1}<_{\sigma} a_{i, 2}<_{\sigma} v_{i}$ para todo $i \in\{2, \ldots, n\}$. A Figura 6.2 mostra o modelo de intersecção do grafo $H$ construído a partir do grafo $G$ da Figura 6.1.

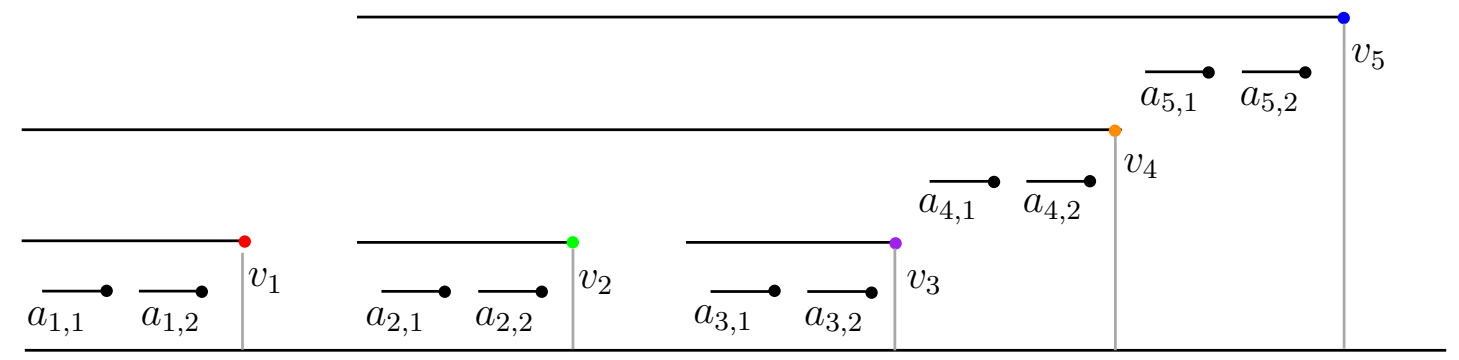

Figura 6.2: Modelo de intersecção do grafo $H$.

Chamamos o grafo construído $H$ de grafo estável-conexo de $G$. Denotamos por $C(H)$ o conjunto de vértices de $H$ que são também vértices de $G$, ou seja, $C(H)=V(G)$. Chamamos os vértices de $C(H)$ de vértices conectores de $H$ e os vértices de $S(H)$ de vértices estáveis de $H$. Observe que $|S(H)|=2|C(H)|$.

Não é difícil ver que, se $G$ é um grafo de intervalos, então o grafo estável-conexo $H$ de $G$ é um grafo de intervalos e $\sigma$ é uma r-ordenação para $H$. Note que os vértices estáveis de $H$ formam um conjunto independente, ou seja, não existe dois vértices estáveis adjacentes. Observe também que os vizinhos de um vértice estável formam um clique em $G$.

\section{Fase 2: encontrando um caminho binormal mais longo em $H$}

Seja $G$ um grafo de intervalos e seja $H$ o grafo estável-conexo construído na Fase 1. Apresentamos, nesta fase, o Algoritmo CML_em_H que computa um caminho binormal mais longo de $H$. Primeiro definimos caminhos binormais e estabelecemos a notação necessária para a descrição do algoritmo.

Definição 35 Seja $H$ um grafo estável-conexo e seja $\sigma=\left(u_{1}, u_{2}, \ldots u_{n}\right)$ uma r-ordenação de $H$. Para todo vértice conector $c \in C(H)$, seja $f(c)=\min \left\{i: u_{i} \in N(c)\right\}$. Para cada par de indices $(i, j)$, $1 \leq i \leq j \leq n$, definimos o grafo $\mathbf{H}(\mathbf{i}, \mathbf{j})$ como o subgrafo $H[S]$ de $H$, induzido pelo conjunto $S=\left\{u_{i}, u_{i+1}, \ldots u_{j}\right\} \backslash\left\{u_{k} \in C(H): u_{f\left(u_{k}\right)}<_{\sigma} u_{i}\right\}$ (veja Figura 6.3). 
Ou seja, $H(i, j)$ é um subgrafo de $H$ que contém os vértices de $u_{i}$ a $u_{j}$ (na r-ordenação $\sigma$ ), exceto os vértices conectores que são adjacentes a algum vértice $u_{\ell} \operatorname{com} \ell<i$.

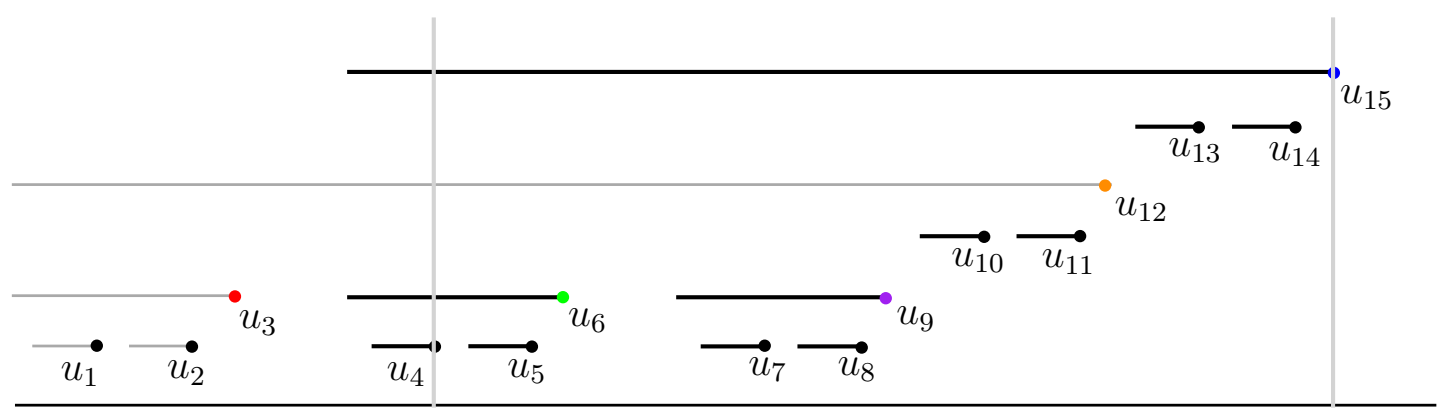

Figura 6.3: $O$ subgrafo $H(4,15)$, sendo $\sigma=\left(u_{1}, u_{2}, \ldots u_{15}\right)$.

O grafo estável-conexo $H$ da Figura 6.2 está ilustrado na Figura 6.3, com os vértices (os estáveis e os conectores) numerado de acordo com a r-ordenação $\sigma=\left(u_{1}, u_{2}, \ldots u_{15}\right)$ de $H$. O subgrafo $H(4,15)$ está ilustrado na Figura 6.3, onde $V(H(4,15))=\left\{u_{4}, u_{5}, u_{6}, u_{7}, u_{8}, u_{9}, u_{10}, u_{11}, u_{13}, u_{14}, u_{15}\right\}$ estão representados com cor mais escura que os demais para facilitar a visualização.

Definição 36 Seja $\pi$ uma r-ordenação de $G$. Um caminho $P=\left(w_{1}, w_{2}, \ldots, w_{k}\right)$ de $G$ é um caminho normal se satisfaz:

(a) para todo $i \in\{2, \ldots, k\}, w_{1}<_{\pi} w_{i}$; e

(b) para todo $i, j \in\{2, \ldots k\}, i<j$, se $w_{j} \in N\left(w_{i-1}\right)$, então $w_{i}<_{\pi} w_{j}$.

Chamamos $w_{k}$ de término de $P$.

Definição 37 Seja $H$ um grafo estável-conexo e seja $P$ um caminho de $H(i, j), 2 \leq i<j \leq n$. $O$ caminho $P$ é binormal se $P$ é um caminho normal de $H(i, j)$, ambas as extremidades de $P$ são vértices estáveis e não existem dois vértices conectores que aparecem consecutivamente em $P$.

Notação 38 Seja $H$ um grafo estável-conexo e seja $\sigma=\left(u_{1}, u_{2}, \ldots u_{n}\right)$ uma r-ordenação de $H$. Para todo vértice estável $u_{k} \in S(H(i, j))$, denotamos por $P\left(u_{k} ; i, j\right)$ um caminho binormal mais longo em $H(i, j)$ com término $u_{k}$, e por $l\left(u_{k} ; i, j\right)$ o comprimento de $P\left(u_{k} ; i, j\right)$.

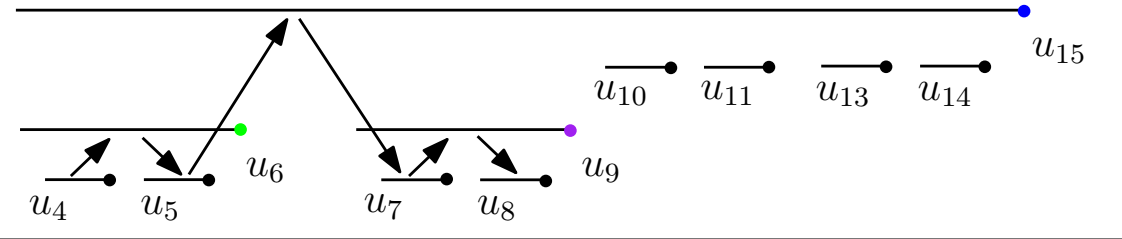

Figura 6.4: $O$ caminho $P\left(u_{8} ; 4,15\right)=\left(u_{4}, u_{6}, u_{5}, u_{15}, u_{7}, u_{9}, u_{8}\right)$ é um caminho binormal mais longo em $H(4,15)$ com término em $u_{8}$.

Usando técnicas de programação dinâmica, o Algoritmo CML_em_H calcula, para cada vértice estável $u_{k} \in S(H(i, j))$, o comprimento $l\left(u_{k} ; i, j\right)$ e o caminho correspondente $P\left(u_{k} ; i, j\right)$. Como $H(1, n)=H$, segue que o maior dos valores dentre $l\left(u_{k} ; 1, n\right)$, onde $u_{k} \in S(H)$, é o comprimento 
do maior caminho binormal $P\left(u_{k} ; 1, n\right)$ de $H$. Apresentamos o algoritmo e em seguida explicamos cada passo. Também aqui $f(c)=\min \left\{i: u_{i} \in N(c)\right\}$.

\section{Algoritmo CML_em_H}

Entrada: um grafo estável-conexo $H$, e uma r-ordenação $\sigma$ de $H$

Saída: um caminho mais longo binormal de $H$

1. $\quad$ para $j=1$ até $n$

2. $\quad$ para $i=j$ decrescendo até 1

3. $\quad$ se $i=j$ e $u_{i} \in S(H)$ então

4. $\quad l\left(u_{i} ; i, i\right) \leftarrow 1 ; P\left(u_{i} ; i, i\right) \leftarrow\left(u_{i}\right) ;$

5. $\quad$ se $i \neq j$ então

6. $\quad$ para cada vértice $u_{k} \in S(H), i \leq k \leq j-1$

7. $\quad l\left(u_{k} ; i, j\right) \leftarrow l\left(u_{k} ; i, j-1\right) ; P\left(u_{k} ; i, j\right) \leftarrow P\left(u_{k} ; i, j-1\right) ;$

8. $\quad$ se $u_{j} \in S(H)$ então

9. $\quad l\left(u_{j} ; i, j\right) \leftarrow 1 ; P\left(u_{j} ; i, j\right) \leftarrow\left(u_{j}\right) ;$

10. $\quad$ se $u_{j} \in C(H)$ e $i \leq f\left(u_{j}\right)$ então

11. $\quad$ execute processa $(H(i, j))$

12. compute $\max \left\{l\left(u_{k} ; 1, n\right): u_{k} \in S(H)\right\}$ e devolva o caminho correspondente $P\left(u_{k} ; 1, n\right)$;

$\operatorname{processa}(H(i, j))$

1. $\quad$ para $y=f\left(u_{j}\right)+1$ até $j-1$

2. $\quad$ para $x=f\left(u_{j}\right)$ até $y-1$

3. $\quad$ se $u_{x}, u_{y} \in S(H)$ então

4. $\quad w_{1} \leftarrow l\left(u_{x} ; i, j-1\right) ; P_{1} \leftarrow P\left(u_{x} ; i, j-1\right) ;$

5. $\quad w_{2} \leftarrow l\left(u_{y} ; x+1, j-1\right) ; P_{2} \leftarrow P\left(u_{y} ; x+1, j-1\right)$;

6. $\quad$ se $w_{1}+w_{2}+1>l\left(u_{y} ; i, j\right)$ então

7. $\quad l\left(u_{y} ; i, j\right) \leftarrow w_{1}+w_{2}+1 ; P\left(u_{y} ; i, j\right) \leftarrow\left(P_{1}, u_{j}, P_{2}\right) ;$

8. devolva o valor $l\left(u_{k} ; i, j\right)$ e o caminho $P\left(u_{k} ; i, j\right), \forall u_{k} \in S\left(H\left(f\left(u_{j}\right)+1, j-1\right)\right)$;

Por simplicidade, quando dizemos que o algoritmo computa $P\left(u_{k} ; i, j\right)$ ou $l\left(u_{k} ; i, j\right)$, queremos dizer que o faz para cada vértice estável $u_{k} \in S(H(i, j))$.

A ideia principal por trás do algoritmo é computar $P\left(u_{k} ; i, j\right)$ a partir de caminhos já computados, ou seja, podemos imaginar que o algoritmo preenche uma tabela com os valores de $l\left(u_{k} ; i, j\right)$ e com os caminhos $P\left(u_{k} ; i, j\right)$ usando dados que já foram preenchidos na tabela.

O Algoritmo CML_em_H começa computando $P\left(u_{k} ; i, j\right)$ para valores pequenos de $j$. Note que, se $i=j$, então o único caminho binormal em $H(i, j)$ é $\left(u_{i}\right)$, se $u_{i}$ for um vértice estável (se $u_{i}$ é um vértice conector, não existe caminho binormal em $H(i, j)$ ). Já para $i<j$, o algoritmo inicializa $P\left(u_{k} ; i, j\right)$ e $l\left(u_{k} ; i, j\right)($ para $k \neq j)$ com os valores já calculados $P\left(u_{k} ; i, j-1\right)$ 
e $l\left(u_{k} ; i, j-1\right)$, respectivamente, pois um caminho binormal em $H(i, j-1)$ é também um caminho binormal em $H(i, j)$. Se $u_{j}$ é um vértice conector, esses valores poderão ser atualizados em uma etapa seguinte. Se $u_{j}$ é um vértice estável, então resta definir que $P\left(u_{j} ; i, j\right)=\left(u_{j}\right)$ e $l\left(u_{j} ; i, j\right)=1$.

A sub-rotina processa $(H(i, j))$ atualiza os valores $P\left(u_{k} ; i, j\right)$ e $l\left(u_{k} ; i, j\right)$, no caso de $u_{j}$ ser um vértice conector de $H(i, j)$. Isto é feito calculando todos os possíveis pares de caminhos binormais que, juntamente com o vértice $u_{j}$, formam um caminho binormal com término em $u_{k}$ e, finalmente, guardando o maior dentre os caminhos resultantes. Por exemplo, no grafo da Figura 6.4, o caminho $P\left(u_{8} ; 4,15\right)=\left(P_{1}, u_{15}, P_{2}\right)$, com $P_{1}=\left(u_{4}, u_{6}, u_{5}\right)$ e $P_{2}=\left(u_{7}, u_{9}, u_{8}\right)$, é formado pela união de dois caminhos, a saber $P_{1}=P\left(u_{5} ; 4,14\right)$ e $P_{2}=P\left(u_{8} ; 6,14\right)$, com o vértice $u_{15}$.

\section{Fase 3: encontrando um caminho mais longo em G}

Seja $P$ o caminho binormal mais longo em $H$ devolvido pelo Algoritmo CML_em_H. Nesta fase, computamos o caminho $\hat{P}$, simplesmente removendo os vértices estáveis de $P$. Para verificar que $\hat{P}$ é de fato um caminho mais longo precisamos do seguinte lema.

Lema 39 Seja $H$ um grafo estável-conexo de $G$. Se $P$ é um caminho binormal mais longo em $H$ e $P^{\prime}$ um caminho mais longo em $G$, então $|P|=2\left|P^{\prime}\right|+1$.

Pela construção de $H$, todos os vizinhos de um vértice estável $v$ são vértices conectores e formam um clique em $G$. Logo, os vizinhos de $v$ em $P$ são vértices de $G$ e são adjacentes em $G$. Portanto, $\hat{P}$ é de fato um caminho. Ademais, como $P$ é binormal, $P$ tem $k$ vértices conectores e $k+1$ vértices estáveis. Segue que $|P|=2 k+1$ e $|\hat{P}|=k$. Pelo Lema 39, $\hat{P}$ é um caminho mais longo em $G$.

Apresentamos abaixo o Algoritmo CML_Intevalos, que encontra um caminho mais longo em um grafo de intervalos $G$.

\section{Algoritmo CML_Intervalos}

Entrada: um grafo de intervalos $G$ e uma r-ordenação $\pi$ de $G$ Saída: um caminho mais longo $\widehat{P}$ de $G$

1. A partir de $G$ e $\pi$, construir $H$ o grafo estável-conexo de $G$ e $\sigma$ uma r-ordenação de $H$; seja $V(H)=C \cup S$, onde $C=V(G)$ e $S$ são os conjuntos dos vértices conectores e estáveis de $H$, respectivamente.

2. Compute $P$ um caminho binormal mais longo em $H$, usando o Algoritmo CML_em_H; seja $P=\left(v_{1}, v_{2}, \ldots, v_{2 k}, v_{2 k+1}\right)$, onde $v_{2 i} \in C, 1 \leq i \leq k$, e $v_{2 i+1} \in S, 0 \leq i \leq k$.

3. Compute o caminho $\widehat{P}=\left(v_{2}, v_{4}, \ldots, v_{2 k}\right)$, que é um caminho mais longo em $G$, removendo os vértices $\left\{v_{1}, v_{3}, \ldots, v_{2 k+1}\right\}$ do caminho $P$. 


\section{Complexidade}

Seja $G$ um grafo de intervalos com $n$ vértices e $m$ arestas. A construção de uma r-ordenação de $G$ pode ser feita em tempo $\mathrm{O}(n+m)[6,76]$.

A Fase 1 leva tempo $\mathrm{O}\left(n^{2}\right)$, pois, para cada um dos $n$ vértices conectores, adicionamos dois vizinhos em tempo $\mathrm{O}(1)$ e calculamos sua vizinhança em tempo $\mathrm{O}(n)$.

Para determinar o tempo gasto na Fase 2, observe que a sub-rotina processa() leva tempo $\mathrm{O}\left(n^{2}\right)$ devido aos $\mathrm{O}\left(n^{2}\right)$ pares de vizinhos do vértice conector $u_{j}$ no grafo $H(i, j)$. Além disso, a sub-rotina processa() é executada no máximo uma vez para cada subgrafo $H(i, j), 1 \leq i \leq j \leq n$, ou seja é executada $\mathrm{O}\left(n^{2}\right)$ vezes. Portando a Fase 2 leva tempo $\mathrm{O}\left(n^{4}\right)$.

A Fase 3 pode ser feita em tempo $\mathrm{O}(n)$, pois basta percorrer o caminho $P$ construído pelo Algoritmo CML_em_H uma vez, removendo os vértices estáveis. Portanto, a complexidade do algoritmo inteiro é $\mathrm{O}\left(n^{4}\right)$.

\subsection{Outros resultados}

Existem outras classes de grafos para as quais já se conhece algoritmo polinomial para resolver o problema do caminho mais longo. Bodlaender $[15,16]$ provou que existe um algoritmo linear que resolve este problema para $k$-árvore parciais, considerando $k$-fixo, (que incluem os grafos série-paralelos). Uehara e Uno $[88,89]$ apresentaram algoritmos polinomiais para grafos de blocos, cactos, grafos de permutação bipartidos, grafos limiares (threshold graphs) e algumas outras classes de grafos. Andreica, Manev, Markov e Ţăpuş [3] melhoraram o algoritmo para cactos, e Uehara e Valiente [90] para grafos de permutação bipartido. Takahara, Teramoto e Uehara [83] propuseram um algoritmo polinomial que encontra um caminho mais longo em grafos ptolomaicos, uma superclasse dos grafos de blocos; e Guo, Ho e Ko [49] em grafos distância-hereditários, uma superclasse dos grafos ptolomaicos. Ghosh, Narayanaswamy e Rangan [44] provaram que para grafos biconvexos, uma superclasse dos grafos de permutação bipartido, o problema também é polinomial. Recentemente, Chang, Hsu e Peng [23] provaram o mesmo fato para os grafos de permutação, outra superclasse dos grafos de permutação bipartido.

Corneil e Mertzios [27], e Ioannidou e Nikolopoulos [58], independentemente, desenvolveram algoritmos polinomiais que encontram um caminho mais longo em grafos de cocomparabilidade, que é uma superclasse dos grafos de intervalos. Bezáková e Mertzios [13] encontraram algoritmos polinomiais que resolvem o problema para os grafos arco-circulares, outra superclasse dos grafos de intervalos.

Embora existam diversas classes em que o problema admite solução polinomial, conforme mencionamos na introdução, sabemos que esse problema é NP-difícil [42] mesmo quando restrito a algumas classes, como grafos planares [43], grafos grade [59], grafos círculo [28], grafos cordais bipartidos, grafos divididos fortemente cordais [70], grafos de caminhos dirigidos [72] e grafos divididos [45].

Uma extensão natural para esse problema é pesquisar se algumas outras classes "intermediárias" admitem solução polinomial, como por exemplo, as classes dos grafos convexos (uma subclasse de grafos cordais bipartidos e uma superclasse de grafos biconvexos) e dos grafos de cointervalos (uma subclasse de grafos de comparabilidade e uma superclasse de grafos limiares).

Nos diagramas das Figuras 2.1 e 2.2, as elipses com fundo branco se referem a classes de grafos 
para as quais existe algoritmo polinomial que resolve o problema do caminho mais longo, as elipses de fundo mais escuro se referem a classes para as quais é sabido que o problema é NP-difícil e, finalmente, as elipses hachuradas se referem a classes para as quais não se sabe se existe algoritmo polinomial. 


\section{Capítulo 7}

\section{Algoritmos de aproximação}

Uma abordagem que tem sido investigada no tratamento do problema do caminho mais longo é a de encontrar algoritmos de aproximação para esse problema. Ou seja, projetar algoritmos polinomiais que recebem como entrada um grafo com $n$ vértices e encontram caminhos de comprimento ao menos $f(n)$ vezes o comprimento de um caminho mais longo, para alguma função $f$. Nesse caso, dizemos que um tal algoritmo tem razão de aproximação $f(n)$.

Nesta seção descrevemos três desses algoritmos que utilizam técnicas distintas e que fornecem razões de aproximação sucessivamente melhores. A melhor razão de aproximação para esse problema conhecida hoje é de Gabow e Nie [41]. Eles apresentam um algoritmo que encontra um caminho de comprimento $\exp (\Omega(\sqrt{\log L}))$, onde $L$ é o comprimento de um caminho mais longo. Não provamos aqui esse resultado, mas a ideia por trás desse algoritmo tem semelhanças com o algoritmo que apresentamos na Seção 7.3.

Observamos que, para facilitar o entendimento e para corrigir pequenos erros nas provas, fizemos algumas modificações, com relação às demonstrações dos autores, e detalhamos algumas passagens mais relevantes.

\subsection{Representantes de famílias}

Em 1985, Monien [69] desenvolveu um algoritmo para encontrar caminhos de comprimento $k$ em um grafo com $n$ vértices, de forma mais eficiente que o algoritmo ingênuo de enumerar todas as sequências de $k+1$ vértices. O algoritmo ingênuo resolve o problema em tempo $\mathrm{O}\left(n^{k+1}\right)$. Obviamente, esse algoritmo só é polinomial em $n$ para $k$ constante.

$\mathrm{O}$ algoritmo de Monien encontra um caminho de comprimento $k$ (se tal caminho existir) em tempo exponencial em $k$, a saber $\mathrm{O}(k ! n m)$, o que permite encontrar, em tempo polinomial em $n$, caminhos de comprimento $\log n / \log \log n$. Esse algoritmo calcula a matriz $D^{(k)}=\left(d_{i j}^{(k)}\right), 1 \leq i, j \leq n$, onde $d_{i j}^{(k)}$ é igual a algum caminho de $i$ a $j$ de comprimento $k$, se tal caminho existir, e $d_{i j}^{(k)}$ é igual a um símbolo especial $\lambda$, caso contrário. O resultado principal de Monien é o seguinte.

Teorema 40 Seja $G$ um grafo com $n$ vértices e $m$ arestas e seja $k$ um número natural. A matriz $D^{(k)}(G)$ pode ser calculada em tempo $\mathrm{O}(k ! n m)$.

Seja $G=(V, E)$ conforme o enunciado. Denotamos por $\{1, \ldots, n\}$ o conjunto dos vértices de $G$. Observe que, para quaisquer vértices $i$ e $j$, se tivermos todos os caminhos de comprimento $p-1$ 
que terminam em $j$, podemos facilmente computar todos caminhos de comprimento $p$ que começam em $i$ e terminam em $j$. Esse método consome muito tempo, pois o número de caminhos de comprimento $p$ pode ser muito grande. Para melhorar o consumo de tempo, em vez de considerar todos os caminhos de comprimento $p$ de $i$ a $j$, o algoritmo considera apenas uma subfamília desses caminhos, desconsiderando aqueles que não são necessários para computar caminhos de comprimento $k$.

Por simplicidade, em vez de considerar caminhos (sequências de vértices), consideramos conjuntos de vértices, ou seja, não fazemos distinção entre caminhos que têm o mesmo conjunto de vértices. Em uma implementação desse algoritmo, seria necessário manter a sequência dos vértices. Uma vez que temos um conjunto de $k+1$ vértices que formam um caminho, também é possível usar o método ingênuo de enumerar todas as permutações desses $k+1$ vértices para encontrar um caminho sobre esses vértices. Esse processo consome tempo $\mathrm{O}\left(k^{k}\right)$, que, para $k=\mathrm{O}(\log n / \log \log n)$, é polinomial em $n$.

Dados um conjunto $C$ e um inteiro $p$, denotamos por $\left(\begin{array}{l}C \\ p\end{array}\right)$ a coleção de todos os conjuntos de $p$ elementos distintos de $C$. Se $i, j$ são vértices do grafo e $p \in\{0, \ldots, n-2\}$, definimos a seguinte família de conjuntos de $p$ vértices:

$F_{i j}^{p}=\left\{U \in\left(\begin{array}{l}V \\ p\end{array}\right) \mid U\right.$ é o conjunto de vértices internos a um caminho com $p+2$ vértices de $i$ a $\left.j\right\}$.

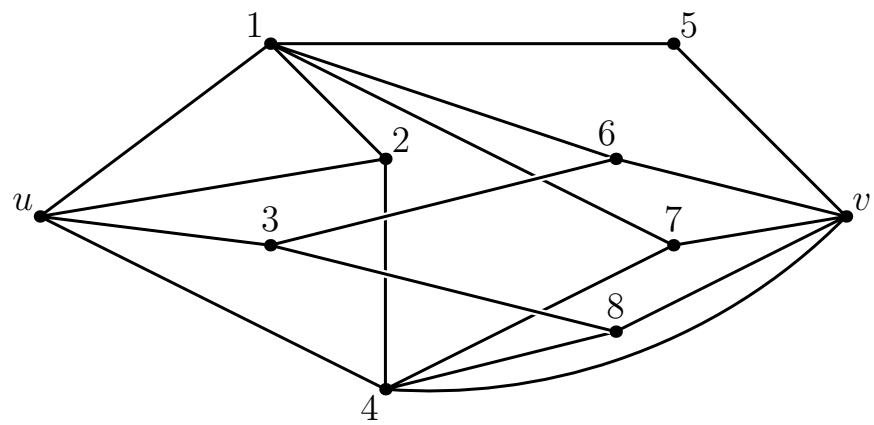

Figura 7.1: Grafo G.

Considere o grafo da Figura 7.1. Observe que os conjuntos de vértices da família $F_{u v}^{2}$ são aqueles que são internos a algum caminho de $u$ a $v$ com 4 vértices. Ou seja,

$$
F_{u v}^{2}=\{\{1,5\},\{1,6\},\{1,7\},\{2,4\},\{3,6\},\{3,8\},\{4,7\},\{4,8\}\} .
$$

Definimos, a seguir, a noção de representantes de família. Seja $q$ um número natural, $0 \leq q<n$ e seja $F$ uma família de conjuntos de vértices. Um $q$-representante $\hat{F}$ de $F$ é um subconjunto de $F$ tal que, se consideramos um conjunto qualquer $W$ de $q$ vértices, $F$ contém um conjunto $U$ disjunto de $W$ se e somente se $\hat{F}$ contém um conjunto $\hat{U}$ disjunto de $W$. Note que, como $\hat{F} \subseteq F$, se $F$ não contém um conjunto disjunto de algum $W, \hat{F}$ também não conterá. Logo, para verificar que um subconjunto $\hat{F}$ de $F$ é de fato um $q$-representante de $F$, basta verificar se, para todo conjunto $W$ de cardinalidade $q$ que é disjunto de algum conjunto de $F$, existe um conjunto em $\hat{F}$ que também é disjunto de $W$.

Considere novamente o grafo da Figura 7.1. Observe que $\hat{F}_{1}=\{\{1,5\},\{2,4\}\}$ é um 1-representante de $F_{u v}^{2}$, De fato, note que, como $F_{u v}^{2}$ contém 2 conjuntos disjuntos, então qualquer vértice é disjunto de um desses dois conjuntos. O mesmo vale para $\hat{F}_{1}$. Analogamente, podemos ver que como $F_{u v}^{2}$ contém 3 conjuntos dois-a-dois disjuntos, então qualquer conjunto de 2 vértices é disjunto 
a algum deles. Logo, $\hat{F}_{2}=\{\{1,5\},\{2,4\},\{3,6\}\}$ é um 2-representante de $F_{u v}^{2}$. Com um pouco mais esforço podemos ver que $\hat{F}_{3}=\{\{1,5\},\{1,7\},\{2,4\},\{3,6\},\{3,8\},\{4,8\}\}$ é um 3-representante de $F_{u v}^{2}$.

Como mencionamos anteriormente, usamos essa ideia de representantes para calcular a matriz $D^{(k)}$, ou seja, para calcular $d_{i j}^{(k)}$ para todo $i, j \in\{1, \ldots, n\}$. Para isso, precisamos decidir se existe um caminho de comprimento $k$ de $i$ a $j$ e, se existir, saber quais os vértices internos desse caminho, o que é equivalente a decidir se a família $F_{i j}^{k-1}$ é vazia e, se não for, encontrar algum conjunto que está em $F_{i j}^{k-1}$.

Sejam $u$ e $v$ dois vértices. Um caminho de $u$ a $v$ consiste em uma aresta $u i \in E$ e um caminho de $i$ a $v$ de comprimento $k-1$ que não contenha $u$. Note que $F_{i v}^{k-2}$ é justamente a família de conjuntos de vértices que são internos a algum caminho de comprimento $k-1$ de $i$ a $v$. Logo, basta sabermos se, para algum $i \in V$ tal que $u i \in E$, existe um conjunto em $F_{i v}^{k-2}$ que não contém $u$ (ou seja, existe um caminho de $i$ a $v$ de comprimento $k-1$ que não contenha $u$ ). Note que essa informação pode ser extraída do 1-representante de $F_{i v}^{k-2}$.

Podemos reformular essa observação da seguinte maneira, suponha que conheçamos um 1-representante para $F_{i j}^{k-2}$, para $i, j \in\{1, \ldots, n\}$. Então é possível calcular 0-representantes de $F_{i j}^{k-1}$, para $i, j \in\{1, \ldots, n\}$. Note que um 0 -representante de uma família $F$ é vazio se $F$ é vazio, e caso contrário, ou seja se $F$ não é vazio, contém um elemento qualquer de $F$.

Podemos facilmente generalizar a observação acima e obter o seguinte lema.

Lema 41 Sejam $p, q \in \mathbb{N}$ tais que $0 \leq p \leq n-2$ e $1 \leq q<n$. Se conhecemos um q-representante para $F_{i j}^{p}$, para $i, j \in\{1, \ldots, n\}$, mas não necessariamente a familia $F_{i j}^{p}$, é possivel calcular $(q-1)$-representantes para todas as familias $F_{i j}^{p+1}$, para $i, j \in\{1, \ldots, n\}$.

Assim, se calcularmos um $(k-1)$-representante para $F_{i j}^{0}$, para todo $i, j \in\{1, \ldots, n\}$, podemos, então, calcular um $(k-2)$-representante para $F_{i j}^{1}$, para $i, j \in\{1, \ldots, n\}$, e assim por diante, até chegarmos a um 0 -representante para $F_{i j}^{k-1}$, para todo $i, j \in\{1, \ldots, n\}$, que é o que precisamos para calcular a matriz $D^{(k)}$.

Resta mostrar como fazer isso de modo eficiente. Para isso, definimos um tipo de árvore que permitirá fazer as computações descritas no Lema 41 de forma rápida.

Definição 42 Seja $F$ uma família de conjuntos de $p$ elementos de $V$ e seja $q$ um número natural. Uma $(q, F)$-árvore é uma árvore p-nária, com rótulos nos vértices e nas arestas, de altura no máximo q e que satisfaz as seguintes condições:

1. Os vértices são rotulados com conjuntos de $F$ ou com o simbolo especial $\lambda$. As arestas são rotuladas com elementos de $V$.

2. Se um vértice u da árvore tem um rótulo $U \in F$ e tem profundidade menor que q, então u tem $p$ filhos e cada um dos $p$ elementos de $U$ ocorre como rótulo de uma aresta entre u e um de seus filhos.

3. Um vértice cujo rótulo é $\lambda$ ou cuja profundidade é igual a q não tem filhos.

4. Para todo vértice u da árvore, seja $P(u)$ o conjunto de elementos que rotula as arestas do caminho da raiz até $u$. Se o rótulo de u é $U \in F$, então vale que $U \cap P(u)=\emptyset$ e, se o rótulo de u é $\lambda$, então não existe $W \in F$ tal que $W \cap P(u)=\emptyset$. 
Como exemplo (veja Figura 7.2 ), descrevemos uma $\left(3, F_{u v}^{2}\right.$ )-árvore para o grafo da Figura 7.1. Note que, para $0 \leq q \leq 2$, os primeiros $q$ níveis dessa árvore formam uma $\left(q, F_{u v}^{2}\right)$-árvore.

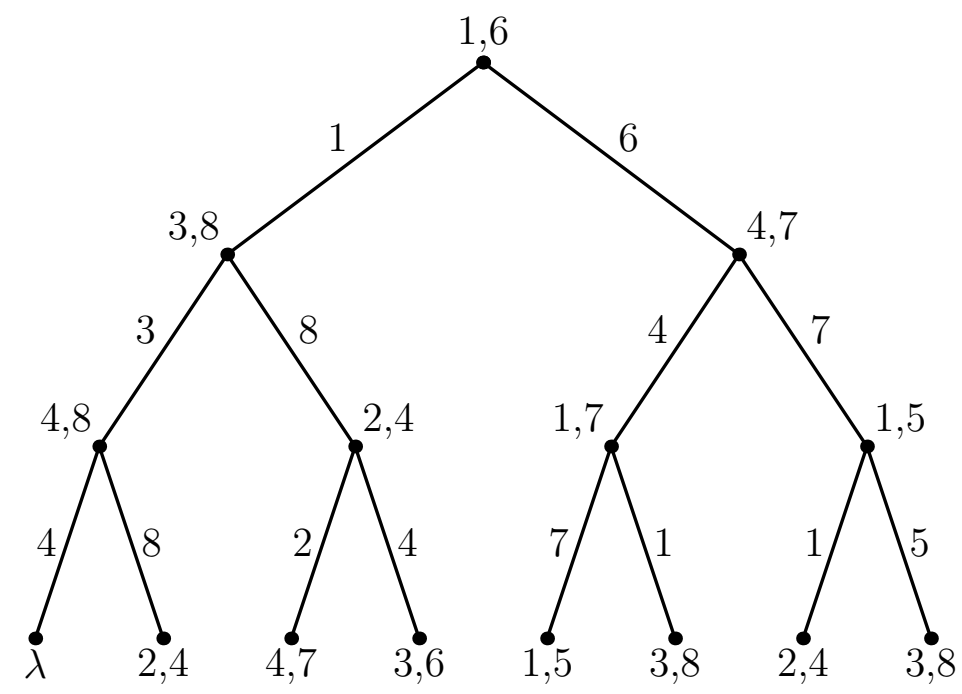

Figura 7.2: $\left(3, F_{u v}^{2}\right)$-árvore.

Para as próximas demonstrações, denotamos por $P(u)$ o conjunto de elementos que rotula as arestas do caminho da raiz até o vértice $u$ da árvore. Observe que, dados $q \in \mathbb{N}$ e uma família $F$ de conjuntos de tamanho $p$, é possível construir uma $(q, F)$-árvore recursivamente da seguinte forma. Primeiro comece com uma árvore que tem apenas um vértice (a raiz) e rotule esse vértice com um elemento qualquer de $F$. Enquanto existe uma folha (um vértice com grau no máximo 1), digamos $v$, na árvore que não esteja rotulada com o símbolo $\lambda$ e que esteja a uma profundidade menor que $q$, adicione $p$ vértices, digamos $v_{1}, v_{2}, \ldots, v_{p}$, adjacentes unicamente a $v$ e rotule cada aresta nova (entre $v$ e um vértice $v_{i}$ ) com um elemento distinto do rótulo de $v$. Rotule cada $v_{i}$ com um conjunto de $F$ que não contém nenhum dos elementos de $P\left(v_{i}\right)$, se tal conjunto existir. Se não existir tal conjunto, rotule $v_{i} \operatorname{com} \lambda$.

Obviamente esse algoritmo para, pois $p$ e $q$ são números finitos e essa árvore tem no máximo $\frac{(p+1)^{q}}{q}$ vértices. Além do mais, a árvore gerada por esse algoritmo obedece as propriedades da definição de uma $(q, F)$-árvore. Como mostra o Lema 43, estas árvores permitem fazer buscas de forma eficiente. O Lema 44 afirma que é possível calcular cada árvore de modo mais rápido, utilizando outras árvores já encontradas previamente no processo.

Lema 43 Sejam $F \subseteq\left(\begin{array}{l}V \\ p\end{array}\right)$ uma família de conjuntos, $q$ um número natural e $B$ uma $(q, F)$-árvore. A família $\hat{F}$, que consiste de todos os conjuntos que ocorrem como rótulos de $B$, forma um q-representante de F. Além disso, podemos decidir em tempo $\mathrm{O}\left(p q^{2}\right)$ se, para um dado $W \in\left(\begin{array}{c}V \\ q\end{array}\right)$, existe $U \in F$ tal que $W \cap U=\emptyset$ e, se existir, calcular um tal $U$.

Prova. Sejam $F, q$ e $B$ conforme o enunciado de lema. Se $b$ é um vértice de $B$, denotamos por $r(b)$ o seu rótulo. Dado $W \in\left(\begin{array}{l}V \\ q\end{array}\right)$, para decidir se existe $U \in F$ tal que $W \cap U=\emptyset$ e, se existir, calcular um tal $U$, basta realizar uma busca na árvore $B$ como descrevemos a seguir. Seja $b_{0}$ a raiz de $B$.

Se $r\left(b_{0}\right)=\lambda$, então o algoritmo responde que não existe conjunto $U \in F$ que satisfaz a propriedade. Caso contrário, $r\left(b_{0}\right) \in F$ é um subconjunto de $V$. Se $W \cap r\left(b_{0}\right)=\emptyset$, então $U=r\left(b_{0}\right)$ satisfaz 
a propriedade desejada. Se $W \cap r\left(b_{0}\right) \neq \emptyset$, seja $v \in W \cap r\left(b_{0}\right)$ e seja $b_{1}$ o filho de $b_{0}$ na árvore tal que $r\left(b_{1} b_{0}\right)=v$. Repita o procedimento para a subárvore enraizada em $b_{1}$.

Observe que o algoritmo necessariamente chega ao fim encontrando um vértice $b$ de $B$ tal que, ou $r(b)=\lambda$, ou $r(b) \in F$ é um subconjunto de $V$ e $W \cap r(b)=\emptyset$. Para isso, observe que se o algoritmo chega em um vértice $b$ com profundidade menor que $q$, ou $b$ satisfaz uma das duas afirmações acima, ou o algoritmo continua para algum filho de $b$. Se o algoritmo chega em um vértice $b$ de profundidade $q$, então, como $P(b) \subseteq W$ e $|P(b)|=q$, concluímos que $P(b)=W$. Logo, se $r(b) \neq \lambda$, então $W \cap r(b)=\emptyset$.

Agora note que, se o algoritmo encontra um vértice da árvore $b$ tal que $W \cap r(b)=\emptyset$, então, como $r(b) \in F, r(b)$ satisfaz a propriedade desejada. Se $r(b)=\lambda$, então, pela definição de $(q, F)$-árvores, não existe $U \in F$ tal que $W \cap U=\emptyset$.

Como a busca na árvore decide corretamente se existe $U \in F$ tal que $W \cap U=\emptyset$ e, se existir, calcula um tal $U$, e como esse $U$ calculado é o rótulo de algum vértice da árvore, concluímos que a família $\hat{F}$, que consiste de todos os conjuntos que ocorrem como rótulos de $B$, forma um $q$-representante de $F$.

Agora basta verificar que essa busca pode ser realizada em tempo $\mathrm{O}\left(p q^{2}\right)$. Não é difícil perceber isso, pois o caminho percorrido na busca é limitado pela altura da árvore, que por definição é no máximo $q$, e para cada vértice do caminho percorrido na busca, o algoritmo compara dois conjuntos um com $p$ e outro com $q$ elementos, o que leva no máximo $p q$ passos.

Mostramos agora que é possível calcular $\left(q-1, F_{i j}^{p+1}\right)$-árvores a partir de $\left(q, F_{i j}^{p}\right)$-árvores, analogamente ao Lema 41. Além disso, provamos um limitante superior no tempo de execução desse procedimento.

Lema 44 Sejam $p, q \in \mathbb{N}$ tais que $0 \leq p \leq n-2$ e $1 \leq q \leq n$. Suponha que $\left(q, F_{i j}^{p}\right)$-árvores já tenham sido calculadas, para $i, j \in\{1, \ldots, n\}$. Dados $u, v \in V$ é possível calcular uma $\left(q-1, F_{u v}^{p+1}\right)$-árvore em tempo $\mathrm{O}\left(q^{2}(p+1)^{q} d(u)\right)$, onde $d(u)$ é o grau do vértice $u$ no grafo $G$.

Prova. Calculamos uma $\left(q-1, F_{u v}^{p+1}\right)$-árvore recursivamente, começando pela raiz. Primeiramente, criamos a raiz da árvore sem nenhum rótulo. Em seguida, repetimos o seguinte procedimento enquanto existir um vértice sem rótulo.

Se existe um vértice sem rótulo, digamos $b$, precisamos encontrar um conjunto $U \in F_{u v}^{p+1}$ tal que $U \cap P(b)=\emptyset$ (se existir). Mostramos a seguir como fazer isso. Se tal conjunto $U$ existir, rotulamos o vértice $b$ com esse conjunto $U$ e criamos $p+1$ vértices adjacentes a $b$ e rotulamos cada uma das novas arestas (arestas que ligam $b$ com um dos vértices novos) com um elemento de $U$. Se não existir tal conjunto, então rotulamos $b \operatorname{com} \lambda$.

Agora mostramos como encontrar tal conjunto $U$ (se existir). Note que um caminho de comprimento $p+2$ de $u$ a $v$ em $G$ consiste em uma aresta $u w \in E$ e um caminho de comprimento $p+1$ de $w$ a $v$ que não contém $u$. Logo, existe um conjunto $U \in F_{u v}^{p+1}$ que satisfaz $U \cap P(b)=\emptyset$ se e somente se existir uma aresta $u w \in E$ e um conjunto $\hat{U} \in F_{w v}^{p}$ com $\hat{U} \cap(P(b) \cup\{u\})=\emptyset$.

Para cada $w \in V$ adjacente a $u$, pelo Lema 43 , podemos decidir em $\mathrm{O}\left(p q^{2}\right)$ passos se existe um conjunto $\hat{U} \in F_{w v}^{p} \operatorname{com} \hat{U} \cap(P(b) \cup\{u\})=\emptyset$. Como essa computação é feita no máximo $d(u)$ vezes, então computamos o rótulo de um vértice em tempo $\mathrm{O}\left(p q^{2} d(u)\right)$. Como uma $\left(q-1, F_{u v}^{p+1}\right)$-árvore tem no máximo $\frac{(p+1)^{q}-1}{p}$ vértices (pois é uma árvore $(p+1)$-nária de altura no máximo $q-1$ ) e 
como o cálculo dos rótulos das arestas leva tempo constante, concluímos que é possível calcular uma $\left(q-1, F_{u v}^{p+1}\right)$-árvore em tempo $\mathrm{O}\left(q^{2}(p+1)^{q} d(u)\right)$.

Prova do Teorema 40. Observe que, se $i j \in E, F_{i j}^{0}$ contém exatamente o conjunto vazio e, se $i j \notin E, F_{i j}^{0}$ é a família vazia. Logo, a $\left(k-1, F_{i j}^{0}\right)$-árvore tem apenas um vértice que está rotulado com $\emptyset$, se $i j \in E$, ou com $\lambda$ se $i j \notin E$.

Pelo Lema 44, o tempo total de execução para calcular todas as $\left(q-1, F_{i j}^{p+1}\right)$-árvores, para $i, j \in\{1, \ldots, n\}$ é proporcional a

$$
\sum_{i=1}^{n} \sum_{j=1}^{n} q^{2}(p+1)^{q} d(i)=n q^{2}(p+1)^{q} \sum_{i=1}^{n} d(i)=2 m n q^{2}(p+1)^{q} .
$$

Logo, podemos calcular a matriz $D^{(k)}$ a partir das $\left(k-1, F_{i j}^{0}\right)$-árvores (que não precisamos computar, pois essas 'árvores' são dadas pelo conjunto de arestas $E)$, primeiramente calculando as $\left(k-2, F_{i j}^{1}\right)$-árvores, e depois as $\left(k-3, F_{i j}^{2}\right)$-árvores, e assim por diante até calcular as $\left(0, F_{i j}^{k-1}\right)$-árvores. Isso levará tempo proporcional a:

$$
\begin{aligned}
& \text { tempo para calcular todas as }\left(q-1, F_{i j}^{p+1}\right) \text {-árvores } \\
= & \sum_{p=0}^{k-2} \text { tempo para calcular a }\left(k-2-p, F_{i j}^{p+1}\right) \text {-árvore } \\
\leq & \sum_{p=0}^{k-2} 2 m n(k-1-p)^{2}(p+1)^{k-1-p} \\
\leq & 2 m n(k-1)^{2} \sum_{p=1}^{k-1} p^{k-p}
\end{aligned}
$$

Por indução em $k$, podemos ver que $\sum_{p=1}^{k-1} p^{k-p} \leq(k-2)$ !, para $k \geq 9$. De fato, note que, para $k=9$, temos que $\sum_{p=1}^{k-1} p^{k-p}=2780<5040=(k-2)$ !. Suponha agora que $k>9$.

$$
\begin{array}{rlr}
\sum_{p=1}^{k-1} p^{k-p} & =k-1+1^{k-1-1}+2 \cdot 2^{k-2-1}+\sum_{p=3}^{k-2} p \cdot p^{k-p-1} & \\
& \leq(k-2) \cdot 1+(k-2) \cdot 2^{k-3}+(k-2) \sum_{p=3}^{k-2} p^{k-p-1} & \\
& =(k-2) \sum_{p=1}^{k-2} p^{k-p-1} & \\
& \leq(k-2)(k-3) ! & \text { considerando } k \geq 5
\end{array}
$$

Portanto, é possível calcular a matriz $D^{(k)}$ em tempo $\mathrm{O}(k ! m n)$.

Observando que $k ! \leq k^{k}$, e que $\left(\frac{\log n}{\log \log n}\right)^{\frac{\log n}{\log \log n}}=n^{1-\frac{\log \log \log n}{\log \log n}} \leq n$, o seguinte corolário segue imediatamente.

Corolário 45 Seja $G$ um grafo com $n$ vértices e $m$ arestas. É possivel encontrar um caminho de comprimento $\log n / \log \log n$, se tal caminho existir, em tempo $\mathrm{O}\left(n^{2} m\right)$. 


\subsection{Método de codificação por cores}

Em 1995, Alon, Yuster e Zwick [2] desenvolveram um método que chamaram de "color-coding" (codificação por cores) para resolver alguns problemas de isomorfismo de subgrafos em tempo polinomial. Em particular, esse método permite encontrar em tempo polinomial um caminho de comprimento $\log n$ em um grafo com $n$ vértices, se tal caminho existir. Isso resolve afirmativamente a conjectura de Papadimitriou e Yannakakis [75] de que é possível decidir em tempo polinomial se um grafo de ordem $n$ tem um caminho de comprimento $\log n$.

O método de codificação por cores é mais geral do que o que descrevemos aqui, podendo ser usado para encontrar subgrafos homeomorfos a outros grafos de largura arbórea limitada (grafos que são $k$-árvores parciais para $k$ limitado), como os próprios autores demonstram [2], entre outras aplicações, inclusive em bioinformática, que outros [1,56] desenvolveram mais recentemente. O resultado que apresentamos aqui é o seguinte.

Teorema 46 Em um grafo $G$ com $m$ arestas, é possivel encontrar um caminho de comprimento $k$, se tal caminho existir, em tempo esperado $2^{\mathrm{O}(k)} m$.

Embora o algoritmo que produz esse resultado seja aleatorizado, é possível desaleatorizá-lo usando funções de hashing, como fazem os autores no artigo citado, com uma perda de apenas $\log |V(G)|$ na eficiência. Aqui apresentamos apenas a versão aleatorizada.

Seja $G=(V, E)$ um grafo e seja $c: V \rightarrow\{1, \ldots, k\}$ uma coloração aleatória dos vértices de $G$ com $k$ cores (cada vértice tem probabilidade $1 / k$ de receber a cor $i$, para $i \in\{1, \ldots, k\}$ ). Chamamos um caminho de multicolorido se o caminho não contém dois vértices de mesma cor. Suponha que exista um caminho de comprimento $k-1 \mathrm{em} G$. A probabilidade de que esse caminho seja multicolorido é $k ! / k^{k}>e^{-k}$. Supondo que esse caminho seja multicolorido, quanto tempo levaria para encontrá-lo? O seguinte lema responde a essa pergunta.

Lema 47 Seja $G$ um grafo com $m$ arestas e seja $c: V \rightarrow\{1, \ldots, k\}$ uma coloração dos seus vértices com $k$ cores. Um caminho multicolorido de comprimento $k-1$, se tal caminho existir, pode ser encontrado em tempo $2^{\mathrm{O}(k)} m$.

Prova. Seja $G=(V, E)$ um grafo com $n$ vértices e $m$ arestas. Apresentamos o algoritmo (determinístico) que encontra um caminho multicolorido, se tal caminho existir, no grafo. Primeiramente adicionamos um vértice universal $s$ (um vértice que é vizinho de todos os vértices de $G$ ) e colorimos $s$ com a nova cor 0 . Em seguida, procuramos um caminho multicolorido de comprimento $k$ que começa em $s$ usando programação dinâmica.

Suponha que já tenhamos encontrado para cada $v \in V$ os possíveis conjuntos de cores de caminhos multicoloridos de ordem $i$ de $s$ a $v$. Note que não necessitamos manter todos os caminhos coloridos de $s$ a $v$, apenas guardamos os conjuntos de cores que aparecem em tais caminhos. Logo, para cada $v$, temos uma coleção associada de no máximo $\left(\begin{array}{l}k \\ i\end{array}\right)$ conjuntos de cores. Para cada conjunto de cor $C$ que pertence a coleção associada a um vértice $v$, e para cada aresta $v u \in E$, se $c(u) \notin C$, então acrescentamos $C \cup\{c(u)\}$ a coleção de $u$ correspondente a caminhos multicoloridos de ordem $i+1$. O grafo $G$ contém um caminho multicolorido de comprimento $k$ que começa em $s$ se e somente se a coleção final, correspondente a caminhos multicoloridos de comprimento $k$, de algum vértice é 
não vazia. Em cada fase esse algoritmo realiza no máximo $\mathrm{O}\left(\mathrm{mi}\left(\begin{array}{c}k \\ i\end{array}\right)\right)$ operações. Portanto, o número total de operações realizadas é no máximo $\mathrm{O}\left(m \sum_{i=0}^{k} i\left(\begin{array}{l}k \\ i\end{array}\right)\right)$ que é claramente $2^{\mathrm{O}(k)} m$.

Prova do Teorema 46. Seja $G$ um grafo com $m$ arestas. Como mencionamos anteriormente, em cada coloração do grafo, um caminho de comprimento $k$ tem probabilidade $k ! / k^{k}>e^{-k}$ de ser multicolorido. Logo, o número esperado de colorações aleatórias que devemos produzir até obter uma em que um dado caminho é multicolorido é menor que $e^{k}=2^{\mathrm{O}(k)}$. Pelo Lema 47, para cada coloração, pode-se decidir se existe e, se existir, encontrar um caminho multicolorido de comprimento $k-1 \mathrm{em}$ tempo $2^{\mathrm{O}(k)} m$. Logo, o tempo esperado para encontrar um caminho de comprimento $k-1$ em $G$ é $2^{\mathrm{O}(k)} \cdot 2^{\mathrm{O}(k)} m=2^{\mathrm{O}(k)} m$. Portanto, o Teorema 46 segue.

Como consequência direta desse teorema temos o seguinte resultado.

Corolário 48 Seja grafo $G$ um grafo com n vértices. É possivel encontrar um caminho de comprimento $\log n$, se um tal caminho existir, em tempo esperado polinomial em $n$.

Observe que essa ideia de manter apenas o conjunto das cores que aparecem em um caminho de $s$ a $v$ (ou equivalentemente apenas um caminho para cada conjunto de cor) é similar a ideia do Monien de manter apenas representantes de famílias. Ademais, ambos esses resultados mostram que o problema do caminho mais longo é FPT quando parametrizado pelo comprimento do caminho.

\section{3 Árvore de decomposição em circuitos}

Nesta subseção apresentamos um algoritmo polinomial que encontra um caminho de comprimento $\Omega\left(\frac{\log ^{2} L}{\log \log L}\right)$ em um grafo cujos caminhos mais longos têm comprimento $L$.

Teorema 49 Seja $G$ um grafo com n vértices que contém um caminho de comprimento L. Podemos encontrar um caminho de comprimento $\Omega\left(\frac{\log ^{2} L}{\log \log L}\right)$ em tempo polinomial em $n$.

A ideia principal do algoritmo é a de decompor o grafo em circuito disjuntos "longos" e depois juntá-los formando um caminho longo. Para isso, necessitamos do seguinte lema, fácil de ser provado.

Lema 50 Se um grafo conexo $G$ tem um caminho de comprimento $L$, então todo vértice de $G$ é a extremidade de algum caminho de comprimento pelo menos $\frac{1}{2} \mathrm{~L}$.

Prova. Sejam $P=p_{0} \cdots p_{r}$ um caminho e $v$ um vértice de $G$. Encontre $i$ que minimiza $d\left(v, p_{i}\right)$. Pela minimalidade, existe um caminho $Q$ de $v$ a $p_{i}$ que não contém nenhum outro vértice de $P$. Agora $Q P\left[p_{i}, p_{r}\right]$ ou $Q P\left[p_{i}, p_{0}\right]$ tem comprimento pelo menos $\frac{1}{2} r$.

Apresentamos a ideia geral do algoritmo e depois detalhamos cada passo. Dado um grafo conexo $G$ com $n$ vértices e dado um vértice $v \in V$, para todo inteiro $k \leq n$, podemos construir uma árvore $T_{k}(G, v)$ com pesos nos vértices, que descreve uma decomposição recursiva do grafo $G$ em circuitos de comprimento pelo menos $k$ e em caminhos (explicado mais a diante).

Seja $L$ o comprimento de um caminho mais longo em $G$. O Lema 50 garante que $v$ é a extremidade de um caminho de comprimento pelo menos $\frac{L}{2}$. Para $k=\left\lceil\frac{1}{4} \log \frac{L}{2}\right\rceil$, podemos garantir (como veremos mais a diante) que um caminho de maior peso em $T_{k}(G, v)$ descreve um caminho em $G$ que 
tem o comprimento desejado. Como não temos o valor de $L$, repetimos o processo de encontrar a árvore $T_{k}(G, v)$ para $k=3, \ldots,\left\lceil\frac{1}{4} \log \frac{n}{2}\right\rceil$ e dentre os caminhos encontrados, devolvemos o de maior comprimento.

Resumidamente, o algoritmo procede da seguinte maneira.

1 Escolha um vértice qualquer $v \in G$

2 Para cada $k=3, \ldots,\left\lceil\frac{1}{4} \log \frac{n}{2}\right\rceil$

$3 \quad$ Construa $T_{k}(G, v)$

$4 \quad$ Encontre um caminho de maior peso em $T_{k}(G, v)$

$5 \quad$ Encontre o caminho correspondente em $G$

6 Devolva o maior caminho encontrado

Os passos 3, 4 e 5 levam tempo polinomial (conforme provamos mais a diante), logo o algoritmo inteiro leva tempo polinomial.

\section{Fase 1: Construindo a árvore de decomposição em circuitos}

Dado um vértice $v$ em $G$, o algoritmo constrói uma árvore com peso nos vértices $T_{k}(G, v)$, enraizada em $v$, chamada de árvore de decomposição em circuitos. Para construir essa árvore, precisamos encontrar circuitos longos no grafo G. O seguinte resultado de Gabow e Nie [40, Corolário 4.4] garante que isso é possível.

Teorema 51 Dado um grafo $G$ com $n$ vértices e $m$ arestas, um de seus vértices s e um inteiro $k$, é possivel encontrar em $G$ um $k^{+}$-circuito que passa por s (se existir) em tempo $\mathrm{O}(m)+2^{\mathrm{O}(k)} n \log n$.

Definimos agora a árvore $T_{k}=T_{k}(G, v)$. Um vértice de $T_{k}$, ou é um vértice-singular, ou é um vértice-circuito. Um vértice-singular corresponde a um único vértice $u \in G$, é denotado por $\langle u\rangle$ e tem peso unitário, enquanto um vértice-circuito corresponde a um circuito $C$ com um vértice especificado $u \in C$, é denotado por $\langle C, u\rangle$ e tem peso $\frac{1}{2}|C|$.

Inicialmente, $T_{k}$ contém o vértice-singular $\langle v\rangle$, e uma chamada é feita para o seguinte procedimento com parâmetros de entrada $G$ e $v$.

Algoritmo $T_{k}(G, v)$

1 para cada componente $G[W]$ de $G-v$

2 busque um $k^{+}$-circuito passando por $v$ em $G[W+v]$

3 se tal circuito $C$ for encontrado

$4 \quad$ então insira o vértice $\langle C, v\rangle$ e a aresta $\langle v\rangle\langle C, v\rangle$

para cada componente $H$ de $G[W-C]$

escolha um vizinho $u \in H$ de $C-v$

9 senão escolha um vizinho $u \in G[W+v]$ de $v$ 
Note que cada passo recursivo constrói uma árvore que está conectada a outra árvore por uma única aresta, $\operatorname{logo} T_{k}$ é de fato uma árvore. Dizemos que a raiz dessa árvore é $\langle v\rangle$. Observe também que o antecessor de um vértice-circuito é necessariamente um vértice-singular.

Para vermos que esse procedimento leva tempo polinomial, primeiramente note que a linha 2 é polinomial pelo Teorema 51. Além disso, o número de passos recursivos é linear, pois a cada passo um vértice é acrescentado a árvore $T_{k}$, que claramente tem tamanho linear após a conclusão do algoritmo.

\section{Fase 2: Caminhos na árvore de decomposição em circuitos}

O próximo passo do algoritmo é encontrar um caminho mais pesado em $T_{k}$. Isso pode ser feito em tempo linear, usando o algoritmo de Dijkstra apresentado na Seção 6.1. O caminho encontrado em $T_{k}$ representa um caminho em $G$, conforme explicamos a seguir.

Lema 52 Seja $G$ um grafo. Se $x$ é um vértice de $G$ e $Q$ é um caminho em $T_{k}(G, x)$ de peso $p$, então $Q$ representa um caminho $P$ em $G$ de comprimento pelo menos $p$.

Prova. Sejam $G$ e $Q$ conforme o enunciado do lemma. Construímos o caminho $P$ em $G$ interpretando subcaminhos de $Q$, a partir do início de $Q$. Para cada vértice-singular $\langle v\rangle$ de $Q$, acrescentamos o vértice $v$ a $P$.

Suponha que $Q$ contenha um vértice-circuito $\langle C, u\rangle$ no seu interior. Ambos os vizinhos desse vértice são vértices-singulares, então considere o subcaminho $\langle u\rangle\langle C, u\rangle\langle v\rangle$. Por construção, $v$ é vizinho de algum vértice $w \in C$ com $w \neq u$. Um dos dois caminhos de $u$ a $w$ em $C$ tem comprimento pelo menos metade do comprimento de $C$, chame-o de $C^{\prime}$. Interpretamos o caminho $\langle u\rangle\langle C, u\rangle\langle v\rangle$ como o caminho $u C^{\prime} v$ em $G$ e, portanto, acrescentamos o caminho $C^{\prime}$ a $P$.

Por outro lado, se $Q$ contém um vértice-circuito $\langle C, u\rangle$ em uma extremidade, podemos associá-lo ao caminho $C \backslash\{u w\}$, onde $w$ é um dos dois vizinhos de $u$ no circuito $C$. Nesse caso, acrescentamos $C \backslash\{u w\}$ a $P$. Esse caminho tem comprimento $|C|-1$.

Portanto, um caminho de peso $p$ em $T_{k}$, está associado a um caminho de comprimento pelo menos $p$ em $G$.

O próximo lema é central para garantir que a árvore de decomposição em circuitos tem um caminho pesado.

Lema 53 Seja $G$ um grafo conexo e v um vértice de $G$. Suponha que $G$ contenha um caminho que começa em $v$ de comprimento $\ell_{G}(v)>1$. Então existe uma componente $G[W]$ de $G-v$ tal que as seguintes afirmações valem.

1. Se $G[W+v]$ não contém um circuito que passa por $v$ de comprimento pelo menos $k$, então todo vizinho $u \in W$ de $v$ é a extremidade de um caminho de comprimento

$$
\ell_{G[W]}(u) \geq \ell_{G}(v)-k .
$$

2. Se $C$ é um circuito em $G[W+v]$ que passa por $v$ tal que $|C|<\ell_{G[W+v]}(v)$, então existe uma componente $H$ de $G[W-C]$ que tem um caminho de comprimento ao menos $\frac{\ell_{G}(v)}{|C|}-1$. Além 
disso, $H$ contém ao menos um vizinho u de $C-v$ em $G[W+v]$, e todo tal vizinho u é a extremidade de algum caminho em $H$ de comprimento

$$
\ell_{H}(u) \geq \frac{\ell_{G}(v)}{2|C|}-1
$$

Prova. Seja $r=\ell_{G}(v)$ e $P=p_{0} \cdots p_{r}$, onde $p_{0}=v$. Note que $P\left[p_{1}, p_{r}\right]$ está inteiramente em uma das componentes $G[W]$ de $G[V-v]$.

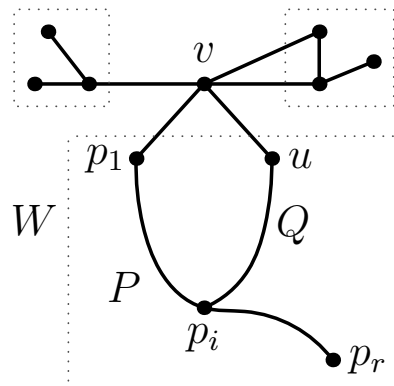

Figura 7.3: Afirmação 1 do Lema 53.

Primeiramente, provamos a primeira afirmação (veja Figura 7.3). Seja $u \in W$ um vizinho de $v$. Como $G[W]$ é conexo, existe um caminho $Q$ de $u$ para algum vértice de $P$. Considere tal caminho. O primeiro vértice $p_{i}$ de $P$ que aparece em $Q$ deve ser tal que $i<k$, pois senão os caminhos $v u, Q\left[u, p_{i}\right]$ e $P\left[p_{0}, p_{i}\right]$ formariam um circuito de comprimento maior ou igual a $k$. Logo, o caminho $Q\left[u, p_{i}\right] P\left[p_{i}, p_{r}\right]$ tem comprimento pelo menos $r-k+1>r-k$.

Agora prosseguimos para a segunda afirmação. Considere qualquer circuito $C$ em $G[W+v]$ que passa por $v$ tal que $|C|<\ell_{G[W+v]}(v)$.

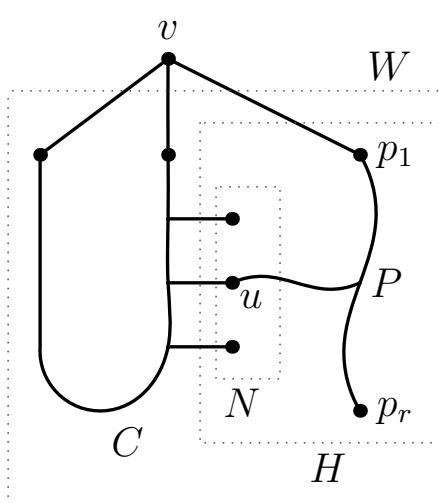

(a)

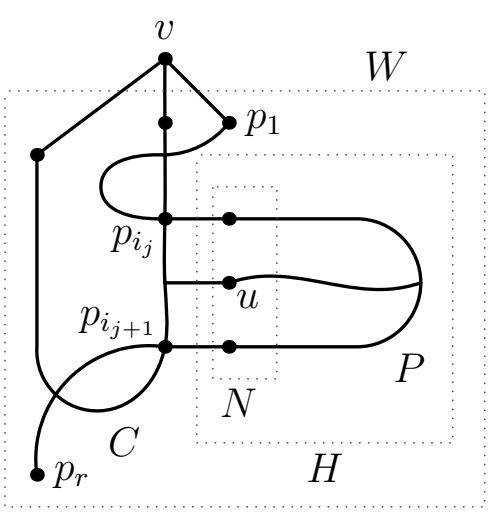

(b)

Figura 7.4: Afirmação 2 do Lema 53.

Caso 1. Suponha que $P \cap C=\{v\}$ (veja Figura 7.4(a)). Então uma das componentes $H$ de $G[W-C]$ contém todos os vértices de $P$, exceto $v$. Seja $N$ o conjunto de vizinhos de $C-v$ em $H$. Primeiro note que $N$ é não vazio, pois $G[W]$ é conexo. Além disso, existe um caminho em $H$ de comprimento $r-1$, a saber, $P-v$. Portanto, pelo Lema 50, todo $u \in N$ é a extremidade de um caminho em $H$ de comprimento pelo menos $(r-1) / 2$. 
Caso 2. Suponha, pelo contrário, que $|P \cap C|=s>1$ (veja Figura 7.4(b)). Sejam $i_{1}, \ldots, i_{s}$ os índices dos vértices de $P$ que pertencem a $P \cap C$ em ordem crescente. Seja $i_{s+1}=r$. Por um argumento de média e notando que os índices são inteiros, sabemos que existe $j$ tal que $i_{j+1}-i_{j} \geq\lceil r / s\rceil$. Portanto, existe uma componente $H$ de $G[W-C]$ que contém um caminho de comprimento ao menos $\lceil r / s\rceil-2$. Como esse caminho em $H$ tem pelo menos 1 vértice (pois, como $s \leq|C|<r$, vale que $\lceil r / s\rceil \geq 2)$ e como pelo menos um dos vértices $p_{i_{j}}$ ou $p_{i_{j+1}}$ pertence a $C-v$, então o conjunto $N$ de vizinhos de $C-v$ em $H$ é não vazio. Finalmente, o Lema 50 garante que todo $u \in N$ é a extremidade de um caminho em $H$ de comprimento pelo menos $r / 2 s-1$, o que implica o limitante se notamos que $s \leq|C|$.

Precisamos mostrar que um caminho mais pesado em $T_{k}$ tem peso ao menos $\mathrm{O}\left(\log ^{2} L / \log \log L\right)$. Para isso provamos o seguinte lema.

Lema 54 Se $G$ contém um caminho de comprimento $r>2^{8}$ que começa em $v$, então $T_{k}=T_{k}(G, v)$ para $k=\left\lceil\frac{1}{4} \log r\right\rceil$ contém um caminho de peso pelo menos $\frac{1}{12} k^{2} / \log \log r$.

Prova. Precisamos de alguma notação adicional. Definimos uma função $L: V\left(T_{k}\right) \rightarrow \mathbb{N}$. Dado um vértice $x=\langle w\rangle$ ou $x=\langle C, w\rangle$ em $T_{k}$, seja $T_{k}(x)$ a subárvore enraizada em $x$. Seja $X \subseteq V(G)$ o conjunto de vértices de $G$ correspondentes aos vértices de $T_{k}(x)$. Denotamos por $L(x)$ o comprimento de um caminho mais longo que começa em $w$ na componente $G[X]$.

Ademais, denote por $\mathbf{S}(x)$ os filhos do vértice $x \in T_{k}$ que são vértices-singulares e por $\mathbf{C}(x)$ os que são vértices-circuitos. Considere $\langle u\rangle$ um vértice-singular qualquer de $T_{k}$. O Lema 53 afirma que:

$$
L(\langle u\rangle) \leq \max \left\{f_{1}(u), f_{2}(u)\right\}
$$

onde $f_{1}(u)=\max _{w \in \mathbf{S}(\langle u\rangle)} L(w)+k$ e $f_{2}(u)=\max _{\substack{\langle C, u\rangle \in \mathbf{C}(\langle u\rangle) \\ w \in \mathbf{S}(\langle C, u\rangle)}}(2 L(w)+2)|C|$.

Seja $\left\langle x_{0}\right\rangle,\left\langle x_{1}\right\rangle, \ldots,\left\langle x_{t^{\prime}}\right\rangle$ onde $x_{0}=v$, uma sequência maximal de vértices de $T_{k}$ tal que $\left\langle x_{i+1}\right\rangle$ maximiza o lado direito da desigualdade (7.1) para $u=x_{i}$. Seja $Q$ o caminho em $T_{k}$ formado pelos vértices $\left\langle x_{0}\right\rangle,\left\langle x_{1}\right\rangle, \ldots,\left\langle x_{t^{\prime}}\right\rangle$ e possivelmente vértices-circuitos. Mais precisamente, $Q=b_{0} b_{1} \cdots b_{t}$ é um caminho de comprimento $t$ em $T_{k}$ tal que $b_{0}=\left\langle x_{0}\right\rangle$ e $b_{i}$, para $0<i \leq t$, é definido da seguinte maneira. Se $b_{i-1}$ é um vértice-singular, digamos $\left\langle x_{j}\right\rangle$, então se $\left\langle x_{j+1}\right\rangle$ maximiza a função $f_{1}\left(x_{j}\right)$, então $b_{i}=\left\langle x_{j+1}\right\rangle$; caso contrário, se $\left\langle x_{j+1}\right\rangle\left(\mathrm{e}\left\langle C, x_{j}\right\rangle\right)$ maximiza a função $f_{2}\left(x_{j}\right)$, então $b_{i}=\left\langle C, x_{j}\right\rangle$. Por outro lado, se $b_{i-1}$ é um vértice-circuito, digamos $\left\langle C, x_{j}\right\rangle$, então $b_{i}=\left\langle x_{j+1}\right\rangle$.

Provamos a seguir que o peso de $Q$ é pelo menos $\frac{1}{12} k^{2} / \log \log r$. Para isso, precisamos mostrar que a diferença entre $L\left(b_{i}\right)$ e $L\left(b_{i+1}\right)$ na sequência

$$
L\left(b_{0}\right) \geq L\left(b_{1}\right) \geq \cdots \geq L\left(b_{t}\right)
$$

não pode ser muito grande. De fato, como $L\left(b_{t}\right) \leq 1$ (explicamos o porquê mais a diante) e $L\left(b_{0}\right)=r$, se a diferença entre dois valores consecutivos $L\left(b_{i}\right)$ e $L\left(b_{i+1}\right)$ é pequena, então a sequência $b_{0}, b_{1}, \ldots, b_{t}$ deve ser longa.

Os valores escolhidos para os cálculos têm em vista simplicidade e não a otimalidade da análise. Como $k=\left\lceil\frac{1}{4} \log r\right\rceil$, frequentemente usamos desigualdades como $k^{3} \leq r$, para simplificar os cálculos.

Note que $b_{t}$ é um vértice-singular e $L\left(b_{t}\right) \leq 1$ (caso contrário, $b_{t}=\left\langle x_{t^{\prime}}\right\rangle$ não seria uma folha da árvore, pois poderíamos encontrar $\left\langle x_{t^{\prime}+1}\right\rangle$ que maximiza a desigualdade (7.1) para $u=x_{t^{\prime}}$. 
Seja $s=t-t^{\prime}$ o número de vértices-circuitos em $Q$. Como cada vértice-circuito tem peso ao menos $\frac{1}{2} k$, então o peso de $Q$ é pelo menos $\frac{1}{2} s k+t^{\prime}$. Seja $c_{i}$ o $i$-ésimo vértice-circuito de $Q, 1 \leq i \leq s$. Denote por $a\left(c_{i}\right)$ o vértice que antecede $c_{i}$ em $Q$ e por $s\left(c_{i}\right)$ o vértice que sucede $c_{i}$ em $Q$.

Suponha que $L\left(s\left(c_{s}\right)\right) \geq k^{3}$. Considere o subcaminho de $Q$ a partir de $s\left(c_{s}\right)$, digamos $Q^{*}$, e seja $t^{*}$ o seu comprimento. Note que $Q^{*}$ só tem vértices-singulares, pois $c_{s}$ é o último vértice-circuito de $Q$. Logo, pela primeira parte do Lema 53, para todo vértice $b_{i}$ de $Q^{*}$ vale que $L\left(b_{i}\right) \leq L\left(b_{i+1}\right)+k$. Considerando que $L\left(b_{t}\right) \leq 1$, temos que $k^{3} \leq L\left(s\left(c_{s}\right)\right) \leq k t^{*}$, e, portanto, $t^{*} \geq k^{2}$. Assim, $Q^{*}$ é um caminho em $T_{k}$ do peso desejado.

Daqui em diante, consideramos que $L\left(s\left(c_{s}\right)\right)<k^{3}$. Seja $j$ o maior índice tal que todos os vértices $b_{i}$, com $1 \leq i \leq j$, são vértices-singulares. Note que, pela primeira parte do Lema 53, esses vértices satisfazem a relação $L\left(b_{i}\right) \geq L\left(b_{i-1}\right)-k$. Logo, $L\left(b_{j}\right) \geq L\left(b_{0}\right)-j k=r-j k$.

Se $j=t$ (só existem vértices-singulares em $Q$ ), temos que $1 \geq L\left(b_{t}\right) \geq r-t k$, logo $t \geq \frac{r-1}{k} \geq k^{2}$, pois $r-1 \geq k^{3}$, e, portanto, $Q$ tem o peso desejado.

Caso contrário (ou seja $j<t$ ), podemos supor que $t \leq \frac{1}{12} k^{2}$, se não $Q$ já teria o peso desejado. Assim temos que $L\left(b_{j}\right) \geq r-j k>r-\frac{1}{12} k^{3} \geq \frac{11}{12} r>\frac{5}{6} r$, pois $k^{3} \leq r$.

Pela segunda parte do Lema 53 temos que

$$
L\left(b_{j+2}\right) \geq \frac{L\left(b_{j}\right)}{2|C|}-1 \geq \frac{\frac{5 r}{6}}{2 \frac{1}{6} k^{2}}-1=\frac{\frac{5 r}{2}-k^{2}}{k^{2}} \geq \frac{2 r}{k^{2}},
$$

considerando que $|C| \leq \frac{1}{6} k^{2}$ (pois se não, $b_{j+1}$ já seria um caminho de peso suficiente em $T_{k}$ ) e $r \geq k^{2}$.

Podemos repetir esse raciocínio para $c_{i}$ se $L\left(s\left(c_{i-1}\right)\right) \geq k^{3}$, conforme vemos a seguir. Indutivamente, mostramos que $L\left(s\left(c_{i}\right)\right) \geq \frac{2^{i} r}{k^{2 i}}$, se $L\left(s\left(c_{i-1}\right)\right) \geq k^{3}$.

Note que para $i=1\left(c_{i}=b_{j+1}\right)$, a desigualdade é válida. Dado $i>1$, suponha que a desigualdade valha para $i-1$. Observe que $L\left(a\left(c_{i}\right)\right) \geq L\left(s\left(c_{i-1}\right)\right)-p_{i} k$, onde $p_{i}$ é o número de vértices-singulares entre $c_{i-1}$ e $c_{i}$. Como vimos anteriormente, $p_{i} \leq \frac{k^{2}}{12}$ (se não já teríamos o peso desejado). Portanto, $L\left(a\left(c_{i}\right)\right) \geq L\left(s\left(c_{i-1}\right)\right)-\frac{k^{3}}{12} \geq \frac{2^{i-1} r}{k^{2(i-1)}}-\frac{k^{3}}{12}$.

Logo, temos que

$$
L\left(s\left(c_{i}\right)\right) \geq \frac{L\left(a\left(c_{i}\right)\right)}{2|C|}-1 \geq \frac{\frac{2^{i-1} r}{k^{2(i-1)}}-\frac{k^{3}}{12}}{2 \frac{1}{6} k^{2}}-1=\frac{2^{i} r+2^{i-1} r-\frac{k^{2 i+1}}{4}-k^{2 i}}{k^{2 i}} \geq \frac{2^{i} r}{k^{2 i}},
$$

onde a última desigualdade segue do fato de estarmos supondo que $L\left(s\left(c_{i-1}\right)\right) \geq k^{3}$, ou seja $\frac{2^{i-1} r}{k^{2(i-1)}} \geq k^{3}$, e, portanto, $2^{i-1} r \geq k^{2 i+1} \geq \frac{k^{2 i+1}}{4}+k^{2 i}$.

Seja $s^{\prime}$ o menor índice tal que $L\left(s\left(c_{s^{\prime}}\right)\right)<k^{3}$ (sabemos que existe tal índice, pois $L\left(s\left(c_{s}\right)\right)<k^{3}$ ), ou seja, $\frac{2^{s^{\prime}} r}{k^{2 s^{\prime}}}<k^{3}$. Aplicando a função logarítmica em ambos os lados dessa desigualdade, temos que $s^{\prime}+\log r-2 s^{\prime} \log k<3 \log k$, e, portanto,

$$
s^{\prime}>\frac{\log r-3 \log k}{2 \log k-1} \geq \frac{4 k-3 \log k}{2 \log k} \geq \frac{k}{\log k} \geq \frac{k}{\log \log r},
$$

considerando que $\frac{1}{4} \log r \leq k<\frac{1}{4} \log r-1$.

Como $s \geq s^{\prime}$, o peso de $Q$ é ao menos 


$$
\frac{1}{2} s k+t^{\prime} \geq \frac{k^{2}}{2 \log \log r}
$$

Concluímos que, para o valor correto de $k$, a saber $k=\left\lceil\frac{1}{4} \log r\right\rceil$, existe em $T_{k}$ um caminho de peso

$$
\frac{k^{2}}{12 \log \log r}=\Omega\left(\frac{\log ^{2} r}{\log \log r}\right)=\Omega\left(\frac{\log ^{2} L}{\log \log L}\right),
$$

pois $r \geq \frac{1}{2} L$, pelo Lema 50. O Teorema 49 segue do fato de que, pelo Lema 52, $Q$ representa um caminho em $G$ de comprimento pelo menos igual ao peso de $Q$.

Conforme mencionamos anteriormente, esse algoritmo não é o melhor algoritmo de aproximação conhecido hoje. O algoritmo de Gabow e Nie [41] encontra caminhos de comprimento $\exp \Omega(\sqrt{\log L})$ ), onde $L$ é o comprimento de um caminho mais longo no grafo. Para entender melhor a relação entre esses resultados, observe que, para garantir que o algoritmo de Björklund e Husfeldt devolva um caminho de comprimento $\Omega(k)$, é necessário que um caminho mais longo tenha ao menos $2^{\sqrt{k}}$ vértices (pois a garantia é de encontrar um caminho de comprimento $\log ^{2} L / \log \log L<\log ^{2} L$ ), enquanto que, para o algoritmo de Gabow e Nie, bastam $k^{\log k}=2^{\log ^{2} k}$ vértices em um caminho mais longo. 


\section{Capítulo 8}

\section{Resultados de inaproximabilidade}

Como vimos no Capítulo 7, para o problema do caminho mais longo, a melhor razão de aproximação que se conhece hoje é bastante fraca. É natural perguntar se é possível melhorar esse resultado ou se uma razão melhor implicaria que $\mathbf{P}=\mathbf{N P}$. Na realidade, para esse problema falta ainda compreender melhor aspectos da sua inaproximabilidade [38]. Sabemos que o problema não pode ser aproximado por uma razão constante em tempo polinomial a menos que $\mathbf{P}=\mathbf{N P}$, nem por uma razão $2^{\mathrm{O}\left(\log ^{1-\epsilon} n\right)}$ para qualquer constante $\epsilon>0$ a menos que NP $\in \operatorname{DTIME}\left(2^{\log ^{1 / \epsilon} n}\right)$ [66]. Ambos os resultados valem também para o caso especial de grafos hamiltonianos cúbicos [12].

Entretanto, os resultados de aproximação conhecidos estão bem distantes dos resultados de inaproximabilidade. Com isso, fica em aberto se o problema é de fato tão difícil como aparenta ser, e, portanto, seria possível provar resultados mais fortes de inaproximabilidade, ou se existiriam algoritmos de aproximação muito melhores do que os que conhecemos hoje. Nessa linha, apresentamos uma conjectura de Karger, Motwani e Ramkumar [66], que afirma que esse problema é tão difícil de aproximar quanto outros problemas conhecidamente difíceis, como o problema de determinar um clique máximo [52] ou o número cromático [106] de um grafo.

\subsection{Fator constante}

Nesta seção, apresentamos o resultado de Karger e outros [66] de que, se existir um algoritmo de aproximação com razão constante para o problema do caminho mais longo, então $\mathbf{P}=\mathbf{N P}$. Reproduzimos a prova deste autores com pequenas alterações para facilitar a compreensão e detalhando alguns passos que nos pareceram mais relevantes.

Primeiramente mostramos que, se o problema do caminho mais longo puder ser aproximado com alguma razão constante $k$ em tempo polinomial, então pode ser aproximado com qualquer razão constante $k^{\prime}$ em tempo polinomial. Definimos um novo conceito de potência de grafos que será essencial para essa demonstração.

Definição 55 Seja $G=(V, E)$ um grafo. $O$ quadrado-aresta de $G$, denotado por $G^{2}$, é obtido da seguinte forma. Substituímos cada aresta $e=u v \in E$ em $G$ por uma cópia de $G$, digamos $G_{e}$, e conectamos u e $v$ a todos os vértices de $G_{e}$. Os vértices u e v são chamados de vértices de contato de $G_{e}$.

Se o grafo $G$ tem $n$ vértices, então $G^{2}$ tem no máximo $n^{3}$ vértices. Observe que o quadrado-aresta de um grafo hamiltoniano não é necessariamente hamiltoniano. Por essa razão, a seguinte prova 
só se aplica para o problema de aproximar um caminho mais longo em grafos quaisquer, e não ao problema, talvez mais fácil, de aproximar um caminho mais longo em grafos que são sabidamente hamiltonianos. O lema a seguir relaciona o comprimento de um caminho mais longo em $G$ e em $G^{2}$.

Lema 56 Seja $G$ um grafo. Se $L$ é o comprimento de um caminho mais longo em $G$, então o comprimento de um caminho mais longo em $G^{2}$ é ao menos $L^{2}$.

Prova. Seja $P$ um caminho mais longo em $G$ e sejam $s$ e $t$ os vértices das extremidades de $P$. Vamos exibir em $G^{2}$ um caminho $P^{\prime}$ de comprimento $L^{2}$. O caminho $P^{\prime}$ começa em $s$, passa pelos grafos $G_{e}$ na mesma ordem que $P$ passa pelas arestas $e$ e termina em $t$. Além disso, em cada $G_{e}$ pelo qual $P^{\prime}$ passa, $P^{\prime}$ percorre exatamente o mesmo caminho que $P$. Logo, é fácil ver que $P^{\prime}$ tem comprimento $L(L+2)$.

Lema 57 Seja $G$ um grafo. Dado um caminho em $G^{2}$ de comprimento $L^{\prime}$, podemos obter em tempo polinomial um caminho de comprimento $\sqrt{L^{\prime}}-2 \mathrm{em} G$.

Prova. Seja $P^{\prime}$ um caminho de comprimento $L^{\prime}$ em $G^{2}$. O caminho $P^{\prime}$ pode entrar e sair de uma cópia $G_{e}$ de $G$ apenas através dos vértices de contato de $G_{e}$. Portanto, podemos supor que $P^{\prime}$ começa visitando vértices de alguma cópia, digamos $G_{e^{*}}$, e depois visita uma sequência de cópias $G_{e}$ distintas, a menos da última cópia que possivelmente é igual a primeira. A sequência de vértices visitados em uma cópia $G_{e}$ forma um caminho em $G$, a menos dos vértices visitados de $G_{e^{*}}$, que possivelmente formam dois caminhos.

Seja $s$ o maior número de vértices percorridos por $P^{\prime}$ consecutivamente dentro de alguma cópia $G_{e}$ e $r$ o número de vértices de contato que o caminho $P^{\prime}$ visita. Note que $P^{\prime}$ pode ser particionado em vértices de contato e no máximo $r+1$ caminhos com no máximo $s$ vértices. Logo, $P^{\prime}$ tem no máximo $r+(r+1) s$ vértices. Afirmamos que $s \geq \sqrt{L^{\prime}}-1$ ou $r \geq \sqrt{L^{\prime}}$. Se supormos que ambas as afirmações acima são violadas, ou seja $s<\sqrt{L^{\prime}}-1$ e $r<\sqrt{L^{\prime}}-1$, concluímos que

$$
L^{\prime}+1 \leq r+(r+1) s<\left(\sqrt{L^{\prime}}-1\right)+\sqrt{L^{\prime}}\left(\sqrt{L^{\prime}}-1\right)=L^{\prime}-1 .
$$

Uma contradição.

Usando estes lemas, podemos obter o seguinte resultado.

Teorema 58 Se existir um algoritmo de aproximação com razão constante para o problema do caminho mais longo, então este problema possui um PTAS.

Prova. Seja $A_{k}$ um algoritmo de aproximação com razão $k$, ou seja, $A_{k}$ encontra um caminho de comprimento pelo menos $L / k$ em um grafo cujos caminhos mais longos têm comprimento $L$. Vamos mostrar que, para qualquer $\epsilon>0$ fixo, existe um algoritmo de aproximação com razão $1 /(1+\epsilon)$. Note que isso implica que existe, para qualquer $\epsilon^{\prime}>0$ fixo, um algoritmo de aproximação com razão $\left(1-\epsilon^{\prime}\right)$. De fato, basta definir $\epsilon=1 /\left(1-\epsilon^{\prime}\right)-1$.

Seja

$$
p=\left\lceil\log \frac{2 \log k}{\log (1+\epsilon)}\right\rceil
$$


Dado um grafo $G$ com um caminho mais longo de comprimento $L$, se executamos o algoritmo $A_{k}$ no grafo $G^{2^{p}}$ obtido elevando $G$ ao quadrado $p$ vezes, então, pelo Lema 56, encontramos um caminho de comprimento pelo menos $L^{2^{p}} / k$ em $G^{2^{p}}$. Usando o Lema 57, mostramos a seguir, por indução em $p$, que podemos encontrar em $G$ um caminho de comprimento pelo menos

$$
\left(\frac{L^{2^{p}}}{k}\right)^{2^{-p}}-2 p
$$

De fato, para $p=1$, o resultado segue direto do Lema 57. Para $p>1$, pela hipótese de indução, podemos encontrar um caminho de comprimento $\left(\frac{L^{2^{p}}}{k}\right)^{2^{-(p-1)}}-2(p-1)$ no grafo $G^{2}$. Pelo Lema 57 , e considerando que $1<p \leq \sqrt{L}$ e $k \leq L$, podemos encontrar em $G$ um caminho de comprimento

$$
\left(\left(\frac{L^{2^{p}}}{k}\right)^{2^{-(p-1)}}-2(p-1)\right)^{2^{-1}}-2 \geq\left(\frac{L^{2^{p}}}{k}\right)^{2^{-p}}-2 p .
$$

Finalmente, observe que

$$
\left(\frac{L^{2^{p}}}{k}\right)^{2^{-p}}-2 p \geq \frac{L}{\sqrt{1+\epsilon}}-p \geq \frac{L}{1+\epsilon} .
$$

De fato, a primeira desigualdade segue da definição de $p$ e a segunda vale desde que $L \geq p(1+\epsilon) / \epsilon$. Observe que para valores pequenos de $L\left(L<p^{2}\right.$ ou $\left.L<p(1+\epsilon) / \epsilon\right)$, é possível calcular a solução ótima usando um algoritmo de força bruta.

Além disso, o tempo de execução do algoritmo é polinomial para $\epsilon$ fixo, pois o grafo $G^{2^{p}}$ tem no máximo $n^{3^{p}}$ vértices.

Mostramos a seguir que não existe um PTAS para o problema do caminho mais longo a menos que $\mathbf{P}=\mathbf{N P}$. A demonstração original de Karger e outros [66] continha um erro: consideram que, para $\epsilon>0$ fixo, um PTAS para o problema do caminho mais longo encontraria um caminho de comprimento $(1-\epsilon) n$, quando na realidade seria de $(1-\epsilon)(n-1)$. Utilizando o mesmo resultado de Arora, Lund, Motwani, Sudan e Szegedy [7] que serviu de base para a demonstração original, produzimos uma prova correta do teorema.

Teorema 59 Não existe PTAS para o problema do caminho mais longo a menos que $\mathbf{P}=\mathbf{N P}$.

Prova. Provamos a seguir um resultado um pouco mais forte do que o enunciado. Mostramos que esse teorema vale mesmo no caso restrito em que as instâncias contêm um circuito hamiltoniano.

Seja TSP $(1,2)$ o problema de encontrar uma solução ótima para o problema do caixeiro viajante (traveling salesman problem) em um grafo completo com $n$ vértices, onde todas as arestas têm peso 1 ou 2. Papadimitriou e Yannakakis [74] mostraram que este problema restrito é MAX SNPdifícil. A redução é a partir de uma versão do MAX 3SAT que também é MAX SNP-difícil. A seguinte afirmação pode ser obtida como consequência desse resultado. Se para todo $\delta>0$ existe um algoritmo polinomial que, para qualquer instância do $\operatorname{TSP}(1,2)$ de valor ótimo $n$ (ou seja, contendo um circuito hamiltoniano formado apenas por arestas de peso 1), devolve um circuito de peso no máximo $(1+\delta) n$, então MAX 3SAT tem um PTAS (o que implica que $\mathbf{P}=\mathbf{N P}$, como demonstrou Arora e outros [7]).

Suponha agora que exista um PTAS para o problema do caminho mais longo em grafos que contêm um circuito hamiltoniano. Isso implica que podemos achar, em tempo polinomial, caminhos 
de comprimento pelo menos $(1-\epsilon)(n-1)$ em grafos hamiltonianos, para qualquer $\epsilon>0$ fixo. Queremos mostrar que isso implica que existe um PTAS para as instâncias do $\operatorname{TSP}(1,2)$ que possuem valor ótimo $n$, ou seja, que para qualquer $\delta>0$ fixo existe um algoritmo polinomial que, para qualquer instância do $\operatorname{TSP}(1,2)$ de valor ótimo $n$, devolve um circuito de peso no máximo $(1+\delta) n$.

Seja $G$ uma instância do $\operatorname{TSP}(1,2)$ com valor ótimo $n$ e seja $\delta>0$ fixo. Seja $H$ o subgrafo de $G$ formado apenas pelas arestas de peso 1 . Note que $H$ é hamiltoniano. Definimos $\epsilon=\frac{\delta}{2}$. Vamos distinguir dois casos.

Caso 1: $\delta \geq \frac{1}{n}$.

Usando o PTAS para o problema do caminho mais longo, podemos encontrar em $H$ um caminho de comprimento no mínimo $\left(1-\frac{\delta}{2}\right)(n-1)=n-1-\frac{\delta}{2}(n-1)$. Um tal caminho pode ser estendido a um circuito hamiltoniano em $G$, digamos $C$, acrescentando-se no máximo $1+\frac{\delta}{2}(n-1)$ arestas de peso no máximo 2. Assim, $C$ tem peso no máximo $c=n-1-\frac{\delta}{2}(n-1)+2\left(1+\frac{\delta}{2}(n-1)\right)=n+1+\frac{\delta}{2}(n-1)$.

Se $\delta \geq \frac{2}{n+1}$, temos $c=n+1+\delta n-\frac{\delta}{2}(n+1) \leq n+1+\delta n-\frac{2 /(n+1)}{2}(n+1)=(1+\delta) n$.

Se $\delta<\frac{2}{n+1}$, temos que $c=n+1+\frac{\delta}{2}(n-1)<n+1+\frac{n-1}{n+1}<n+2$. Como o peso do circuito é um número inteiro, concluímos que é no máximo $n+1 \mathrm{e}$, para $\delta \geq \frac{1}{n}, n+1 \leq(1+\delta) n$.

Caso 2: $\delta<\frac{1}{n}$.

Nesse caso, para cada aresta $e=u v$ do grafo $H$, definimos um novo grafo $H_{e}$, com $V\left(H_{e}\right)=$ $V(H) \cup\left\{u^{\prime}, v^{\prime}\right\}$ e $E\left(H_{e}\right)=\left\{u u^{\prime}, v v^{\prime}\right\} \cup E(H) \backslash\{u v\}$. Note que, para qualquer aresta $e$ que pertence a um circuito hamiltoniano de $H$, o grafo $H_{e}$ possui um caminho hamiltoniano. Para uma tal aresta $e$, usando o PTAS para o problema do caminho mais longo, podemos encontrar em $H_{e}$ um caminho, digamos $P$, de comprimento no mínimo $\left(1-\frac{\delta}{2}\right)(n+1)>\left(1-\frac{1}{2 n}\right)(n+1)=n+\frac{1}{2}-\frac{1}{2 n}>n$. Como o comprimento de $P$ é um número inteiro, concluímos que é no mínimo $n+1$, ou seja, $P$ é um caminho hamiltoniano em $H_{e}$ cujas extremidades são $u^{\prime}$ e $v^{\prime}$. Considere em $H$ o circuito hamiltoniano obtido a partir de $P$ removendo-se as suas extremidades $u^{\prime}$ e $v^{\prime}$, e acrescentando-se a aresta $e$. Assim, se $e$ é uma aresta que pertence a um circuito hamiltoniano de $H$, sabemos que existe em $G$ um circuito hamiltoniano de peso $n$ e $n \leq(1+\delta) n$, para $\delta>0$.

Como não sabemos quais arestas pertencem a algum circuito hamiltoniano de $H$, podemos utilizar o algoritmo PTAS para o problema do caminho mais longo para cada grafo $H_{e}, e \in E(H)$, até que obtenhamos um caminho de comprimento $n+1$. Isto implica que usando-se o algoritmo PTAS para o problema do caminho mais longo no máximo $|E(H)| \leq n^{2}$ vezes, podemos encontrar um circuito hamiltoniano em $G$ de peso $n$. O tempo gasto nesse processo permanece polinomial em $n$ (para $\epsilon$ fixo).

Concluímos que um PTAS para o problema do caminho mais longo pode ser transformado em um PTAS para as instâncias do TSP $(1,2)$ que possuem valor ótimo $n$.

O seguinte corolário segue dos Teoremas 58 e 59.

Corolário 60 Se existir um algoritmo de aproximação com razão constante para o problema do caminho mais longo, então $\mathbf{P}=\mathbf{N P}$.

\subsection{Conjectura sobre a dificuldade de aproximação}

Karger e outros [66] também conjecturam que o problema do caminho mais longo é tão difícil de aproximar quanto outros problemas que são conhecidamente difíceis, como o problema do clique 
máximo [52] e o de determinar o número cromático de um grafo [106].

Conjectura 61 Para alguma contante $\delta>0$, se existir um algoritmo de aproximação para o problema do caminho mais longo com razão $n^{-\delta}$, onde $n$ é a ordem do grafo, então $\mathbf{P}=\mathbf{N P}$.

Como evidência de que essa conjectura deve valer, os mesmos autores também provam outros resultados que enunciamos a seguir.

Teorema 62 Se existir um algoritmo de aproximação para o problema do caminho mais longo com razão $2^{-\mathrm{O}\left(\log ^{1-\epsilon} n\right)}$, onde $n$ é a ordem do grafo, então $\mathbf{N P} \subseteq \mathbf{D T I M E}\left(2^{\mathrm{O}\left(\log ^{1 / \epsilon} n\right)}\right)$. Esse resultado também vale para o caso especial onde o grafo tem grau limitado.

Teorema 63 Para qualquer $\delta>0$, se existir um algoritmo de aproximação para o problema do caminho mais longo com razão $2^{-\mathrm{O}\left(\frac{\log n}{\log \log n}\right)}$, onde $n$ é a ordem do grafo, então $\mathbf{N P} \subseteq \mathbf{D T I M E}\left(2^{\mathrm{O}\left(n^{\delta}\right)}\right)$. 


\section{Capítulo 9}

\section{Considerações Finais}

Como mencionado ao longo do trabalho, existem muitas questões que poderiam ser investigadas em trabalhos futuros. Reunimos aqui alguns dos problemas em aberto mencionados ao longo da dissertação e outros de especial interesse. Ao final desse capítulo, apresentamos os trabalhos publicados que resultaram desse estudo.

\subsection{Problemas correlatos em aberto}

É realmente muito intrigante o fato de existirem tantos problemas elementares que ainda não foram resolvidos. Embora tenhamos mencionado apenas de passagem o problema da intersecção de circuitos mais longos, o problema é tão difícil quanto o de caminhos mais longos e a maior parte das perguntas citadas a seguir podem ser feitas trocando "caminhos" por "circuitos" e exigindo que o grafo seja 2-conexo. Alguns dos problemas que citamos aqui foram levantados por Zamfirescu [100, 104] e Voss [93].

Um primeira questão natural, é determinar para que classes de grafos a pergunta de Gallai tem resposta positiva. Vimos anteriormente que foi provado que todos os caminhos mais longos de grafos divididos [68] e de grafos de intervalos [10] necessariamente têm um vértice em comum. Nós também provamos que o mesmo vale para grafos exoplanares e 2-árvores. Observamos que grafos divididos, grafos de intervalos e 2-árvores são subclasses de grafos cordais para os quais o problema continua em aberto.

Pergunta 64 Todos os caminhos mais longos de um grafo cordal têm um vértice em comum?

Outra subclasse dos grafos cordais são as $k$-árvores. Também seria interessante investigar se a Pergunta 65 tem resposta positiva, para $k \geq 3$.

Pergunta 65 Todos os caminhos mais longos de uma k-árvore têm um vértice em comum?

Vale notar que 2-árvore são grafos série-paralelos maximais. Assim, é natural investigar a questão para grafos série-paralelos. Conforme mencionamos, Ehremüller e outros [34] obtiveram um novo resultado nessa linha, ainda não publicado em periódico. Esse resultado generaliza os resultados para grafos exoplanares e 2-árvores.

Mencionamos anteriormente que existem exemplos que mostram que para grafos 2-conexos e 3-conexos nem sempre todos os caminhos mais longos têm um vértice em comum. Porém, para grafos 4-conexos, o problema está em aberto. 
Pergunta 66 Todos os caminhos mais longos de um grafo 4-conexo têm um vértice em comum?

Como mencionamos anteriormente sabe-se apenas que isso é verdade quando se trata de grafos 4conexos planares (já que, pelo Teorema de Tutte [87], tais grafos são hamiltonianos). Podemos também fazer a seguinte pergunta, mais geral:

Pergunta 67 Existe um inteiro $k$ tal que todo grafo $k$-conexo possui um vértice comum a todos os seus caminhos mais longos? Se existe, qual é o menor $k$ que satisfaz essa propriedade?

Outra variante do problema explorada por Walther [96] e por Zamfirescu [100], é a seguinte:

Pergunta 68 Existe um inteiro $j$ tal que, para todo grafo conexo $G$, algum conjunto de $j$ vértices de $G$ tem interseç̧ão não vazia com qualquer caminho mais longo? Se existe, qual o menor $j$ que satisfaz essa propriedade?

O fato da pergunta de Gallai ter resposta negativa, exclui o caso $j=1$. O caso $j=2$ também está excluído [48], mas de resto o problema continua em aberto. Em particular não se sabe a resposta para a seguinte pergunta:

Pergunta 69 Para qualquer grafo conexo, existe um conjunto de três vértices que intersecta todo caminho mais longo do grafo?

Aludimos anteriormente ao fato de que 2 caminhos mais longos sempre têm um vértice em comum, e que o mesmo não vale para 7 caminhos mais longos. Portanto, as seguintes perguntas continuam sem respostas.

Pergunta 70 Quaisquer três caminhos mais longos sempre têm um vértice em comum?

Pergunta 71 Existe um grafo no qual seis caminhos mais longos não têm um vértice em comum?

Pergunta 72 Qual é o menor inteiro $p$ tal que quaisquer $p$ caminhos mais longos sempre têm um vértice em comum? (Sabemos que $2 \leq p \leq 6$.)

Outra abordagem, sugerida por Jimenez [61], para o problema da intersecção de caminhos mais longos seria uma combinação da variante que considera um conjunto de $j$ vértices e da que considera a intersecção de um número fixo de caminhos mais longos.

Pergunta 73 Para todo grafo conexo $G$ e um inteiro $p$, qual o menor inteiro $j$ tal que algum conjunto de $j$ vértices intersecta cada caminho de qualquer conjunto com p caminhos mais longos?

Como quaisquer 2 caminhos mais longos se intersectam, obviamente $j \leq p / 2$. Em particular, parece interessante investigar se é verdade que para quaisquer 5 caminhos mais longos existe um conjunto de 2 vértices que intersecta cada um dos 5 caminhos.

Também vimos que o número de vértices na intersecção de dois caminhos mais longos depende da conexidade do grafo. A seguinte pergunta está em aberto:

Pergunta 74 Em um grafo $k$-conexo, quaisquer dois caminhos mais longos têm ao menos $k$ vértices em comum?

Vimos que a resposta para a Pergunta 74 é afirmativa para $k \leq 7$. Hippchen [54] conjecturou que a resposta é afirmativa para qualquer $k$. 


\subsection{Trabalhos publicados}

Esse trabalho se divide em duas partes: a primeira trata de problemas estruturais relativos à intersecção de caminhos mais longos; e a segunda trata do problema de encontrar um caminho mais longo.

A primeira parte desse trabalho teve início em 2010, quando ainda estava cursando o bacharelado, e começamos a estudar o problema da intersecção de caminhos mais longos. Obtivemos um primeiro resultado que, juntamente com o estudo prévio, deu origem a uma monografia que foi premiada com medalha de ouro no V Simpósio Nacional / Jornadas de Iniciação Científica organizado pelo IMPA. Em seguida, Profa. Cristina Fernandes, Prof. Daniel Martin, Profa. Yoshiko Wakabayashi e eu continuamos trabalhando no problema e obtivemos um novo resultado. Apresentamos o trabalho realizado até então na Sexta Conferência de Combinatória, Teoria dos Grafos e Aplicações (EuroComb 2011), e um resumo estendido foi publicado na revista da conferência [31].

Durante meu mestrado, continuamos investigando o problema e pudemos obter um outro resultado que, juntamente com os anteriores, foram publicados na revista Discrete Mathematics [32]. Além disso, realizamos uma ampla pesquisa bibliográfica e estudamos com profundidade resultados relacionados já existentes. Procuramos apresentar aqui, de forma clara e didática, todos os que nos pareceram mais relevantes.

A segunda parte desse trabalho consistiu principalmente em estudar a fundo resultados da literatura relativos a busca de caminhos mais longos. Procuramos apresentá-los nessa dissertação em mais detalhe, o que exigiu, em alguns momentos, que se desenvolvessem trechos de provas que não estavam explicados ou que continham erros. 


\section{Referências Bibliográficas}

[1] N. Alon, P. Dao, I. Hajirasouliha, F. Hormozdiari, and S. C. Sahinalp. Biomolecular network motif counting and discovery by color coding. Bioinformatics, 24(13):i241-i249, 2008. 61

[2] N. Alon, R. Yuster, and U. Zwick. Color-coding. J. ACM, 42(4):844-856, 1995. 5, 61

[3] M. I. Andreica, K. Manev, M. Markov, and N. Ţăpuş. A linear time algorithm for computing longest paths in cactus graphs. Serdica J. Comput., 6(3):287-298, 2012. 5, 53

[4] M. Araya and G. Wiener. On cubic planar hypohamiltonian and hypotraceable graphs. Electron. J. Combin., 18(1):\#P85, 2011. 39, 42

[5] M. Araya and G. Wiener. On planar hypohamiltonian graphs. J. Graph Theory, 67(1):55-68, 2011. 41

[6] S. R. Arikati and C. P. Rangan. Linear algorithm for optimal path cover problem on interval graphs. Inform. Process. Lett., 35(3):149-153, 1990. 46, 48, 53

[7] S. Arora, C. Lund, R. Motwani, M. Sudan, and M. Szegedy. Proof verification and the hardness of approximation problems. J. ACM, 45(3):501-555, 1998. 71

[8] K. Asdre and S. D. Nikolopoulos. The 1-fixed-endpoint path cover problem is polynomial on interval graphs. Algorithmica, 58(3):679-710, 2010. 46

[9] M. Axenovich. When do three longest paths have a common vertex? Discrete Math. Algorithms Appl., 1:115-120, 2009. 5, 20, 27, 28

[10] P. N. Balister, E. Gyôri, J. Lehel, and R. H. Schelp. Longest paths in circular arc graphs. Combin. Probab. Comput., 13(3):311-317, 2004. 4, 15, 17, 18, 75

[11] Y. Bashir and T. Zamfirescu. Lattice graphs with Gallai's property. Bull. Math. Soc. Sci. Math. Roumanie, 56(1):65-71, 2013. 15

[12] C. Bazgan, M. Santha, and Z. Tuza. On the approximation of finding a(nother) Hamiltonian cycle in cubic Hamiltonian graphs. Lecture Notes in Comput. Sci., 1373:276-286, 1998. 69

[13] I. Bezáková and G. B. Mertzios. Computing and counting longest paths on circular-arc graphs in polynomial time. Electron. Notes Discrete Math., 37:219-224, 2011. 5, 53

[14] A. Björklund and T. Husfeldt. Finding a path of superlogarithmic length. SIAM J. Comput., 32(6):1395-1402 (electronic), 2003. 5

[15] H. L. Bodlaender. On linear time minor tests with depth-first search. J. Algorithms, 14(1):123, 1993. 5, 53

[16] H. L. Bodlaender. A linear-time algorithm for finding tree-decompositions of small treewidth. SIAM J. Comput., 25(6):1305-1317, 1996. 5, 53

[17] J. A. Bondy and U. S. R. Murty. Graph theory, volume 244 of Grad. Texts in Math. Springer, New York, 2008. 7 
[18] A. Brandstädt, V. B. Le, and J. P. Spinrad. Graph Classes: A Survey. Society for Industrial and Applied Mathematics, Philadelphia, PA, USA, 1999. 9

[19] R. W. Bulterman, W. H. J. Feijen, F. W. van der Sommen, A. J. M. van Gasteren, T. Verhoeff, and G. Zwaan. On computing a longest path in a tree. Inform. Process. Lett., 81(2):93-96, 2002. $5,46,47$

[20] S. A Burr and T. Zamfirescu. Unpublished manuscript. 33

[21] P. Cameron (Ed.). Research problems. Discrete Math., 167/168:605-615, 1997. Problem 276, from the Fifteenth British Combinatorial Conference. 27

[22] M.-S. Chang, S.-L. Peng, and J.-L. Liaw. Deferred-query - an efficient approach for problems on interval and circular-arc graphs. In Algorithms and Data Structures, volume 709 of Lecture Notes in Comput. Sci., pages 222-233. 1993. 46

[23] R.-Y. Chang, C.-H. Hsu, and S.-L. Peng. The longest path problem on permutation graphs. In The 29th Workshop on Combinatorial Mathematics and Computation Theory, pages 294-297, 2012. 5,53

[24] G. Chen, R. J. Faudree, and R. J. Gould. Intersections of longest cycles in k-connected graphs. J. Combin. Theory Ser. B, 72(1):143 - 149, 1998. 33

[25] G. Chen, J. Xu, and X. Yu. Circumference of graphs with bounded degree. SIAM J. Comput., 33(5):1136-1170, 2004. 5

[26] V. Chvátal and P. Erdös. A note on Hamilton circuits. Discrete Math., 2:111-113, 1972. 37

[27] D. G. Corneil and G. B. Mertzios. A simple polynomial algorithm for the longest path problem on cocomparability graphs. SIAM J. Discrete Math., 26(3):940-963, 2012. 5, 53

[28] P. Damaschke. The Hamiltonian circuit problem for circle graphs is NP-complete. Inform. Process. Lett., 32(1):1 - 2, 1989. 5, 53

[29] P. Damaschke. Paths in interval graphs and circular arc graphs. Discrete Math., 112(1-3):49 - 64, 1993. 46

[30] P. Damaschke, J. S. Deogun, D. Kratsch, and G. Steiner. Finding Hamiltonian paths in cocomparability graphs using the bump number algorithm. Order, 8(4):383-391, 1992. 46

[31] S. F. de Rezende, C. G. Fernandes, D. M. Martin, and Y. Wakabayashi. Intersection of longest paths in a graph. Electron. Notes Discrete Math., 38(0):743 - 748, 2011. The Sixth European Conference on Combinatorics, Graph Theory and Applications, EuroComb 2011. 77

[32] S. F. de Rezende, C. G. Fernandes, D. M. Martin, and Y. Wakabayashi. Intersecting longest paths. Discrete Math., 313(12):1401 - 1408, 2013. 4, 15, 20, 22, 28, 34, 77

[33] G. A. Dirac. Some theorems on abstract graphs. Proc. Lond. Math. Soc. (3), 2(1):69-81, 1952. 36

[34] J. Ehrenmüller, C. G. Fernandes, and C. G. Heise. Nonempty intersection of longest paths in series-parallel graphs. arXiv:1310.1376, submitted, 2013. 4, 15, 75

[35] P. Erdős and G. Katona, editors. Theory of Graphs. Proceedings of the Colloquium held at Tihany, Hungary, September 1966. Academic Press, New York, 1968. Problem 4 (T. Gallai), p. $362.1,15$

[36] P. Erdős and G. Katona, editors. Theory of Graphs. Proceedings of the Colloquium held at Tihany, Hungary, September 1966. Academic Press, New York, 1968. Problem 50 (H. Sachs), p. 368.38 
[37] T. Feder and R. Motwani. Finding large cycles in Hamiltonian graphs. Discrete Appl. Math., 158(8):882-893, 2010. 5

[38] T. Feder, R. Motwani, and C. Subi. Approximating the longest cycle problem in sparse graphs. SIAM J. Comput., 31(5):1596-1607, 2002. 5, 69

[39] H. N. Gabow. Finding paths and cycles of superpolylogarithmic length. SIAM J. Comput., 36(6):1648-1671, 2007. Also appeared in Proceedings of the Thirty-sixth Annual ACM Symposium on Theory of Computing, STOC '04, pages 407-416, 2004. 5

[40] H. N. Gabow and S. Nie. Finding a long directed cycle. ACM Trans. Algorithms, 4(1):7:17:21, 2008. Also appeared in Proceedings of the Fifteenth Annual ACM-SIAM Symposium on Discrete Algorithms, SODA '04, pages 49-58, 2004. 63

[41] H. N. Gabow and S. Nie. Finding long paths, cycles and circuits. In Algorithms and Computation, volume 5369 of Lecture Notes in Comput. Sci., pages 752-763. 2008. 6, 55, 68

[42] M. R. Garey and D. S. Johnson. Computers and intractability. W. H. Freeman and Co., San Francisco, Calif., 1979. A guide to the theory of NP-completeness, A Series of Books in the Mathematical Sciences. 5, 10, 46, 53

[43] M. R. Garey, D. S. Johnson, and R. E. Tarjan. The planar Hamiltonian circuit problem is NP-complete. SIAM J. Comput., 5(4):704-714, 1976. 5, 53

[44] E. Ghosh, N. S. Narayanaswamy, and C. P. Rangan. A polynomial time algorithm for longest paths in biconvex graphs. In Proceedings of the 5th international conference on WALCOM: algorithms and computation, WALCOM'11, pages 191-201, Berlin, Heidelberg, 2011. 5, 53

[45] M. C. Golumbic. Algorithmic Graph Theory and Perfect Graphs, volume 57 of Ann. Discrete Math. North-Holland Publishing Co., Amsterdam, The Netherlands, 2004. 5, 53

[46] M. Grötschel. On Intersections of Longest Cycles. In Graph Theory and Combinatorics, pages 171-189. Academic Press, 1984. 33, 35

[47] M. Grötschel and G. L. Nemhauser. A polynomial algorithm for the max-cut problem on graphs without long odd cycles. Math. Program., 29(1):28-40, 1984. 35, 45

[48] B. Grünbaum. Vertices missed by longest paths or circuits. J. Combin. Theory Ser. A, 17(1):31-38, 1974. $38,40,41,76$

[49] Y.-L. Guo, C.-W. Ho, and M.-T. Ko. The longest path problem on distance-hereditary graphs. In Advances in Intelligent Systems and Applications - Volume 1, volume 20 of Smart Innovation, Systems and Technologies, pages 69-77. 2013. 5, 53

[50] R. K. Guy. Monthly research problems 1969-73. Amer. Math. Monthly, 80:1120 - 1128, 1973. 39

[51] J. Harris, J.L. Hirst, and M. Mossinghoff. Combinatorics and Graph Theory. Undergrad. Texts Math. Springer, 2008. 27

[52] J. Hastad. Clique is hard to approximate within 1- $\epsilon$. Acta Math., 182(1):105-142, 1999. 69, 73

[53] W. Hatzel. Ein planarer hypohamiltonscher Graph mit 57 Knoten. Math. Ann., 243(3):213216, 1979. 38, 41

[54] T. Hippchen. Intersections of longest paths and cycles. Mathematics Theses, 80(Paper 53), 2008. $33,35,76$ 
[55] J. D. Horton. A hypotraceable graph. Technical Report Research Report CORR 73-4, Dept. of Combinatorics and Optimization, University of Waterloo, 1973. 39

[56] F. Hüffner, S. Wernicke, and T. Zichner. Algorithm engineering for color-coding with applications to signaling pathway detection. Algorithmica, 52(2):114-132, 2008. 61

[57] K. Ioannidou, G. B. Mertzios, and S. D. Nikolopoulos. The longest path problem has a polynomial solution on interval graphs. Algorithmica, 61(2):320-341, 2011. Also appeared in Proceedings of the 34th International Symposium on Mathematical Foundations of Computer Science, pages 403-414, 2009. 5, 48

[58] K. Ioannidou and S. D. Nikolopoulos. The longest path problem is polynomial on cocomparability graphs. Algorithmica, 65(1):177-205, 2013. Also appeared in $W G$, pages 27-38, 2010. 5,53

[59] A. Itai, C. H. Papadimitriou, and J. L. Szwarcfiter. Hamiltonian paths in grid graphs. SIAM J. Comput., 11(4):676-686, 1982. 5, 53

[60] R. Jain and M. Sakalle. Survey on intersection of two maximum length paths in connected graph. Res. J. Math. Stat. Sci., 2(3):1-3, 2014. 35

[61] A. Jiménez. Private communication. 2013. 76

[62] F. Joos. Longest paths in circular arc graphs. arXiv:1312.3075, 2013. 4, 18

[63] M. Jooyandeh, B. D. McKay, P. R. J. Östergård, V. H. Pettersson, and C. T. Zamfirescu. Planar hypohamiltonian graphs on 40 vertices. arXiv:1302.2698, submitted, 2013. 39, 41

[64] C. Jordan. Sur les assembalges des lignes. J. Reine Angew. Math., 70:185-190, 1869. 16

[65] A. D. Jumani and T. Zamfirescu. On longest paths in triangular lattice graphs. Util. Math., 89:269-273, 2012. 15

[66] D. Karger, R. Motwani, and G. D. S. Ramkumar. On approximating the longest path in a graph. Algorithmica, 18(1):82-98, 1997. 1, 5, 69, 71, 72

[67] S. Kensell. Intersection of longest paths. Master's thesis, Central European University, 2011. $1,28,39$

[68] S. Klavžar and M. Petkovšek. Graphs with nonempty intersection of longest paths. Ars Combin., 29:43-52, 1990. 4, 15, 16, 18, 20, 75

[69] B. Monien. How to find long paths efficiently. Ann. Discrete Math., 25:239-254, 1985. 5, 55

[70] H. Müller. Hamiltonian circuits in chordal bipartite graphs. Discrete Math., 156(1-3):291 298, 1996. 5, 53

[71] F. Nadeem, A. Shabbir, and T. Zamfirescu. Planar lattice graphs with Gallai's property. Graphs Combin., 29(5):1523-1529, 2013. 15

[72] G. Narasimhan. A note on the hamiltonian circuit problem on directed path graphs. Inform. Process. Lett., 32(4):167 - 170, 1989. 5, 53

[73] S. O, D. B. West, and H. Wu. Longest cycles in k-connected graphs with given independence number. J. Combin. Theory, Ser. B, 101(6):480-485, 2011. 37

[74] C. H. Papadimitriou and M. Yannakakis. The traveling salesman problem with distances one and two. Math. Oper. Res., 18(1):1-11, 1993. 71 
[75] C. H. Papadimitriou and M. Yannakakis. On limited nondeterminism and the complexity of the V-C dimension. J. Comput. System Sci., 53(2):161-170, 1996. 61

[76] G. Ramalingam and C. P. Rangan. A unified approach to domination problems on interval graphs. Inform. Process. Lett., 27(5):271-274, 1988. 48, 53

[77] D. Rautenbach and J.-S. Sereni. Transversals of longest paths and cycles. SIAM J. Discrete Math., 28(1):335-341, 2014. 4, 18

[78] W. Schmitz. Über längste Wege und Kreise in Graphen. Rend. Semin. Mat. Univ. Padova, 53:97-103, 1975. 3, 38

[79] A. Shabbir, C. Zamfirescu, and T. Zamfirescu. Intersecting longest paths and longest cycles: A survey. Electron. J. Graph Theory Appl., 1(1):56-76, 2013. 4

[80] A. Shabbir and T. Zamfirescu. Gallai's property for graphs in lattices on the torus and möbius strip. submitted, 2013. 15

[81] Z. Skupień. Smallest sets of longest paths with empty intersection. Combin. Probab. Comput., 5(4):429-436, 1996. 5, 39

[82] I. A. Stewart. On the intersections of longest cycles in a graph. Technical Report Series, (241), 1987. 36

[83] Y. Takahara, S. Teramoto, and R. Uehara. Longest path problems on ptolemaic graphs. IEICE - Trans. Inf. Syst., E91-D:170-177, 2008. 5, 53

[84] C. Thomassen. Hypohamiltonian and hypotraceable graphs. Discrete Math., 9:91-96, 1974. 40

[85] C. Thomassen. Planar and infinite hypohamiltonian and hypotraceable graphs. Discrete Math., 14(4):377-389, 1976. 4, 22, 41

[86] C. Thomassen. Planar cubic hypo-Hamiltonian and hypotraceable graphs. J. Combin. Theory Ser. B, 30(1):36-44, 1981. 38

[87] W. T. Tutte. A theorem on planar graphs. Trans. Amer. Math. Soc., 82:99-116, 1956. 76

[88] R. Uehara and Y. Uno. Efficient algorithms for the longest path problem. In Algorithms and Computation, volume 3341 of Lecture Notes in Comput. Sci., pages 1547-1553. 2005. 5, 48, 53

[89] R. Uehara and Y. Uno. On computing longest paths in small graph classes. Internat. J. Found. Comput. Sci., 18(5):911-930, 2007. 5, 53

[90] R. Uehara and G. Valiente. Linear structure of bipartite permutation graphs and the longest path problem. Inform. Process. Lett., 103:71-77, 2007. 5, 53

[91] V. V. Vazirani. Approximation Algorithms. Springer-Verlag New York, Inc., New York, NY, USA, 2001. 10

[92] S. Vishwanathan. An approximation algorithm for finding long paths in Hamiltonian graphs. J. Algorithms, 50(2):246-256, 2004. Also appeared in Proceedings of the Eleventh Annual ACM-SIAM Symposium on Discrete Algorithms, SODA '00, pages 680-685, 2000. 5

[93] H.-J. Voss. Cycles and Bridges in Graphs, volume 49 of Mathematics and its Applications (East European Series). Kluwer Academic Publishers Group, Dordrecht, 1991. 27, 34, 37, 39, 75 
[94] H.-J. Voss and H. Walther. Über Kreise in Graphen. VEB Dt. Verlag der Wissenschaften, 1974. 2,38

[95] J. A. Wald and C. J. Colbourn. Steiner trees, partial 2-trees, and minimum IFI networks. Networks, 13:159-167, 1983. 23

[96] H. Walther. Über die Nichtexistenz eines Knotenpunktes, durch den alle längsten Wege eines Graphen gehen. J. Combin. Theory, 6:1-6, 1969. 1, 2, 38, 76

[97] H. Walther. Über die Nichtexistenz zweier Knotenpunkte eines Graphen, die alle längsten Kreise fassen. J. Combin. Theory, 8:330-333, 1970. 38

[98] D. B. West. Open Problems - Graph Theory and Combinatorics, Hitting all longest paths. www.math.uiuc.edu/ west/openp/pathtran.html, accessed on April 2014. 27

[99] C. T. Zamfirescu and T. Zamfirescu. A planar hypohamiltonian graph with 48 vertices. $J$. Graph Theory, 55(4):338-342, 2007. 38, 41

[100] T. Zamfirescu. A two-connected planar graph without concurrent longest paths. J. Combin. Theory Ser. B, 13:116-121, 1972. 3, 38, 39, 75, 76

[101] T. Zamfirescu. Graphen, in welchen je zwei Eckpunkte von einem längsten Weg vermieden werden. Ann. Univ. Ferrara Sez. VII Sci. Mat., 21:17-24, 1975. 42

[102] T. Zamfirescu. L'histoire et l'état présent des bornes connues pour $P_{k}^{j}, C_{k}^{j}, \bar{P}_{k}^{j}$ et $\bar{C}_{k}^{j}$. Cahiers CERO, 7:427-439, 1975. 4, 38

[103] T. Zamfirescu. On longest paths and circuits in graphs. Math. Scand., 38(2):211-239, 1976. $2,4,38,39,40,42$

[104] T. Zamfirescu. Intersecting longest paths or cycles: a short survey. An. Univ. Craiova Ser. Mat. Inform., 28:1-9, 2001. 27, 33, 75

[105] T. Zamfirescu. Private communication to S. Kensell. 2011. 27

[106] D. Zuckerman. Linear degree extractors and the inapproximability of max clique and chromatic number. Theory Comput., 3(6):103-128, 2007. 69, 73 